\title{
Impact of continuous flow chemistry in the synthesis of natural products and active pharmaceutical ingredients
}

\author{
JULIANA M. DE SOUZA ${ }^{1 * *}$, RENAN GALAVERNA ${ }^{2 * *}$, ALINE A.N. DE SOUZA ${ }^{1 * * *}$, TIMOTHY J. \\ BROCKSOM ${ }^{1}$, JULIO C. PASTRE ${ }^{2}$, RODRIGO O.M.A. DE SOUZA ${ }^{3}$ and KLEBER T. DE OLIVEIRA ${ }^{1}$ \\ ${ }^{1}$ Department of Chemistry, Federal University of São Carlos - UFSCar, Rodovia Washington \\ Luís, Km 235, Bairro Monjolinho, 13565-905 São Carlos, SP, Brazil \\ ${ }^{2}$ Institute of Chemistry, University of Campinas - UNICAMP, Cidade Universitária \\ Zeferino Vaz, P.O. Box 6154, 13083-592 Campinas, SP, Brazil \\ ${ }^{3}$ Institute of Chemistry, Federal University of Rio de Janeiro - UFRJ, Av. Athos da Silveira \\ Ramos, 149, Cidade Universitária, 22941-909 Rio de Janeiro, RJ, Brazil
}

Manuscript received on October 3, 2017; accepted for publication on November 22, 2017

\begin{abstract}
We present a comprehensive review of the advent and impact of continuous flow chemistry with regard to the synthesis of natural products and drugs, important pharmaceutical products and definitely responsible for a revolution in modern healthcare. We detail the beginnings of modern drugs and the large scale batch mode of production, both chemical and microbiological. The introduction of modern continuous flow chemistry is then presented, both as a technological tool for enabling organic chemistry, and as a fundamental research endeavor. This part details the syntheses of bioactive natural products and commercial drugs.
\end{abstract}

Key words: Continuous flow, natural products, APIs, synthesis.

\section{INTRODUCTION}

The apothecary prepared his medications from natural sources, usually as a concoction of a complex mixture of compounds. Progress then brought in the production of isolated natural

\footnotetext{
Correspondence to: Kleber Thiago de Oliveira

E-mail: kleber.oliveira@ufscar.br

Timothy John Brocksom

E-mail: brocksom@terra.com.br

Julio Cezar Pastre

E-mail: juliopastre@iqm.unicamp.br

Rodrigo de Souza

E-mail: souzarod21@gmail.com

**these authors contributed equally to this review

* Contribution to the centenary of the Brazilian Academy of Sciences.
}

products, still as mixtures with occasional pure compounds. This approach is still the most common form of disease treatment throughout the world due to the much lower cost and greater availability of such medications, and obviously the direct use of the natural sources. Beginning in the $19^{\text {th }}$ century, research labs and chemical companies had routinely begun to perform reactions and thus molecular modifications, with the intent of creating new compounds of increased social and commercial value. Discussions of important remedies viewed from the molecular aspect can be found in two very relevant textbooks, written by Corey et al. (2007), and Nicolaou and Montagnon (2008). 
The case of aspirin (4) is a truly fascinating example, starting with the long-known activity of a crude weeping willow bark extract against several kinds of pain. These extracts contain salicin (1), and in the $19^{\text {th }}$ century the conversion to salicylic acid was already well known, both compounds being recommended for treatment as a pain reliever. To reduce gastric acidity problems, the acetyl derivative of salicylic acid (2) was synthesized, becoming universally known as aspirin (4). Thus, the best known, most consumed and first synthetic drug was born, being accessible from phenol (3) and introducing the batch mode of performing organic reactions on a kilogram to ton-scale (Hafner et al. 2016) (Scheme 1). A very important aspect of the drug aspirin is its now well-known utility for the treatment of other health problems, and this approach is becoming very relevant.

The penicillin story starts with the serendipitous discovery by Fleming in 1928, and his decision not to clean or throw away the Petri dish, where the Penicillium notatum mold was destroying bacterial growths. However, this event passed almost unnoticed, the Second World War intervened and created an even bigger necessity for antibiotic medications. Thus, the isolation, structural identification of penicillin and the large-scale production, became multi-national endeavors. The culture of the Penicillium notatum microorganism leads to the large-scale production of natural penicillins, then fermentation transforms them into 6-aminopenicillanic acid (6-APA) (6), the starting material for the semi-synthesis of the many penicillin antibiotics available today (Scheme 2).

In the late 1940's and 1950's, steroid chemistry became very important due to Marker's discovery of a steroidal sapogenin (diosgenin (8)) found in the Mexican yam, its transformation into 16-DPA (9) and then progesterone (10) (Scheme 3) on a kilogram scale (Marker et al. 1947, perhaps the longest full paper to be published; DeCorte 2016). These two steroids thus became the starting materials for the large-scale production of corticosteroids and C-19 demethylated contraceptives (Hirschmann 1991) and the birth-control pill, and a social revolution provoked by a drug. The large-scale process development of both penicillin and cortisone (37 steps from cholic acid) were both performed at Merck, under the leadership of Tishler (Hirschmann 1991). The December issue of Steroids, 1992, volume 57, is dedicated to historical descriptions of the pharmaceutical industries endeavors in steroid chemistry. The steroid nucleus platform has also served as substrate for the discovery of many very important synthetic methodologies, a target for total synthesis, and the fundamental concepts of conformational analysis.

After the Second World War, the growing pharmaceutical industry began to look more seriously at totally synthetic molecules, as opposed to true natural products, their semi-synthetic derivatives, or molecules inspired or resembling natural products (analogues). The industrial building block era was then introduced, but with a strict preference for planar achiral heteroaromatics: this is obviously a strategic copy of Nature, which has also always used a relatively small group of biosynthetic building blocks, but which are chiral enantiomerically pure, with many stereogenic centers, and not frequently heteroaromatic. The present drug distribution based upon Nature or synthetic origins can be seen in the following Figure 1. We have simplified the groups of categories and rounded off the percentages, to be easier to analyze (based on Newman and Cragg 2016 and references cited therein).

Useful examples of the totally synthetics are the erectile dysfunction drugs, introduced first with sildenafil (Viagra, Pfizer) in 1998, and then "honored" by the me-too imitations vardenafil (Levitra, Bayer), tadalafil (Cialis, Eli Lilly) and avanafil (Stendra, Vivus). The building block approach can be seen in the synthesis of sildenafil (Scheme 4) (Dale et al. 2000), and the four 


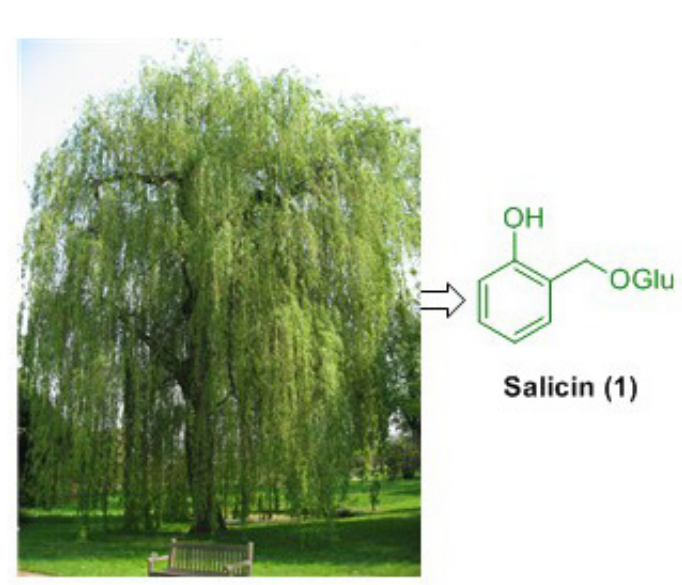

Salix Alba

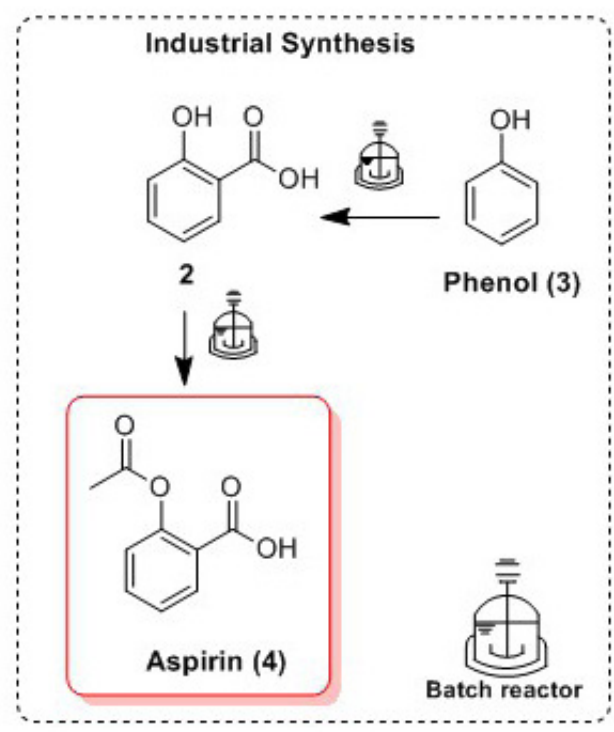

Scheme 1 - The aspirin saga and the "first" synthetic drug.

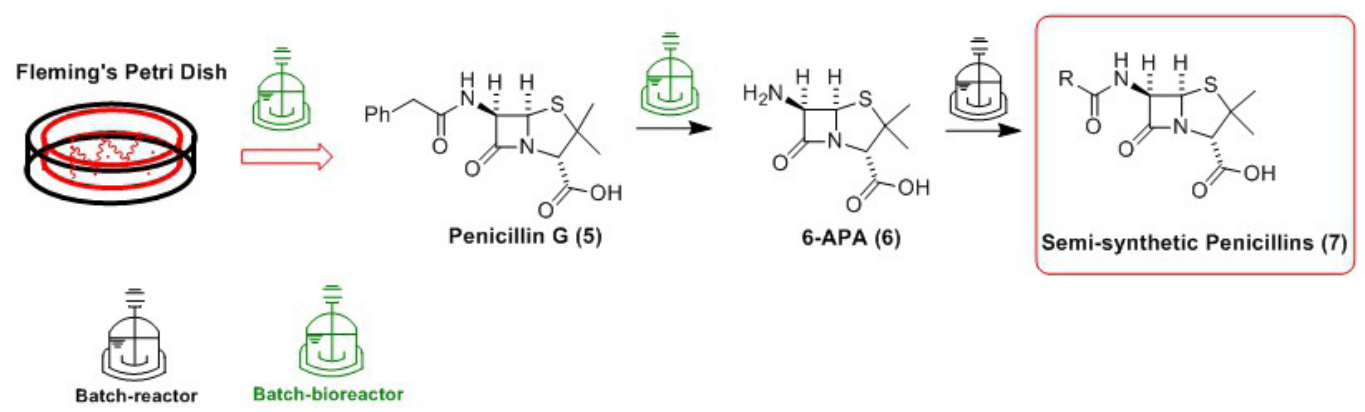

Scheme 2 -The penicillin antibiotics.

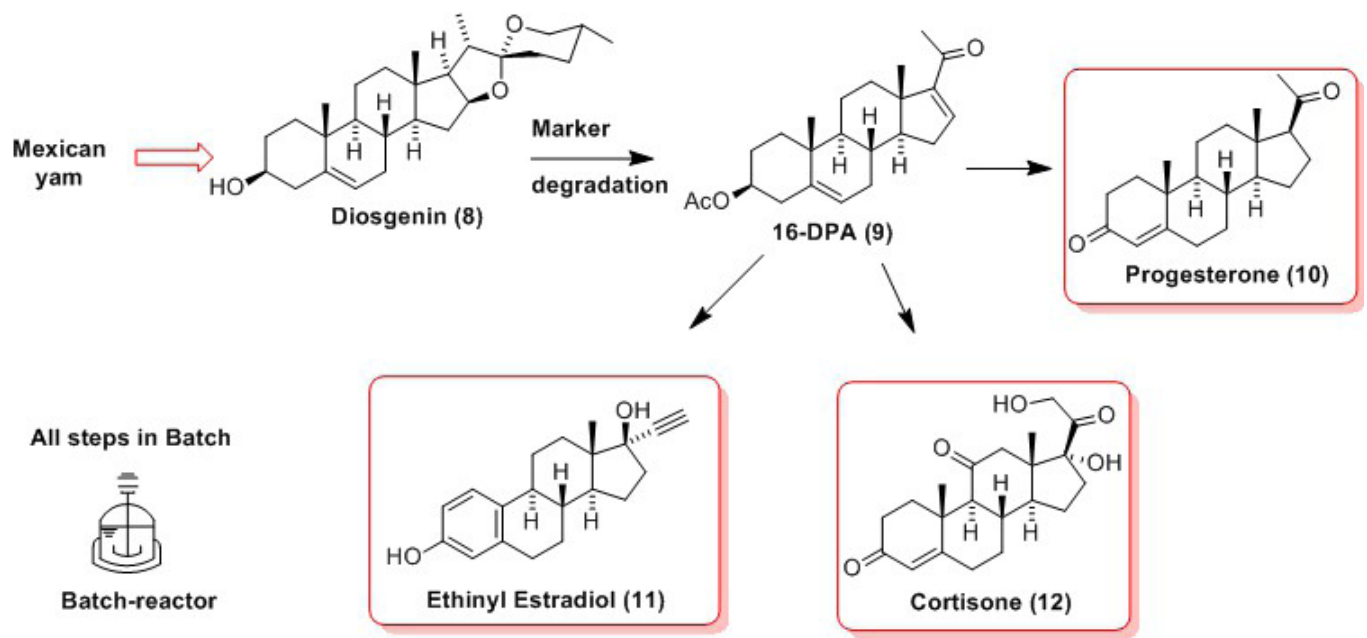

Scheme 3 - From the Mexican yam to steroidal drugs and the birth-control pill. 


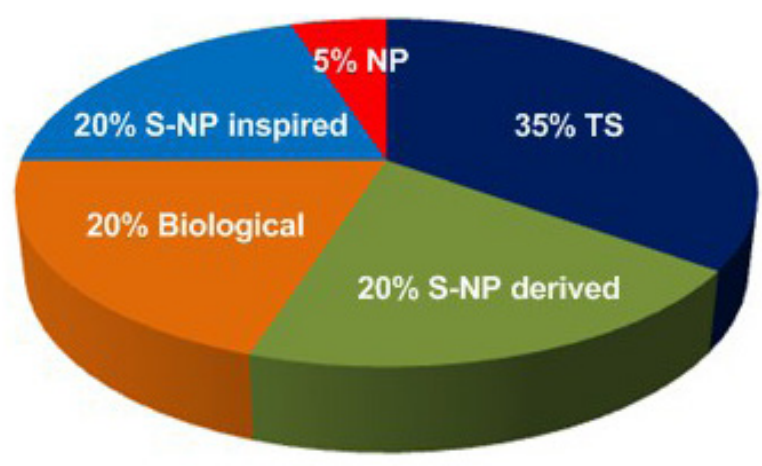

Figure 1 - Drug origins: TS, totally synthetic; S-NP inspired, synthetics inspired by NPs; S-NP derived, synthetics derived from NPs; Biologicals + vaccines; NP, isolated NPs.

commercially available drugs can be structurally compared in Scheme 5.

Other drug highlights developed over the last 60 years include the statins, antivirals to treat HIV, anti-cancer medicines, immunosuppressants, and treatments for depression and anxiety, as exemplified in Figure 2. The so-called neglected or forgotten diseases, basically encountered in the southern hemisphere, have found more limited success only in the case of malaria (Figure 2). The Figures help to visualize the quite distinct molecular structures of natural product derived or totally synthetic drugs. Clearly, these structural differences lead to important synthetic variations and diverse chemical methodologies, and consequently practices of large-scale production. The conventional chemical transformations and the fermentation processes should be understood simply as being reactions conducted with different species of reagents, but requiring the very same capacities of organic chemists for their success.

An important annual review of approved new drugs, as seen from the viewpoint of synthesis, has now reached year 2015 (Flick et al. 2017). We have reviewed the changing face of organic synthesis with special emphasis on the current century, dealing with natural products, synthetics and their use as drugs (Brocksom et al. 2015). The medicinal chemistry group (Holbrook and Garneau-Tsodikova
2017) designs and then synthesizes possible drugs (candidates, hits and leads) (Nadin et al. 2012) at the laboratory bench level (gram scale), then passes on to the process development group at the pilot plant level scale (up to kilogram scale), before eventually entering into commercial production on the ton-scale (Eastgate et al. 2017, Federsel 2009, 2013). All the drugs previously described are available worldwide on very large scales (up to hundreds of tons per year in some cases), usually produced in the batch mode.

After at least a century of accumulated experience in the fine chemical and pharmaceutical industries, the batch mode of production on a significant scale (at least multi-kilogram) is generally very effective. The batch reactor can be easily adapted to both chemical and microbiological reactions in the liquid phase, with addition, stirring, and extensive temperature and pressure variation facilities. The experimental conditions can be changed during use in the one-pot mode, being frequently multi-use for quite different reactions. The mechanics of the batch mode are difficult and laborious as far as the manipulation of reagents and solvents before, during and after the reaction, requiring highly qualified personnel. Next, the logistics become even more complicated with the necessity for transport to the separator, dryer, concentrator, precipitation and crystallization or other purification facilities.

These considerations have convinced process development and commercial production units of the necessity to investigate other equipment. The flow units in use industrially for many decades suggested modernization, with reduction in scale but with continuous operation to permit adequate production levels. This change brings many advantages in safety, economies of time, solvents, energy, equipment and space. The reaction parameters are more quickly optimized, on a much smaller scale with further economies, and principally safety. Without doubt, our chemical 

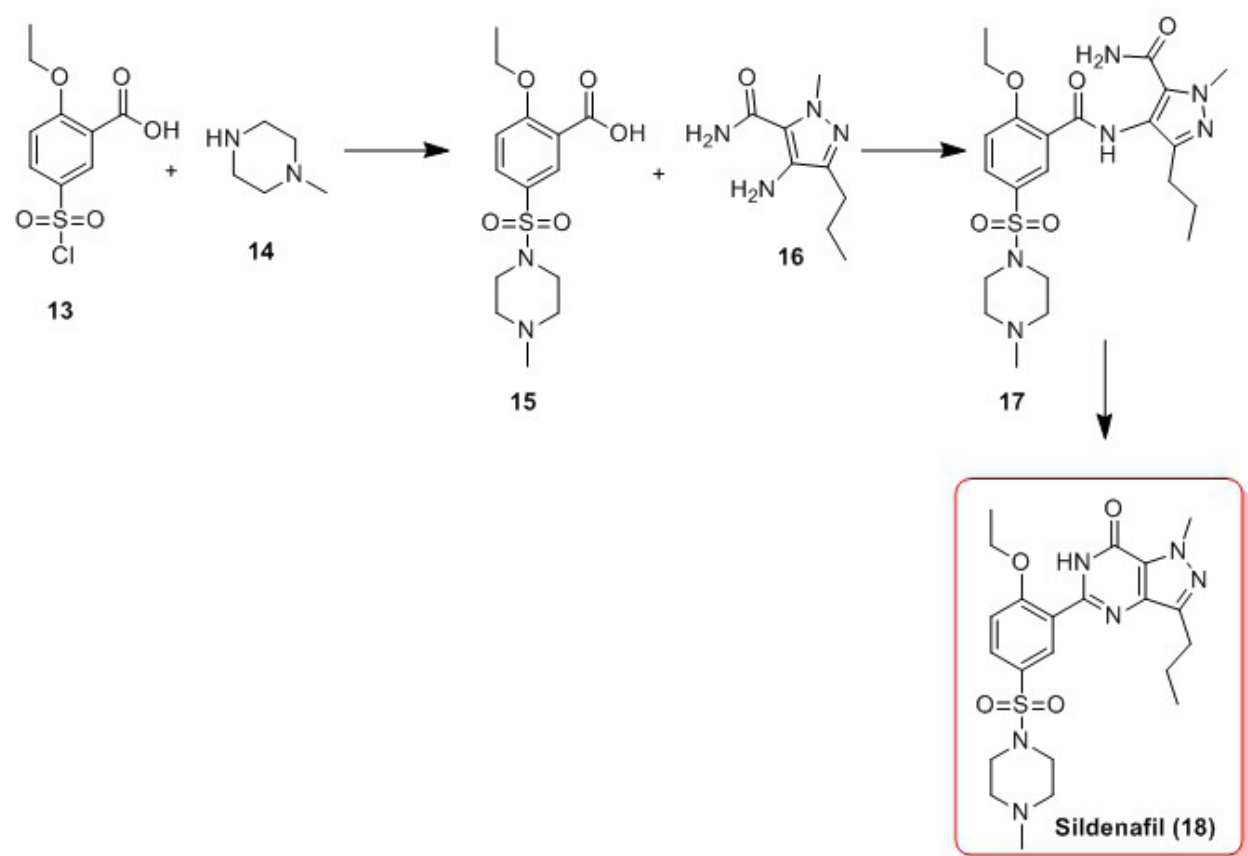

Scheme 4 - The building block approach for the synthesis of sildenafil (18).<smiles>CCCc1nn(C)c2c(=O)[nH]c(-c3cc(S(=O)(=O)N4CCN(C)CC4)ccc3OCC)nc12</smiles>

Sildenafil (18)<smiles>CCCc1nc(C)c2c(=O)[nH]c(-c3cc(OCC)ccc3S(=O)(=O)N3CCN(CC)CC3)nn12</smiles>

Vardenafil (19)<smiles></smiles>

Tadalafil (20)<smiles>COc1ccc(CNc2nc(N3CCCC3CO)ncc2C(=O)NCc2ncccn2)cc1Cl</smiles>

Avanafil (21)

Scheme 5 - The totally synthetics sildenafil (18), vardenafil (19), tadalafil (20) and avanafil (21); a second social revolution?<smiles>CC(C)c1c(C(=O)Nc2ccccc2)c(-c2ccccc2)n(CCC(O)CC(O)CC(=O)O)c1-c1ccc(F)cc1</smiles>

Atorvastatin (22)<smiles>CN1C=NC([N+](=O)[O-])C1Sc1ncnc2nc[nH]c12</smiles>

Azothioprine (25)<smiles>Cc1ccc(NC(=O)c2ccc(CN3CCN(C)CC3)cc2)cc1Nc1nccc(-c2cccnc2)n1</smiles>

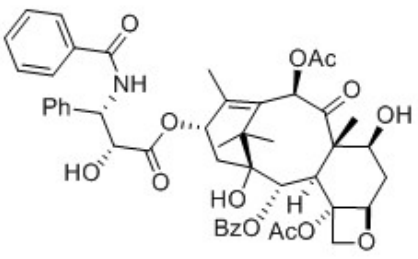

Taxol (24)<smiles>CC(F)(F)c1cc(Cl)ccc1NC(=O)OC#CC1CC1</smiles>

Efavirenz (26)<smiles>CN1C(=O)CCN=C(c2ccccc2)c2cc(Cl)ccc21</smiles>

Diazepam (27)

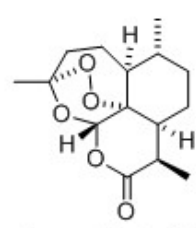

Artemisinin (28)

Figure 2 - Atorvastatin (22), imatinib (23), paclitaxel (24), azathioprine (25), efavirenz (26), diazepam (27) and artemisinin (28). 
industries need less bad news on explosions, fires and environmental damage: certainly, flow chemistry (Hawkins 2015, Porta et al. 2016, Plutschack et al. 2017) is a very real solution as we will demonstrate in this review.

\section{GENERAL REMARKS ABOUT CONTINUOUS FLOW CHEMISTRY}

The use of continuous flow or simply flow chemistry, is not new in chemistry, but in the last 20 years it has spread to a much wider chemical community and found application for the production of many highly valuable intermediates and products (Plutschack et al. 2017, Gutmann et al. 2015).

A synthetic organic chemist works with round bottomed flasks (RBFs) where the scaleup of the optimized process is always a challenge due to the need for many additional adjustments of the reaction parameters. To overcome these and other experimental difficulties, continuous flow reactors can be used as apparatuses for optimization and process development in organic synthesis. Continuous flow reactors are devices in which synthetic transformations take place in a continuously flowing stream within structures with general lateral internal dimensions from $1 / 16$ to $1 / 8$ inches. Several different types of flow reactors are commercially available, and customization to a desired process is generally needed depending on the reaction characteristics (Scheme 6) (Plutschack et al. 2017).

A general continuous flow chemistry setup is presented in Scheme 6 where the reagents are separately pumped through a micromixer into the reaction zone (reactor). The reaction zone is temperature controlled and can be customized in order to meet the reaction needs in terms of length and reactor type, such as: coils (polytetrafluoroethylene (PTFE), perfluoroalkoxy (PFA), stainless steel, among others), microchips, fixed-bed reactors, agitating microsphere reactors and tube-in-tube reactors. Among the reactors cited

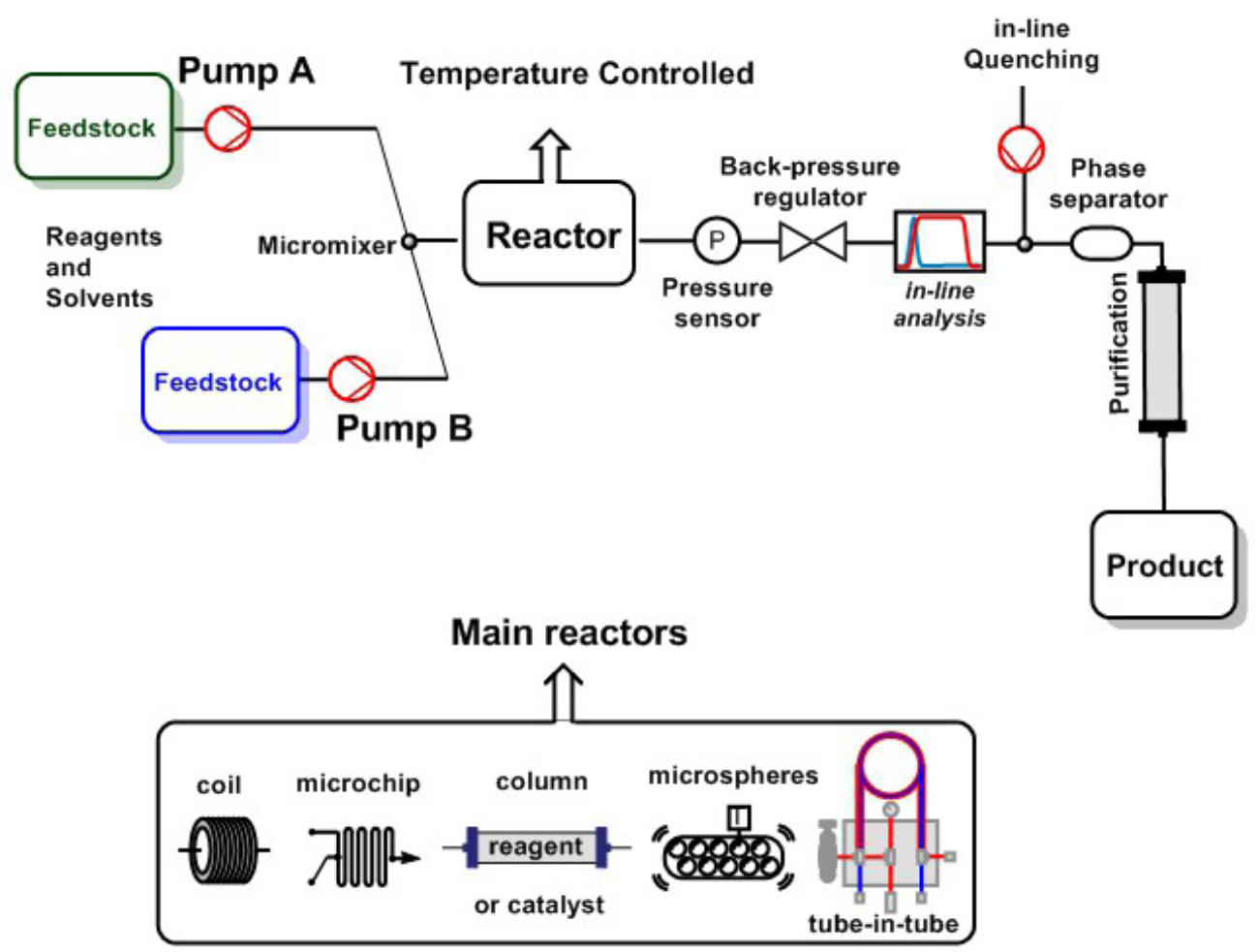

Scheme 6 - General scheme for a continuous flow set-up. 
above, tube-in-tube is a very interesting alternative for gas-liquid reactions involving $\mathrm{CO}_{2}, \mathrm{H}_{2}, \mathrm{O}_{3}$, $\mathrm{NH}_{3}$ among others (Pastre et al. 2013c). This special type of reactor called "tube-in-tube" (TIT) generally comprises a $1.0 \mathrm{~mm}$ o.d. / $0.8 \mathrm{~mm}$ i.d. Teflon AF-2400 permeable tubing inside a PTFE or stainless-steel tube $(3.18 \mathrm{~mm}$ o.d. / $1.59 \mathrm{~mm}$ i. d.). With the TIT reactor, a gas can be pressurized in the inner (or outer) tube and diffuse to the other tube where the reaction mixture is passing through. After the reaction zone, a back pressure regulator is normally installed giving the opportunity to tune the reaction pressure to the desired value. This allows researchers to explore reaction conditions not possible in the batch set-up, such as heating organic solvents at much higher temperatures then their boiling point. As shown in Scheme 6, in-line reaction analysis is also possible by the use of FTIR, HPLC, NMR, MS and/or UV-Vis, as well as quenching and purifications, allowing a researcher to begin with the crude starting material and arrive at the purified product in a telescoped protocol (Plutschack et al. 2017, Movsisyan et al. 2016, Reizman and Jensen 2016)

The advantage of using flow reactor technology, in most cases, is directly related to the size of the reactor, which can achieve a series of properties unreachable in batch reactor conditions. Therefore, the major advantages for using continuous flow conditions (Noël et al. 2015, Hartman et al. 2011, Elliott et al. 2016) are:

- Rapid and efficient mixing of reactants;

- Efficient heat transfer;

- Low operating volumes;

- High temperature and pressure conditions;

- High concentrations or no solvent;

- Inherently safer than batch (Alves et al. 2015);

- Inherently greener;

- Easily scaled-up (e.g. by numbering up - parallel processing or process intensification);
Regulation of many parameters such as heat and mass transfer, mixing and residence times is much improved in comparison with related batch processes. Mixing describes the way in which two or more phases come together and become intertwined. Batch and flow reactors exhibit different mixing mechanisms, where tube reactors inherently have much smaller diffusion times and achieve mixing much faster (higher surface to volume ratio, Figure 3) than in batch. This, in combination with reaction kinetics will determine if flow conditions are beneficial, based, most of the time, on the reaction Reynolds numbers ( $R e)$ (Plutschack et al. 2017).

Furthermore, some batch processes pose operational hazards, particularly with the use of highly reactive reagents. These hazards can be diminished under continuous flow conditions due to increased temperature control and short residence times. Most importantly, since the size of the reactors is very small, the amount of hazardous reagent or intermediates in an operation is minimal, increasing further the safety of the process (Hessel et al. 2013). Although the instant scale is relatively small, the continuous operation over many hours

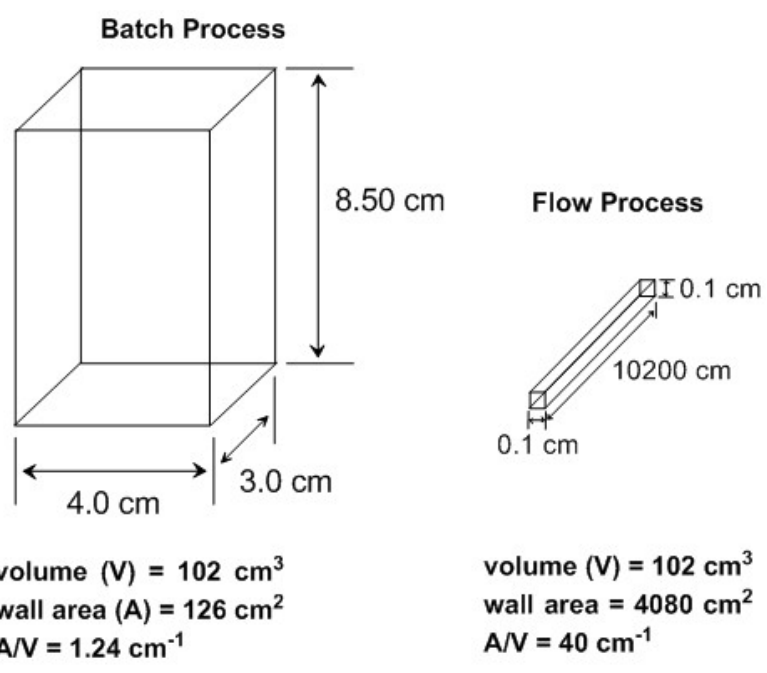

Figure 3 - Surface to volume ratio, Flow vs Batch reactors. 
produces much improved quantities $(\mathrm{STY}=$ space time yield $=$ grams-tons per hour or day).

Scale-up under continuous flow conditions can be performed by two different approaches, in a different design when compared to the batch process:

1) by scaling-up with increased reactor size, without losing microfluidic characteristics, using longer coils and higher flow rates;

2) by numbering-up or scaling-out, a common strategy in continuous-manufacturing where several smaller reactors work in parallel towards a common product (Su et al. 2016 and Kuijpers et al. 2017);

Thus, we can summarize continuous flow chemistry as a real revolution of the present and future in the way to perform chemical synthesis in machine-assisted processes. Telescoped flow chemistry also has a further advantage which permits the combination of "incompatible" reactions. Large scale continuous flow protocols are not new in chemical engineering. However, the last 20 years has established this approach as a consistent enabling technology for chemical transformations.

\section{NOVEL PROCESS WINDOWS (NPWS)}

Enabling technologies allow the execution of many "impracticable" reactions, mainly on the industrial scale by processes intensification (PI). In this context, PI has become a concept of great relevance, since it aims to develop more sustainable and environmentally friendly processes. This concept was introduced by Ramshaw (1999), and then Stankiewicz and Mouljin defined this as the use of new equipment or techniques which promote a significant improvement of production processes on a large-scale. This leads not only to smaller plants but also to significant reduction of energy consumption and waste, resulting in cheaper and greener processes (Stankiewicz and Mouljin 2000).
Therefore, the Novel Process Windows (NPWs) concept emerges as the use of new equipment, micro/macro reactors and reaction conditions to perform chemical transformations in a vigorous, but completely safe and scalable manner (Hessel et al. 2008, 2013, Stouten et al. 2013, Illg et al. 2010) (Figure 4).

The NPWs concept is quite recent, first introduced in 2005 by Hessel, but only in 2009 named as NPWs (Hessel et al. 2005, Hessel 2009). Different from the PI and micro-process technologies, which are capable of increasing mass and heat transfer in reactions with defined kinetics, NPWs aim to accelerate the rates and drastically reduce the reaction time by applying pressurized and superheated conditions. Therefore, the kinetics of the reaction can be completely exploited changing the reactivity of the substrates and maintaining their selectivity at an acceptable level with increase in productivity (Hessel et al. 2011, 2015). In general, NPWs encompass reaction conditions that are far from conventional laboratory practices such as the use of high pressures (p), high temperatures (T), high concentrations (c) or even solvent-free, and reactions that occur on an explosive regime, which make possible the attainment of new chemical transformations (Razzaq and Kappe 2010).

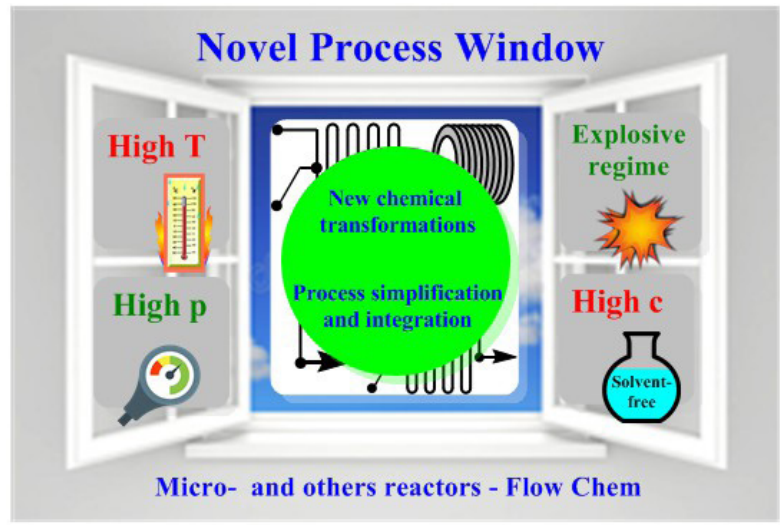

Figure 4 - An overview on Novel Process Windows (NPWs). 
DRUGS OBTAINED UNDER SUPERHEATED PROCESSING (HIGH T) AND SOLVENT-FREE CONDITIONS (HIGH C)

Rufinamide (32) (Scheme 7) is an antiepileptic drug containing a 1,2,3-triazole moiety and is among the best-selling five-membered heterocyclic pharmaceuticals developed by Novartis (2004) and manufactured by Eisai (Inovelon ${ }^{\circledR}$ and Banzel ${ }^{\circledR}$ ) (Baumann et al. 2011a, b).

The key intermediate $\mathbf{3 1}$ can be obtained by a 1,3-dipolar cycloaddition reaction (Scheme 7a) (Mudd and Stevens 2010). Hessel and coworkers (Borukhova et al. 2013) have shown that in batch experiments, a rapid decrease in reaction rate under diluted homogeneous reaction conditions was observed. Therefore, the solvent-free protocol under continuous flow conditions was preferred to attain a higher reaction rate (Scheme 7b). At 200 ${ }^{\circ} \mathrm{C}$ the intermediate 31 was obtained in $82 \%$ yield.

Recently, NPWs have been exploited in porphyrin synthesis (Scheme 8). These dyes are natural or synthetic compounds which present relevant physical and chemical properties and numerous applications as photocatalysts, dyesensitized solar cells, sensors, molecular electronics, non-linear optics and in medicine, especially with regard to photodynamic therapy (PDT) for some cancers treatments (de Oliveira et al. 2015, BaronaCastaño et al. 2016).

De Oliveira and coworkers investigated the one-pot synthesis of meso-tetraarylporphyrins and meso-tetraalkylporphyrins under continuous

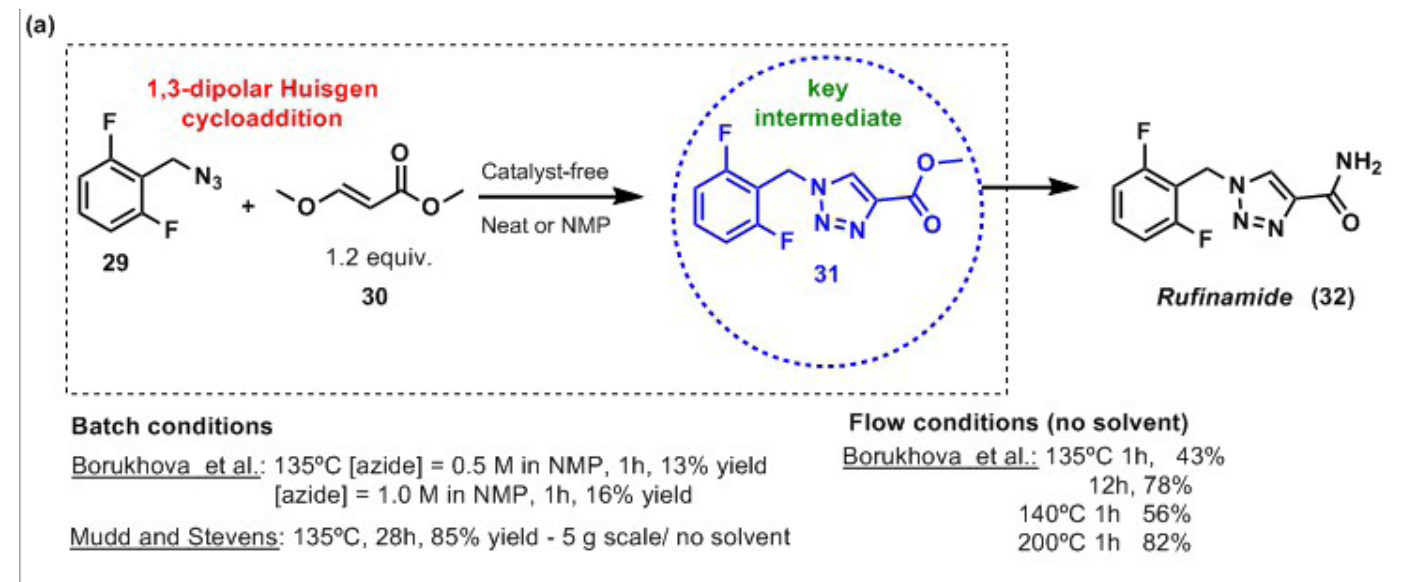

(b)

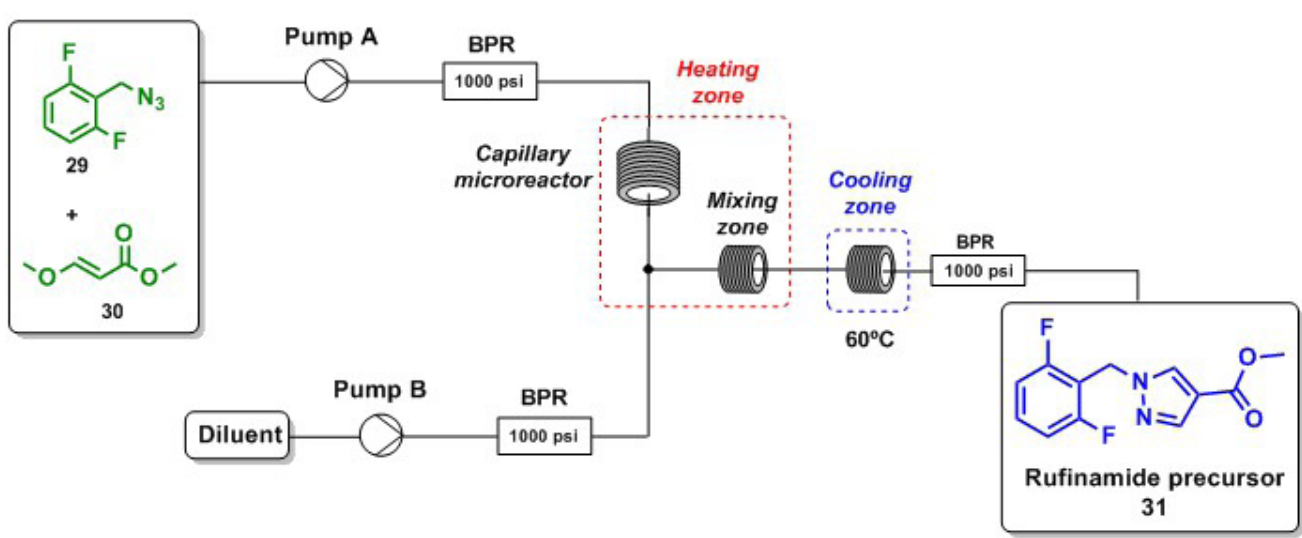

Scheme 7 - Rufinamide (32) synthesis: (a) Solvent- and catalyst-free Huisgen cycloaddition between 29 and 30. (b) Schematic representation of the microcapillary assembly. 


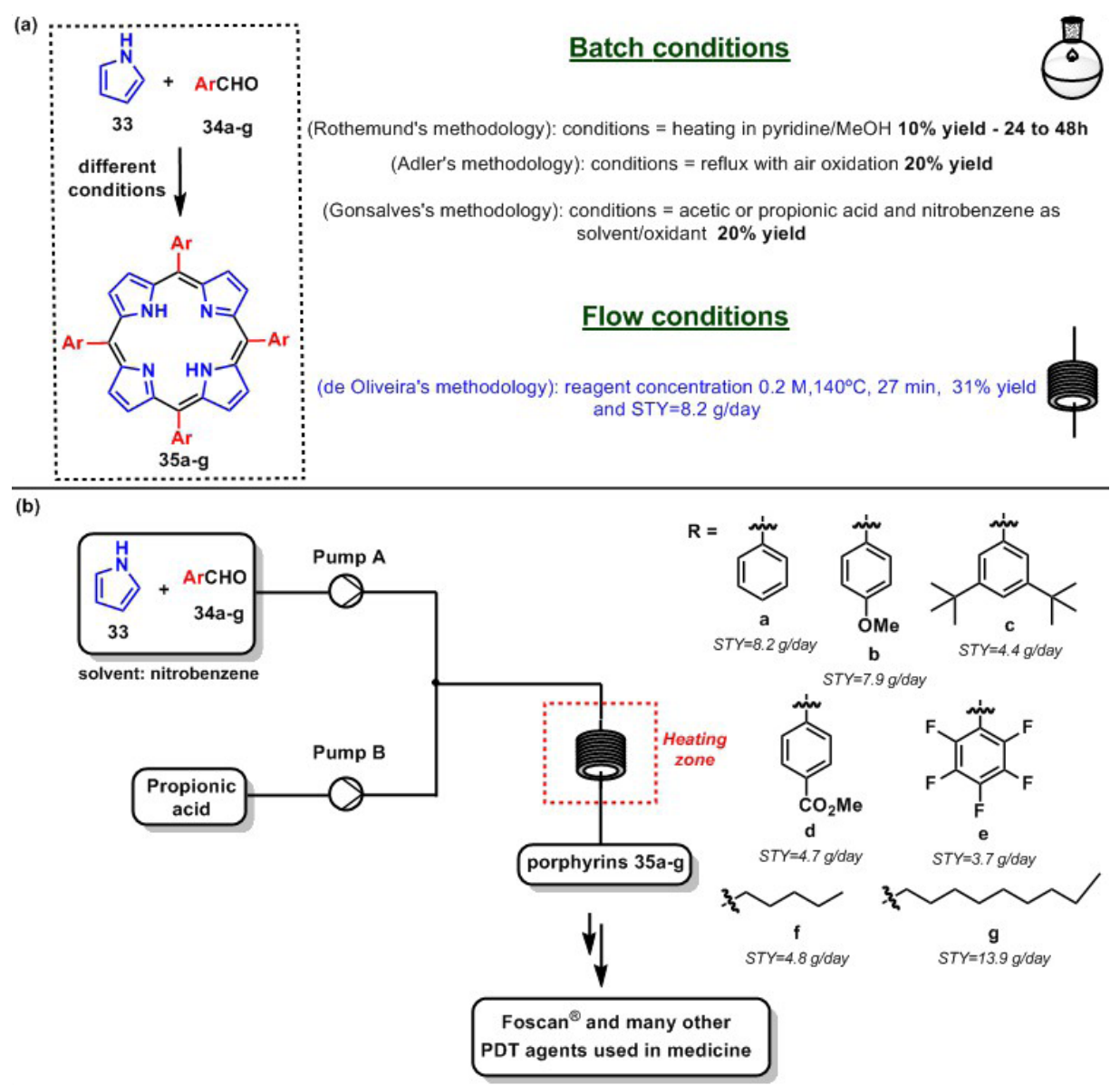

Scheme 8 - a) Comparison of the most common tetraphenylporphyrin (35a) syntheses in batch and flow conditions. b) Set-up for the one-pot 35a synthesis under continuous flow conditions.

flow conditions, and demonstrated improvements and a multi-gram-scale protocol. A safe scale-up, cost-competitive and reproducible protocol was achieved (Momo et al. 2015).

\section{NEW CHEMICAL TRANSFORMATIONS}

A relevant example of NPWs for new chemical transformations is the adipic acid synthesis from cyclohexene by Hessel and coworkers (Shang et al. 2013). From an industrial perspective, this is the most important dicarboxylic acid in use as about 2.5 billion kilograms of this compound are produced annually, mainly for nylon-6,6 production (Musser 2005, Castellan et al. 1991).

Different from other methods described in the literature (Davis 1985), which present $\mathrm{N}_{2} \mathrm{O}$ as byproduct, Hessel and coworkers studied the direct cyclohexene (36) oxidation by hydrogen peroxide. Adipic acid (37) is produced by means of a packedbed microreactor in continuous flow $\left(100{ }^{\circ} \mathrm{C}\right)$, using $\mathrm{Na}_{2} \mathrm{WO}_{4} \cdot 2 \mathrm{H}_{2} \mathrm{O}$ as catalyst and $\left[\mathrm{CH}_{3}\left(\mathrm{n}-\mathrm{C}_{8} \mathrm{H}_{17}\right)_{3} \mathrm{~N}\right]$ $\mathrm{HSO}_{4}$ as a phase transfer without solvent addition. This process is based on a Noyori group seminal publication (Sato et al. 1998) (Scheme 9).

\section{HIGH TEMPERATURE/PRESSURE PROCESSING - (HIGH -T/P)}

Several methodologies that lead to the oxidation of 2-benzylpyridines to the corresponding benzoyl derivatives have been reported (Crook and McKelvain 1930, Akhlaghinia et al. 2012, Zhang et al. 2009, Nakanishi and Bolm 2007). Houwer et 

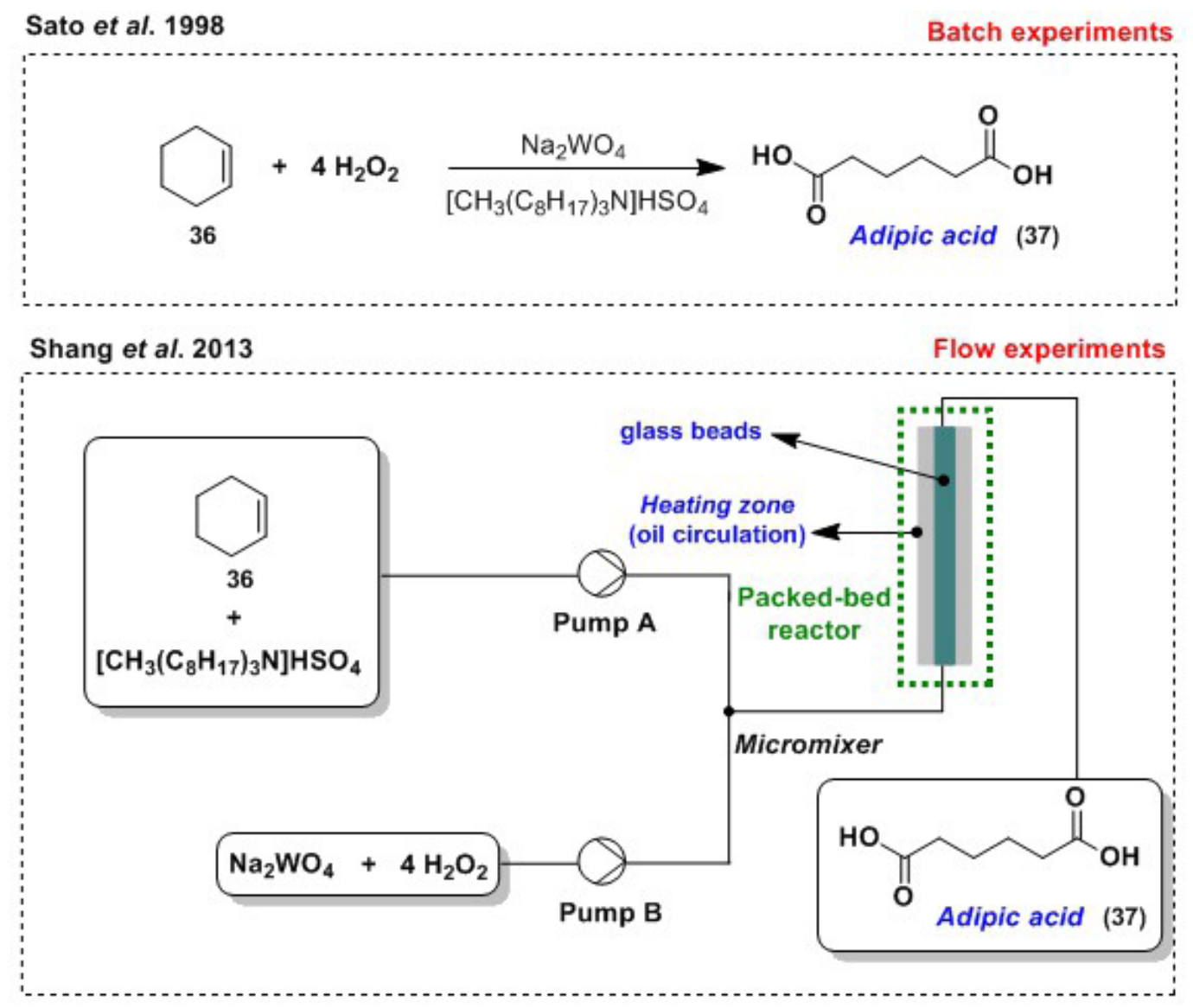

Scheme 9 - Adipic acid (37) synthesis - Set-up of the packed-bed reactor.

al. (2012) discovered that this oxidation can also be carried out using molecular oxygen in the presence of catalytic amounts of iron or copper salts in combination with acetic acid as additive. The ketones obtained as result of this transformation, can be used as building blocks for API synthesis, including the antihistamines, antiarrhythmic agents and others (Houwer et al. 2012) (Scheme 10).

Kappe and coworkers have described a gas-liquid continuous flow protocol for this 2-benzylpyridine oxidation (Scheme 11), using propylene carbonate as a solvent instead of DMSO, providing several advantages of the NPWs concept such as high-T/p (Pieber and Kappe 2013). The authors detected limitations for the temperature when working with aprotic polar solvents such as NMP or DMSO in a continuous flow regime, which makes propylene carbonate a very attractive alternative (b.p. $242^{\circ} \mathrm{C}$ ).

Jamison and coworkers reported the use of high-T/p continuous conditions for $\beta$-amino alcohol formation by using an epoxide aminolysis in the synthesis of metoprolol and indacaterol. Drugs such as Oxycontin ${ }^{\circledR}$, Coreg $^{\circledR}$ and Toprol-XL ${ }^{\circledR}$ present this functional group pattern, and other drugs such as Zyvox $^{\circledR}$ and Skelaxin ${ }^{\circledR}$ feature oxazolidones which can have amino alcohols as precursors (Scheme 12) (Bedore et al. 2010, Bergmeier 2000, Desai et al. 2007).

The synthesis of metoprolol(55) in a microwave (MW) batch or under continuous flow conditions is summarized in Scheme 13. The microreactor 
<smiles>CN(C)CCOC(c1ccc(Cl)cc1)c1ccccn1</smiles>

Carbinoxamine (38)<smiles>[R]c1ccc(C(CCN(C)C)c2ccccn2)cc1</smiles>

$\mathrm{R}=\mathrm{H}$, Pherinamine (42a) $\mathrm{R}=\mathrm{Cl}, \mathrm{Chloropherinamine} \mathrm{(42b)}$

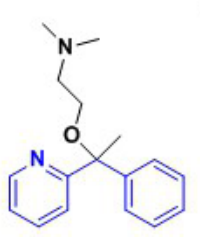

Doxylamine (39)

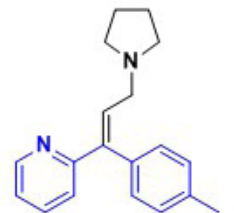

Triprolidine (43)

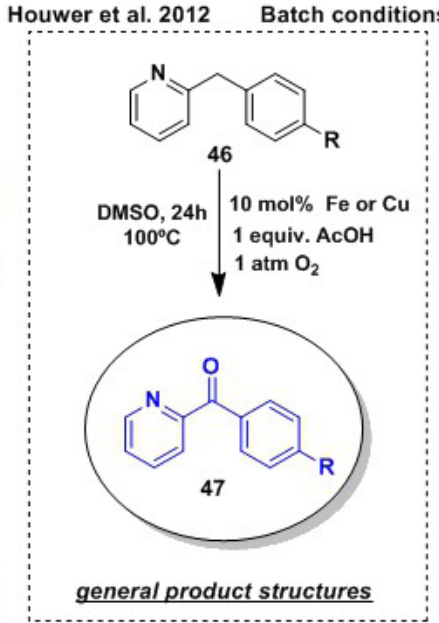<smiles>CC(C)N(CCC(C(N)=O)C(c1ccccc1)c1ccccn1)C(C)C</smiles>

Disopyramide (40)<smiles>[R]c1ccc(/C(=N\Nc2ccccn2)c2ccccn2)cc1</smiles>

2-benzoylpyridine 2'-pyridylhydrazones (44)

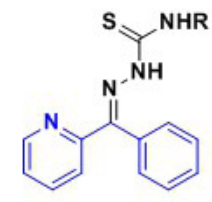

2-benzoylpyridine thiosemicarbazones (41)

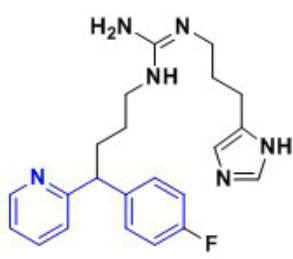

Arpromidine (45)

Scheme 10 - Metal catalyzed molecular oxygen oxidation of 2-benzylpyridines, and some important intermediates for API synthesis.

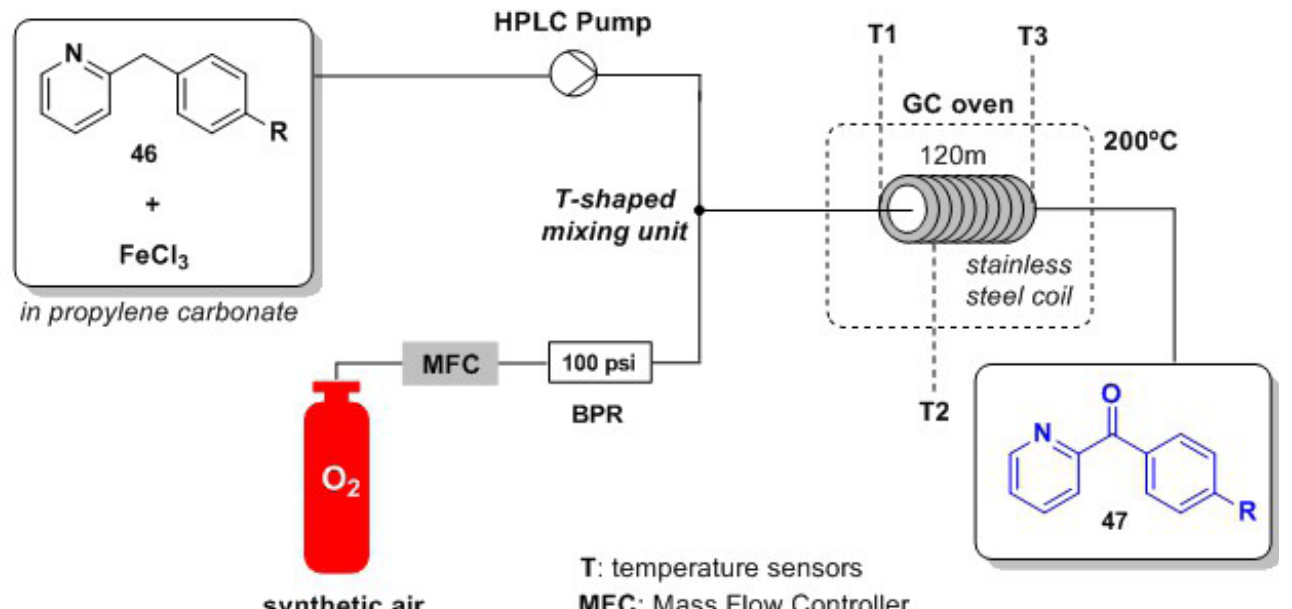

Scheme 11 - Set-up of the gas-liquid continuous flow reactor used by Pieber and Kappe.

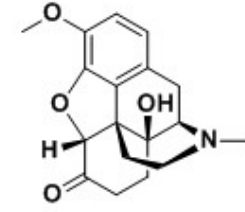

OxyContin ${ }^{\circledast}$ (oxycodone) (48)<smiles>COc1ccccc1OCCNC[C@H](O)COc1cccc2[nH]c3ccccc3c12</smiles>

Coreg ${ }^{\circledR 2}$ (carvedilol) (49)<smiles>COCCc1ccc(OCC(O)CNC(C)C)cc1</smiles>

Toprol-XL ${ }^{\circledast}$ (metoprolol) (50)<smiles>CC(=O)NCC1CN(c2ccc(N3CCOCC3)c(F)c2)C(=O)O1</smiles><smiles>Cc1cc(C)cc(OCC2CNC(=O)O2)c1</smiles>

Skelaxin $^{\circledast 2}$ (metaxalone) (52)

Scheme 12 - Pharmaceutically relevant compounds having $\beta$-amino alcohol moieties. 


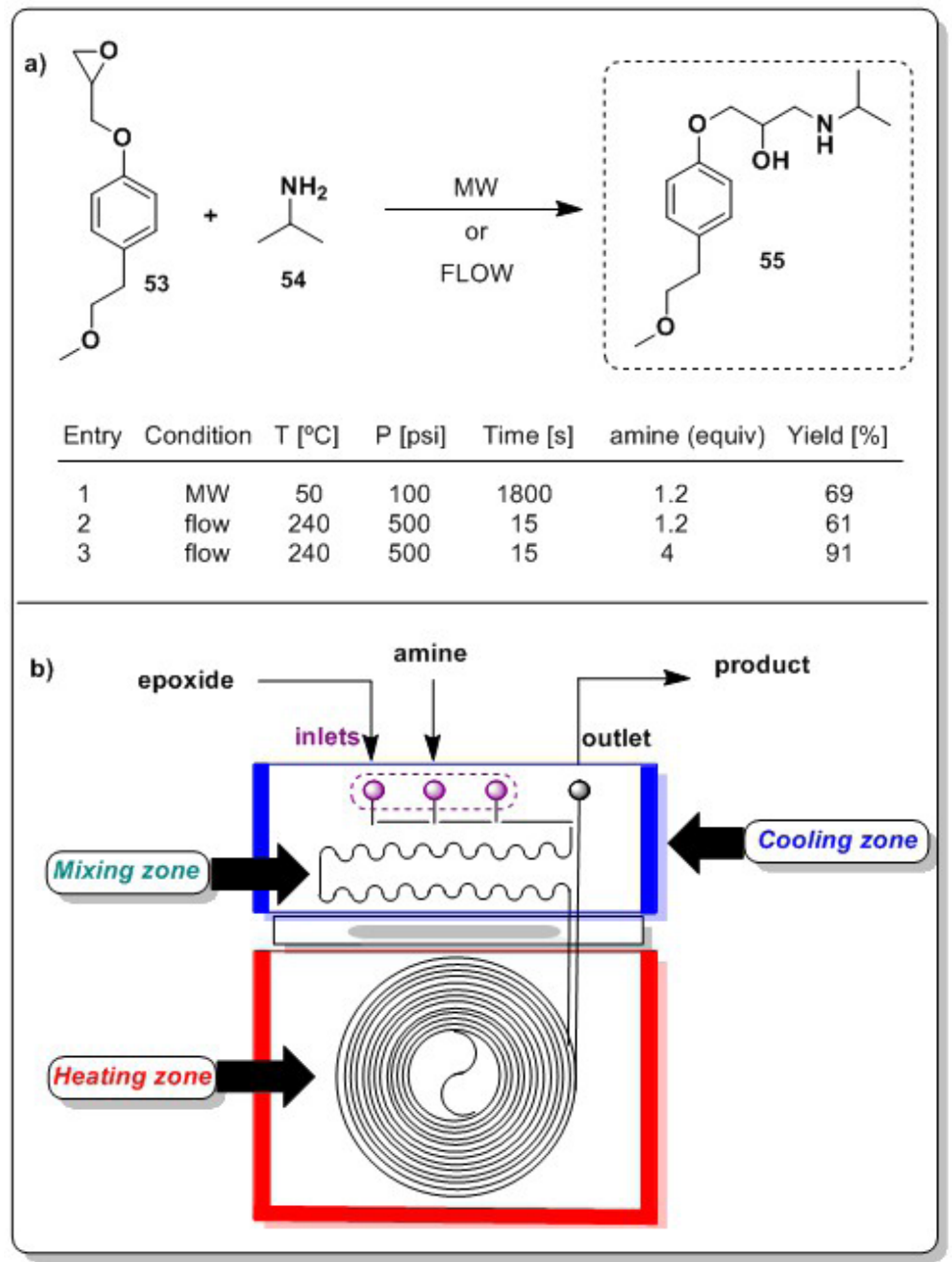

Scheme 13 - a) Metoprolol (55) synthesis - comparison between microwave (MW) and flow conditions. b) Flow chemistry set-up.

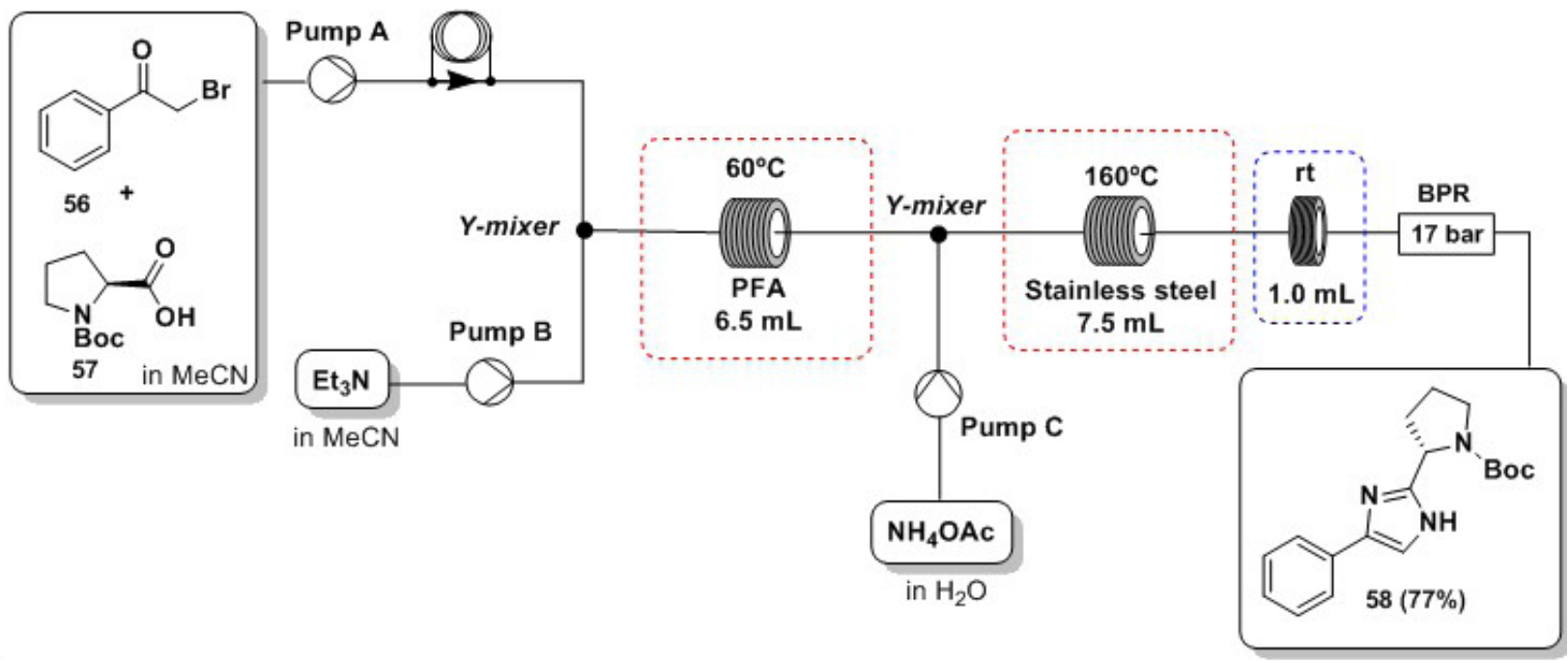

Scheme 14 - Set-up for the $1 H$-4-substituted imidazoles synthesis in continuous flow conditions and highT/p. 
working at high-T $\left(240{ }^{\circ} \mathrm{C}\right)$ and high-p (500 psi) resulted in high yields with residence times of about 15 seconds.

Eli Lilly described a continuous flow process for the high-T synthesis of $1 \mathrm{H}$-4-aryl imidazoles in 2012 (May et al. 2012). After this, Kappe and coworkers achieved a machine assisted process intensification synthesis under high-T/p of $1 H$-4-substituted imidazoles, using $\alpha$-bromoacetophenones and $\alpha$-aminoacids as starting materials (Scheme 14). Such imidazole derivatives are key building blocks in the synthesis of NS5A (a viral phosphoprotein) inhibitors, highlighting daclatasvir (62) as an important drug for hepatitis C (HCV) treatment (Carneiro et al. 2015). The two-step continuous flow protocol described by Kappe et al. afforded the imidazoles with residence times of about 4-10 min (Scheme 14), and daclatasvir (62) (Scheme 15) again demonstrating a very relevant application of the methodology.

Fülöpa and coworkers reported an oxidative homo-coupling of aniline derivatives to azobenzenes in continuous flow high-T conditions (Scheme 16). Approaches to azobenzenes typically require vigorous or special reaction conditions (e.g. the use of strong oxidizing agents, strong inorganic bases or acids), which often lead to extensive byproduct formation and low yields (Georgiádes et al. 2015). Therefore, a simple flow reactor was assembled having as the key element a heated cylindrical column charged with copper powder for the oxidative coupling (Scheme 16).

Kappe and coworkers reported a scaled-up synthesis of 4-aryl-2-butenones under continuous flow conditions, which produces Nabumetone (67), a nonsteroidal anti-inflammatory drug (NSAID) known as Relafen ${ }^{\circledR}$ or Noracet $^{\circledR}$ (Scheme 17) (Viviano et al. 2011).

In the flow experiments, a "two-feed" concept was adopted and the organic stream containing the aromatic aldehyde in acetone was pumped separately and mixed with the aqueous $\mathrm{NaOH}$ stream. Assuming a one-hour processing time for the cross-condensation of $p$-anisaldehyde (65a) at $120{ }^{\circ} \mathrm{C}$ and $1 \mathrm{~min}$ residence time a throughput of $\sim 40 \mathrm{~g}$ of 67 per hour can be calculated. When it comes to the large-scale aldol condensation, a mesofluidic flow set-up was designed with one/ two feed modules, which enables a multipurpose functionality to continuous flow plants. The optimized overall reagent flow processing was 2.4 $\mathrm{kg} / \mathrm{h}$ which corresponds to $0.35 \mathrm{~kg} / \mathrm{h}$ of product. When a $4.65 \mathrm{~L}$ reaction mixture was processed at $120^{\circ} \mathrm{C}, 1.75 \mathrm{~kg} / \mathrm{h}$ of product was obtained (Scheme $18)$.

The selective reduction of the products $\mathbf{6 6}$ double bond to obtain compounds such as $\mathbf{6 7}$ in 90\% yield was also performed under continuous flow conditions, employing a fixed-bed catalyst at temperatures up to $100{ }^{\circ} \mathrm{C}$ and 100 bar of hydrogen pressure.

In general, NPWs have allowed many improvements in continuous flow protocols, and opened up several possibilities to discover and perform new reactions. There are many conditions to be explored under more extreme conditions, particularly when it comes to "forbidden" and "forgotten" chemical reactions.

\section{PHOTOCHEMICAL REACTIONS AND CONTINUOUS PHOTO-FLOW PROCESSES}

Photochemical transformations have regained a new perspective in organic synthesis since they started to be performed in continuous flow conditions. Many old and inefficient photochemical processes have been revisited since a number of technical limitations have been solved by machineassisted protocols. Recently, the efficiency of these reactions has been significantly improved under continuous flow conditions compared to batch due to homogeneous light irradiation allowed by the use of polymer tube reactors (PFA, FEP). In batch conditions, a number of limitations prevent 


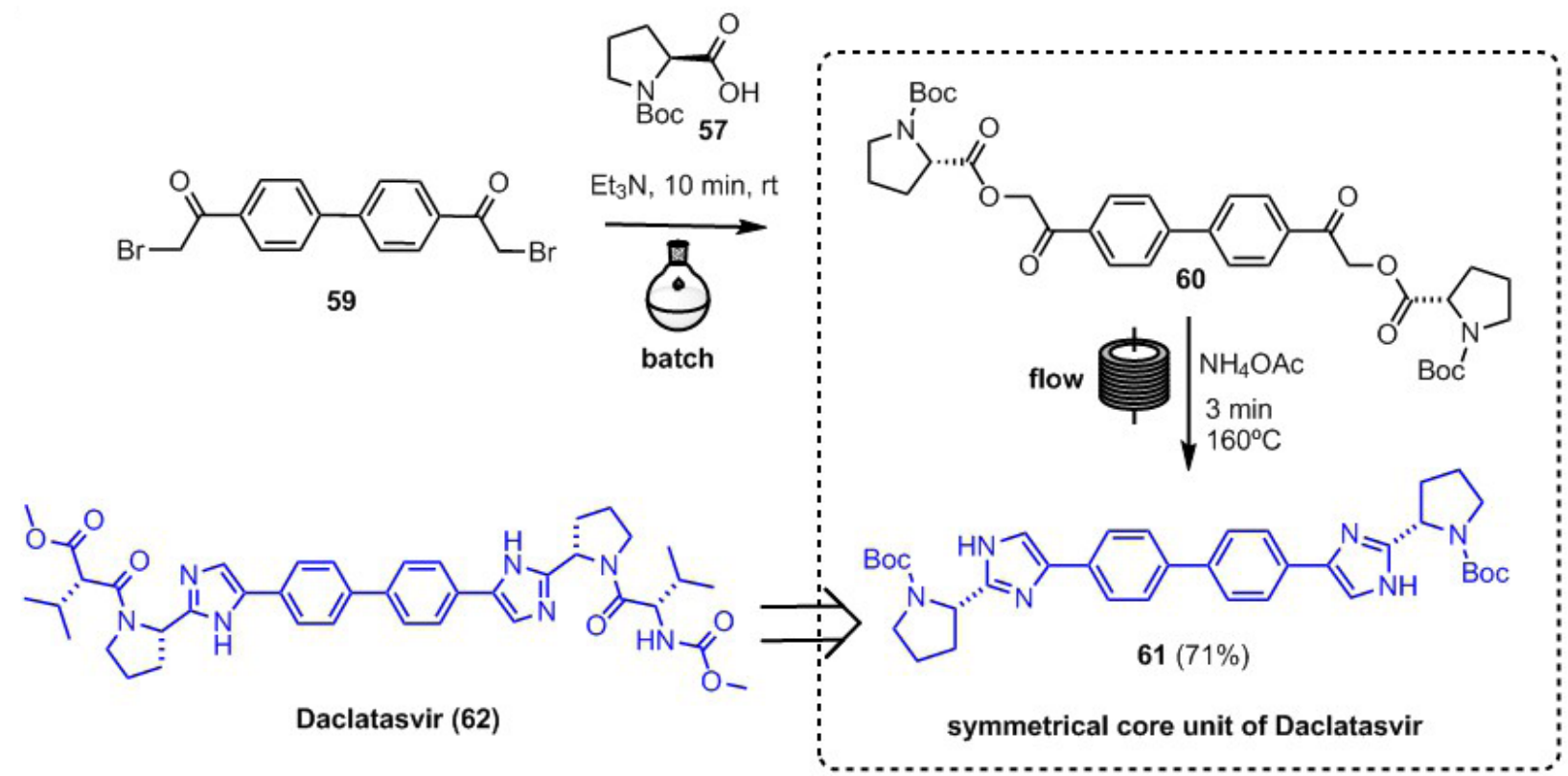

Scheme 15 - Bisimidazole 61 synthesis - symmetrical core unit of daclatasvir (62).

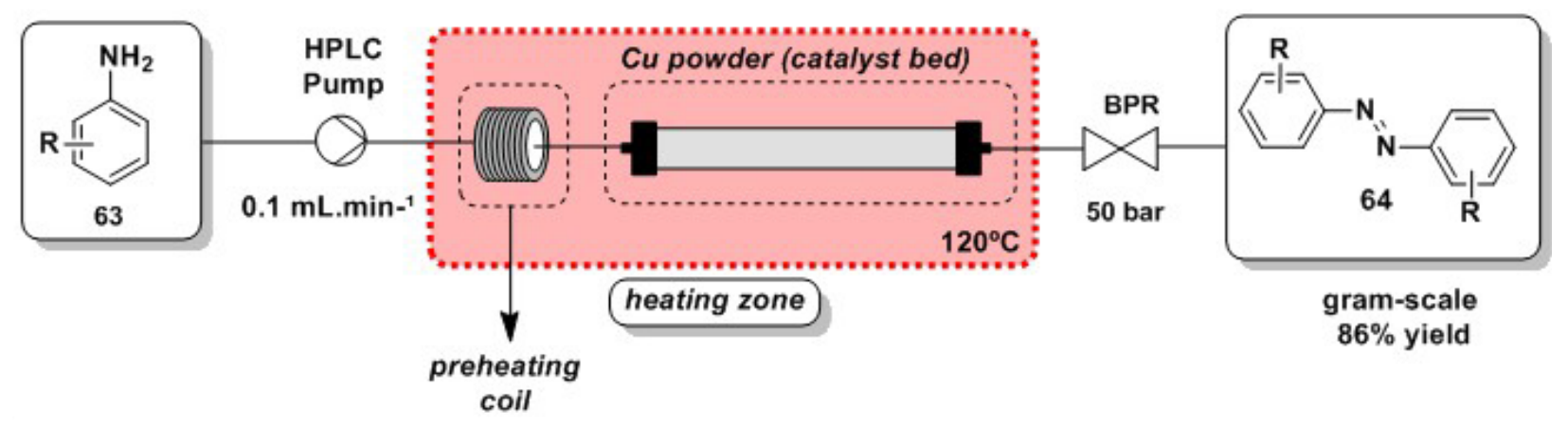

Scheme 16 - Set-up for the copper-catalyzed continuous flow couplings of aniline derivatives.<smiles>COc1ccc(C=O)cc1</smiles>

$65 b$

\section{Aldol reaction}

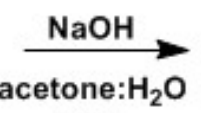

(2:1)

Scheme 17 - Synthesis of 4-aryl-2-butanones - Nabumetone (67). 


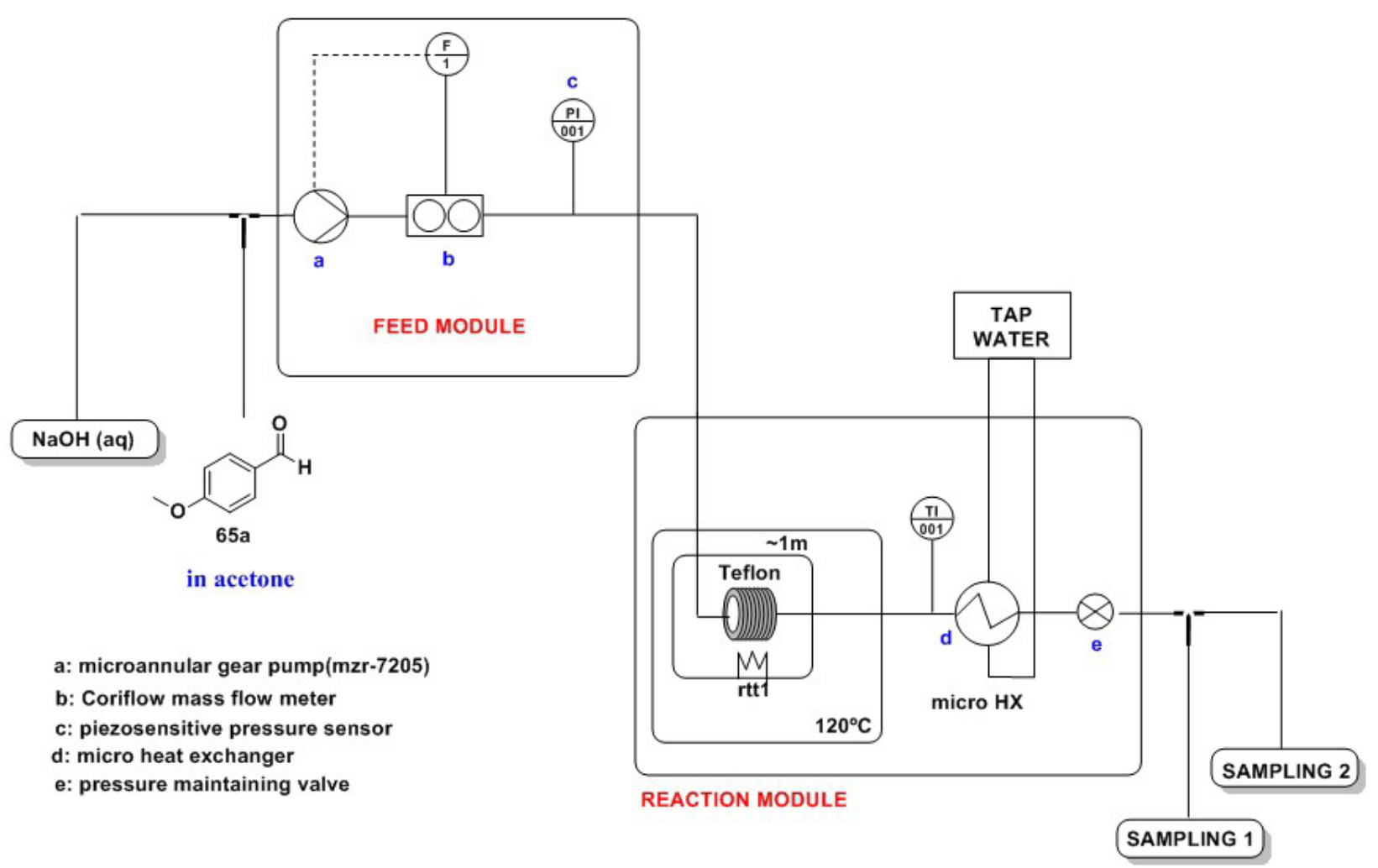

Scheme 18 - Flow-plant system for aldol condensations.

efficient photochemical reactions or photocatalyzed processes when using UV irradiation and common borosilicate glassware, due to UV light absorption. In addition, high dilutions are frequently necessary to avoid the excess of by-products occasioned by the intrinsic non-homogeneous batch-irradiation with the light penetration diminishing in ca $90 \%$ after 5-10 mm of light pathway (Su et al. 2014, Cambié et al. 2016, Nöel et al. 2017). Under continuous flow conditions these problems can easily be solved by using falling film plates or long length fluoropolymer tube reactors (regularly $1 / 16$ or 1/8 inch I.D. $x 10-100 \mathrm{~m}$ ) with multidirectional light irradiation inside the reactors (Figure 5).

Both numbering up ( $\mathrm{Su}$ et al. 2016, Kuijpers et al. 2017) and process intensification of the photoreactors has allowed the scale up of many key molecules for the pharmaceutical industry (Cambié et al. 2016). Another important advantage of continuous conditions in photochemical reactions is related to safety. Since small amounts of reagents and solutions are continuously irradiated, very unstable or explosive intermediates can be produced with no incidents, such as endoperoxides and organic peroxides (Lévesque and Seeberger 2012, de Oliveira et al. 2016).

It is important to highlight the relevance of temperature-control in photochemical processes, mainly in photocatalyzed reactions which depend on the efficiency of the photocatalysts. In this case, it is well known that the triplet lifetime of photosensitizers can be strongly diminished at temperatures above $0{ }^{\circ} \mathrm{C}$, impairing the efficient collision between the substrates and excited photosensitizers in both energy and single electron transfer processes. This factor is important in batch photochemical reactors, making them quite expensive. Now, continuous flow tube reactors are easily temperature-controlled thus keeping high levels of light irradiation with the use of LED light 


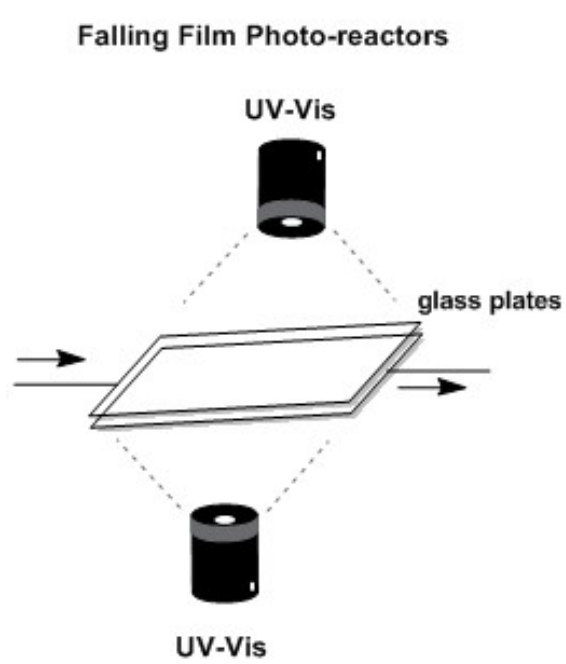

Figure 5 - The two main flow-photoreactor types.

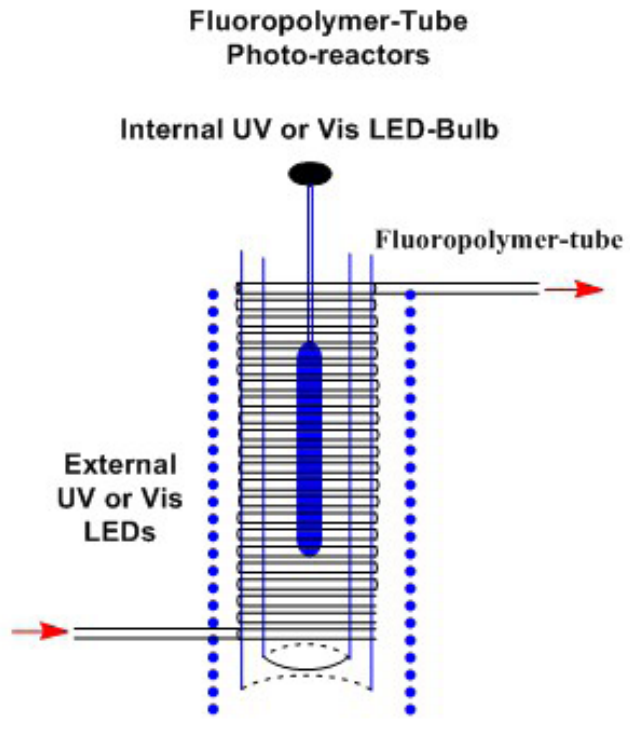

flow the intermediate $\mathbf{6 8}$ was obtained in $90 \%$ yield, showing a relevant example of industrial improvements promoted by continuous photoflow conditions. The Oelgemöller and Shvyndkiv (2011) review the original reference do not attempt to explain the transformation of $\mathbf{6 6}$ to $\mathbf{6 8}$ (Scheme 19).

Vitamin $\mathrm{D}_{3}$ (74) is an important example of a valuable API for the pharma industry. This compound is responsible for several metabolic and immunity regulations and can be obtained from provitamin $\mathrm{D}_{3}$ (70) (Scheme 20). In 2010, Takahashi and co-workers reported the synthesis of vitamin $\mathrm{D}_{3}$ (74) combining batch and two-stage continuous flow conditions by optimizations of thermal and photoisomerization precursors. The method developed afforded 74 in HPLC-UV: $60 \%$, isolated: $32 \%$ yield, and no intermediate purifications nor high-dilution conditions were necessary (Fuse et al. 2010).

One of the most significant syntheses reported under continuous photo-flow conditions is the synthesis of artemisinin (28) and derivatives, all of them well-known and potent antimalarial endoperoxides (Scheme 21) (Lévesque and Seeberger 2012). In 2014, the Sanofi laboratory 


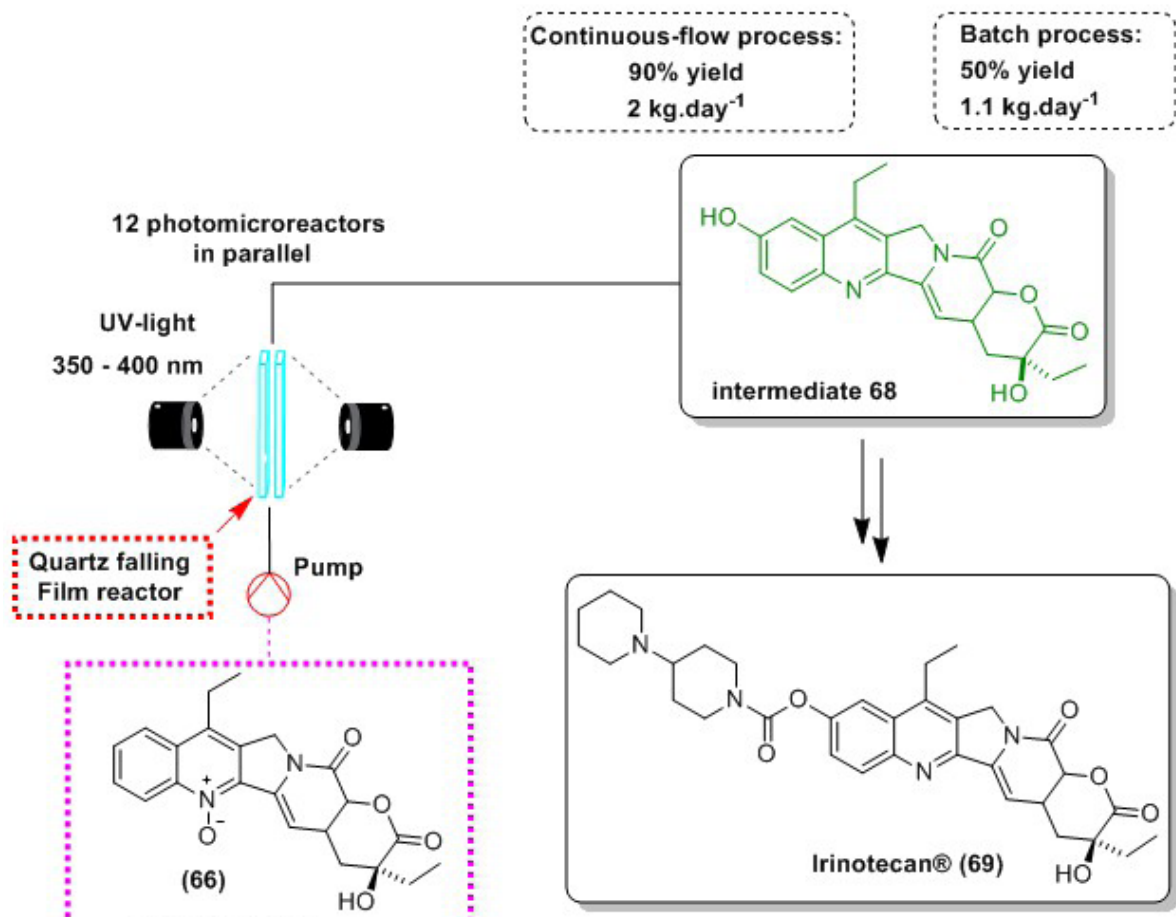

Scheme 19 - Continuous flow synthesis of $\operatorname{Irinotecan}^{\circledR}$ (69) by Heraeus Noblelight (Germany).

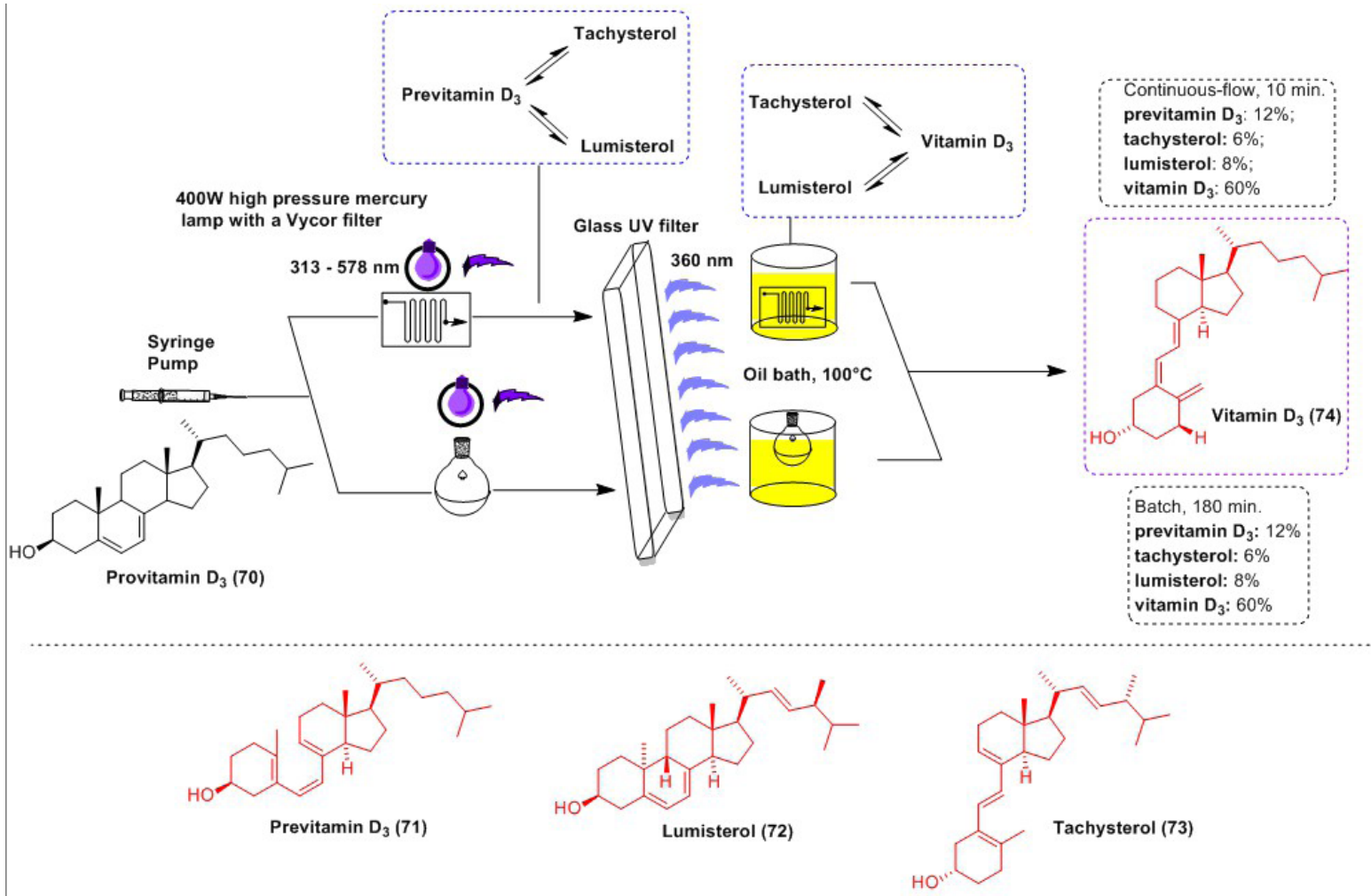

Scheme 20 - Batch and continuous flow syntheses of vitamin $D_{3}(74)$. 
established a continuous photo-flow plant for an annual production of almost 60 ton.year $^{-1}$ (Nöel et al. 2017). Artemisinic acid (75a) is isolated from natural sources and chemically reduced to dihydroartemisinic acid (75b), the starting material for the photochemical process. Allylic peroxidation to $\mathbf{7 6}$ is followed by a photochemical cycloaddition and rearrangement with $\mathrm{O}_{2}$ to artemisinin (28). The first part of this sequence is now executed by fermentation, while artemisinin (28) is further transformed chemically into the derivatives 77 to 79.

In 2013, Lek Pharmaceuticals described significant improvements in the synthesis of a brominated intermediate $\mathbf{8 2}$ for rosuvastatin (83) production (Scheme 22), a super-statin used for cholesterol control (Šterk et al. 2013).

Fluorinations are considered to be very relevant functionalizations under continuous flow conditions, due to several safety issues involving these transformations. In addition, many API intermediates present fluorine atoms in their structures, thus justifying the recent studies in this field. For example, Britton and co-workers have recently described (Halperin et al. 2015) a fluorination protocol for natural leucine (Scheme $23)$, which is an intermediate for Odanacatib ${ }^{\circledR}(\mathbf{8 6})$, a drug under clinical trial against osteoporosis. This protocol was developed on a gram-scale by Britton's group and recently scaled up by Merck (Nöel et al. 2017).

Endoperoxidations with posterior rearrangements are relevant reactions that can be performed under continuous photo-flow conditions. Several protocols have been described using different photocatalysts for the generation of singlet oxygen (Yavorskyy et al. 2012a). Recently, de Oliveira and coworkers (de Oliveira et al. 2016) described a very efficient protocol for hydroxynaphthol oxidation using a home-made photoreactor (Scheme 24). The scope of naphthol oxidation was presented, producing a number of naphthoquinones including vitamin $\mathrm{K}_{3}(\mathbf{8 8})$, an important big pharma API. TPP was used as the photocatalyst, which is produced in our laboratory by continuous flow (Momo et al. 2015).

As an example of a dehydrogenation reaction catalyzed by iridium complexes, Knowles and co-workers at Merck (Yayla et al. 2016) have described the Elbasvir (91) synthesis starting from an advanced indoline intermediate $\mathbf{8 9}$ (Scheme 25). In this protocol, the researchers reported a gramscale transformation to the indole $\mathbf{9 0}$, with several advantages when compared to the batch mode, and with no significant by-product formation.

A photo-Favorskii rearrangement protocol was recently reported (Baumann and Baxendale 2016a) for the synthesis of Ibuprofen (Scheme 26). Improvements were obtained when compared to the previous methodologies described by McQuade (Bogdan et al. 2009) or Jamison (Snead and Jamison 2015).

Approaches to the synthesis of very important peptides such as oxytocin or modified arylated peptides (Bottecchia et al. 2016, 2017, Talla et al. 2015) are also described in the literature, opening up many possibilities for flow-photo-assisted biomedical chemistry.

As shown in this section, photochemical transformations have routinely been incorporated by the pharmaceutical industry for API production, and the development of continuous photoflow technologies has been responsible for this successful progress. Continuous flow chemistry is now very present in the pharmaceutical industry, and certainly photochemical processes already occupy an important place in this scenario.

\section{NATURAL PRODUCTS SYNTHESIS UNDER CONTINUOUS FLOW CONDITIONS}

Since Wohler's urea synthesis (1828) from ammonium cyanate, and acetic acid was prepared by Kolbe in 1845, synthetic chemists have demonstrated exceptional creativity for the 


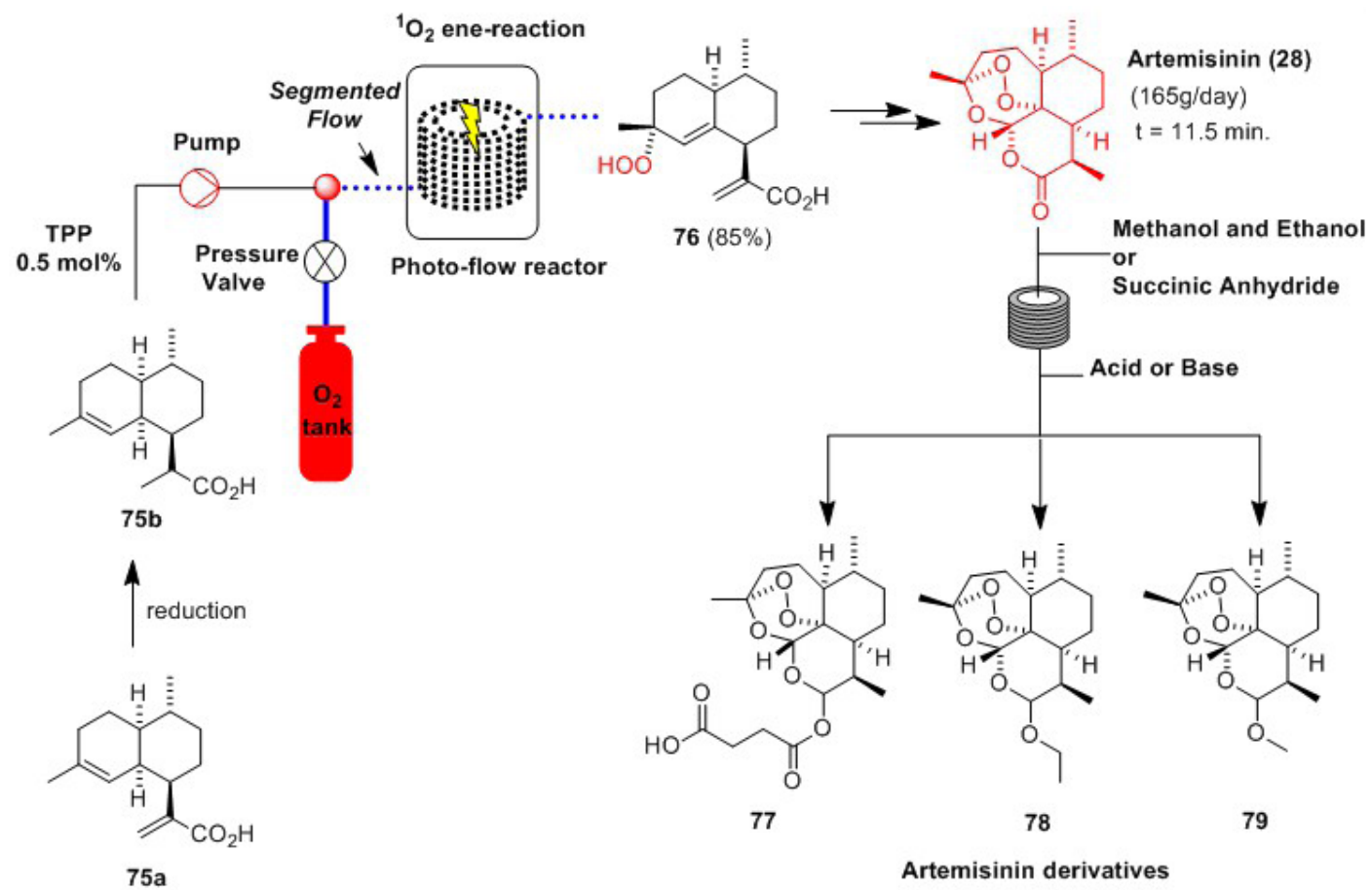

Scheme 21 - Synthesis of artemisinin (28) under continuous photo-flow conditions, and transformation into derivatives 77-79.

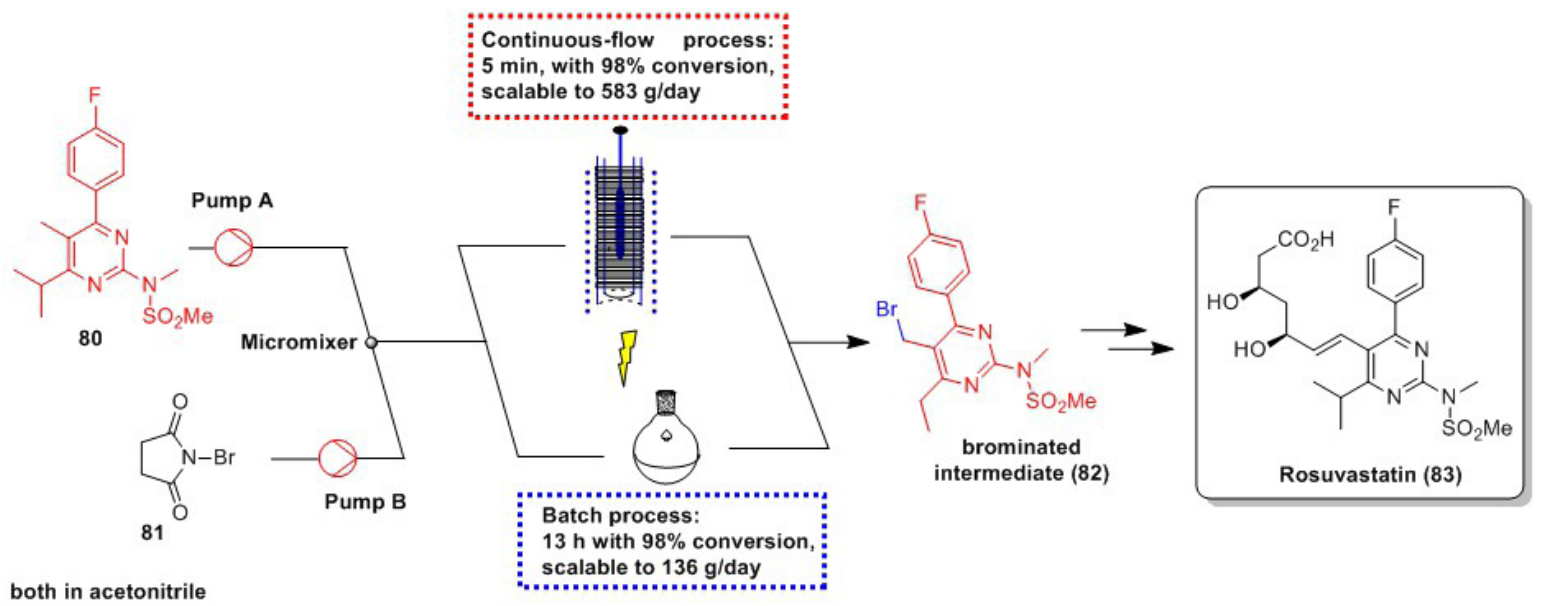

Scheme 22 - The brominated rosuvastatin intermediate (82) synthesis.

construction of natural and non-natural organic molecules (Nicolaou and Rigol 2017, Morrison and Hergenrother 2014). This becomes clear if we consider the outstanding total syntheses of complex natural products (NPs) performed in the last seven decades (Corey and Li 2013).

In NP synthesis, a complex target molecule is prepared and analytically characterized according to the naturally occurring compound, termed a natural product. Although there are a large number of new methodologies for the synthesis of NPs, the synthetic strategies and tactics have not followed the same development, and it is still a timeconsuming and labor-intensive practice involving manual procedures performed by a highly-trained and skilled workforce (Ley et al. 2015). In this 


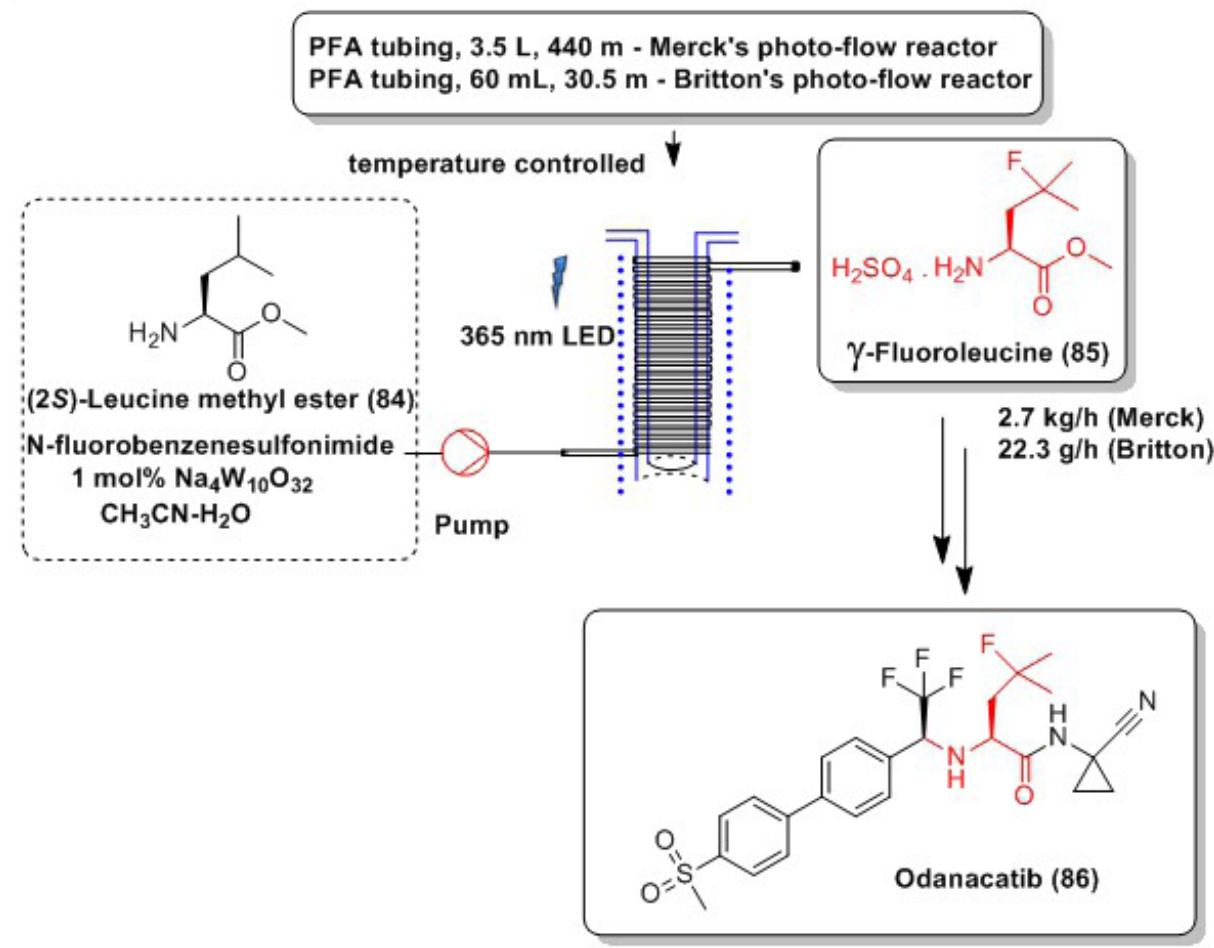

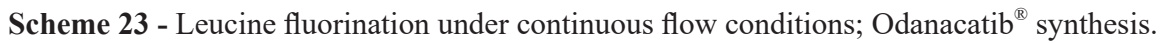

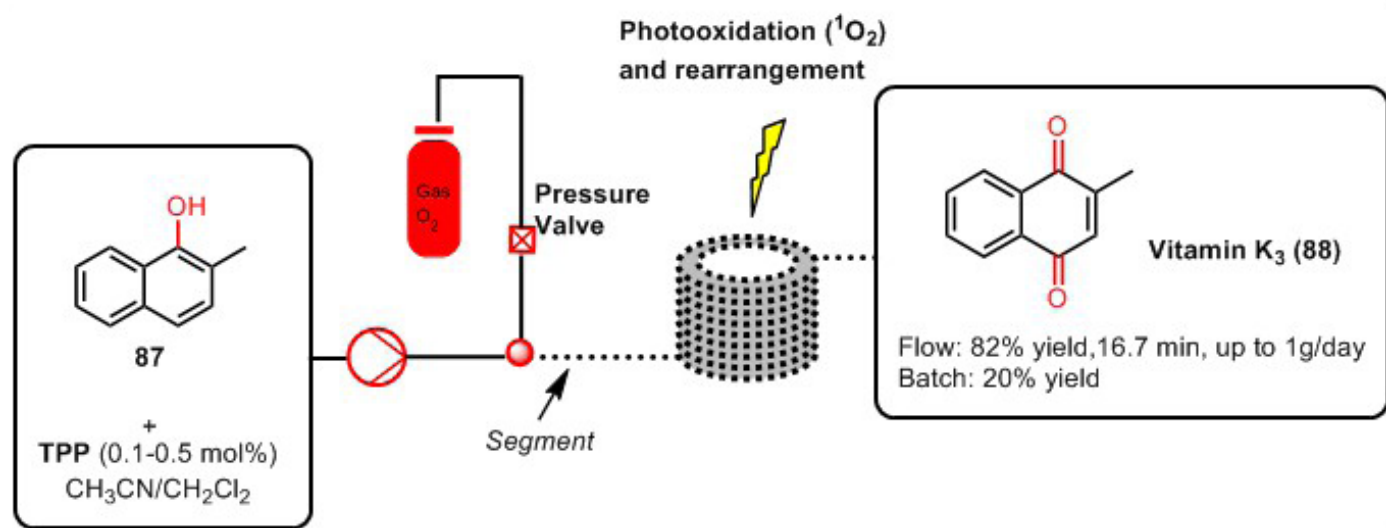

Scheme 24 - Naphthol photooxidations followed by rearrangement; vitamin $\mathrm{K}_{3}$.

context, enabling technologies, such as continuous flow chemistry employing microreactors, have been broadly explored in order to circumvent the limitations of the traditional batch procedures for the synthesis of NPs (Pastre et al. 2013a).

In a multi-step synthesis performed in flow, the chemicals are directly pumped through the system containing mixers, coil reactors, microchips, columns, in-line liquid-liquid separators, analytical techniques for in-line and real-time monitoring, and back pressure regulators. A target molecule can thus be prepared in a well-designed continuous flow configuration, avoiding many manual operations, which are typically performed individually in batch (Scheme 27) (Fitzpatrick et al. 2016, Ley et al. 2015). 


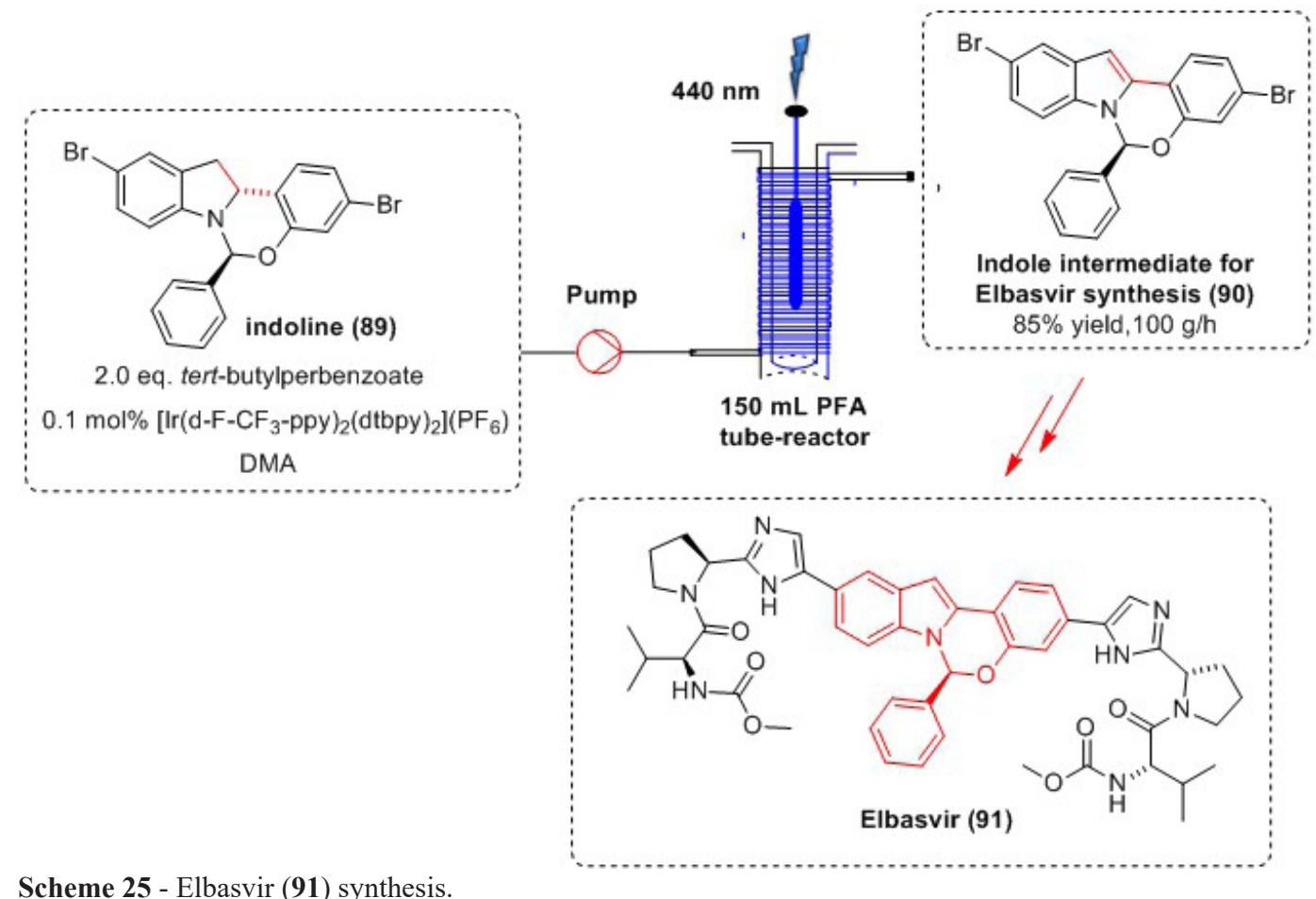

(91) synthesis.

photo-flow reactor

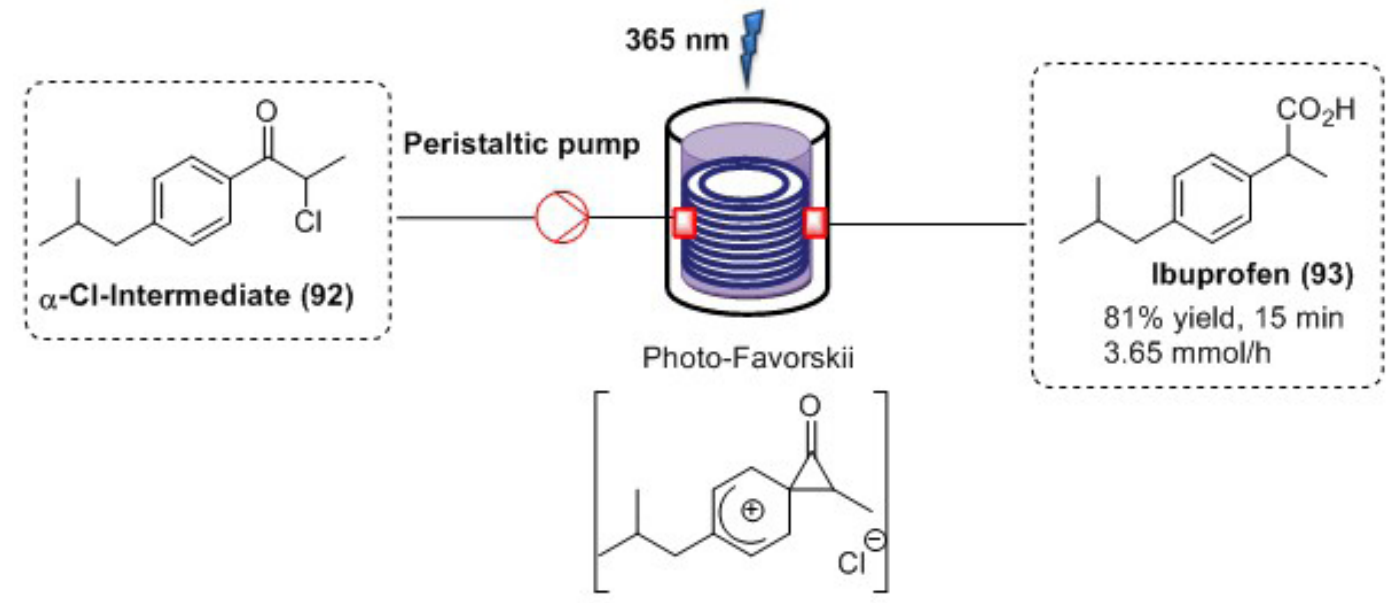

Scheme 26 - Ibuprofen (93) synthesis by the photo-Favorskii rearrangement.

Over the last decade, the development of flow chemistry (or microreactor technologies) by several research groups has contributed to the improvement of the tools of organic synthesis towards a more sustainable practice (Fanelli et al. 2017). Multi-step telescoped synthesis, machineassisted synthesis, in-line purifications and in-line reaction monitoring are some of the key features which have been extensively explored in the continuous flow regime (Elvira et al. 2013). In this section we will highlight these advances and the successful applications of flow chemistry for the synthesis of NPs.

In 2005, the first synthesis of a NP was demonstrated by the Ley research group using an automated flow system capable of preparing 


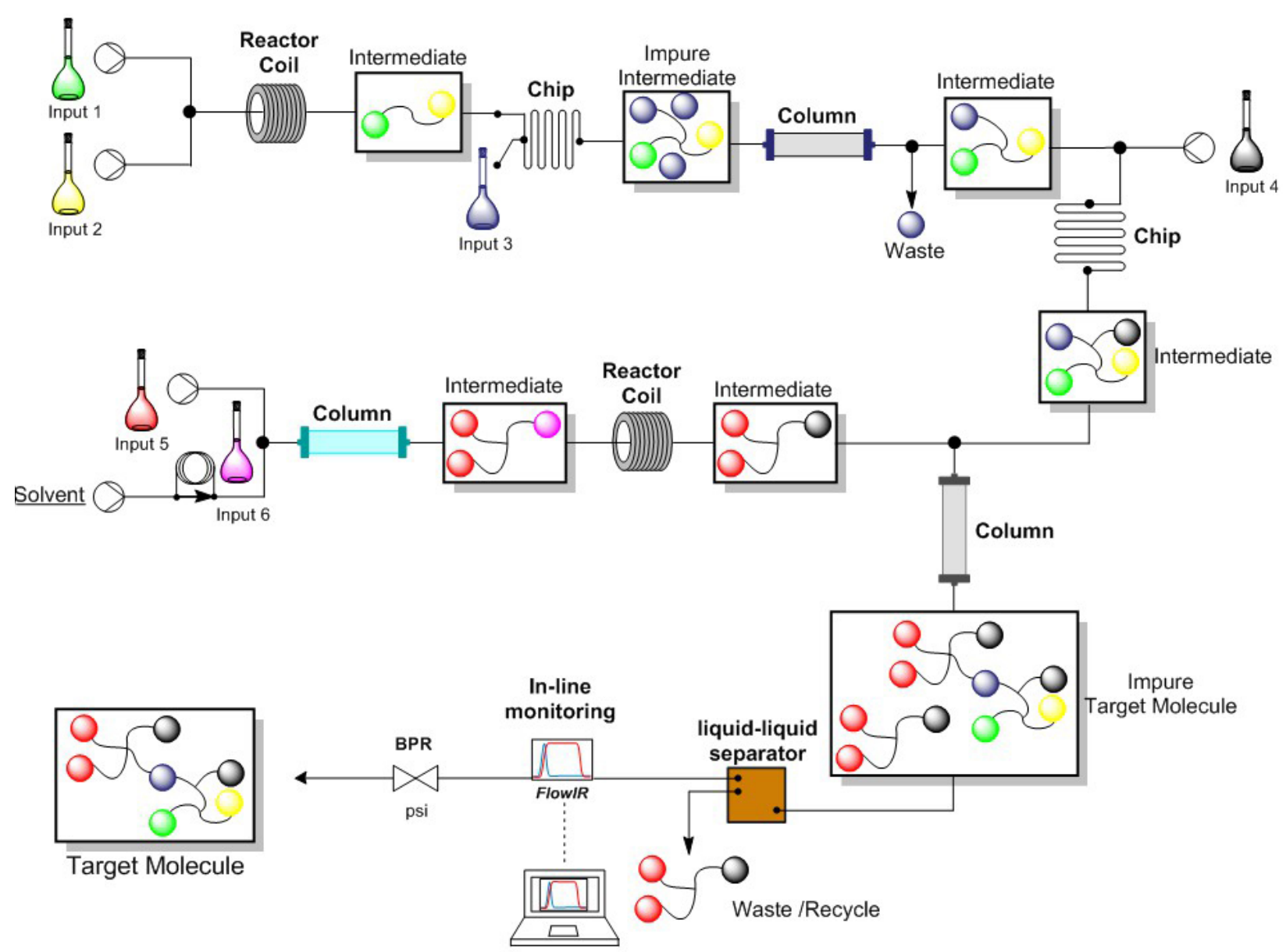

Scheme 27 - General strategy for the multi-step continuous flow synthesis of NPs.

the neolignan NP grossamide (95) in a gram scale (Baxendale et al. 2006a). For this purpose, several columns of immobilized reagents and scavenging reagents were used to mediate each individual reaction and also to avoid the need for exhaustive manual purification of the intermediates in the synthetic sequence (Scheme 28). For both coupling and intramolecular cyclization steps, inline monitoring by LC-MS or UV-Vis techniques were used to optimize the reactions parameters and speed-up the whole process. Notice that these strategies of in-line purification and monitoring are part of the advantages which can be explored in flow, to give highly pure synthetic intermediates and to completely follow the reaction progress. Under optimized conditions, grossamide (95) was prepared after a three-step protocol including an enzymatic reaction.

Although it may be considered an easy task, the three-step synthesis of grossamide brought innovative concepts for multi-step assembly in flow. This opened up novel opportunities for multistep syntheses of compounds using immobilized reagents in a fixed-bed reactor, and also in-line monitoring employing bench top analytical tools (Baxendale et al. 2006a).

In 2006, the second NP synthesized in flow was the alkaloid oxomaritidine (104) isolated from Amaryllideacae oxomaritidine, (Scheme 29) (Baxendale et al. 2006b). This is considered a milestone in method development given the fact that seven separate synthetic steps are combined 


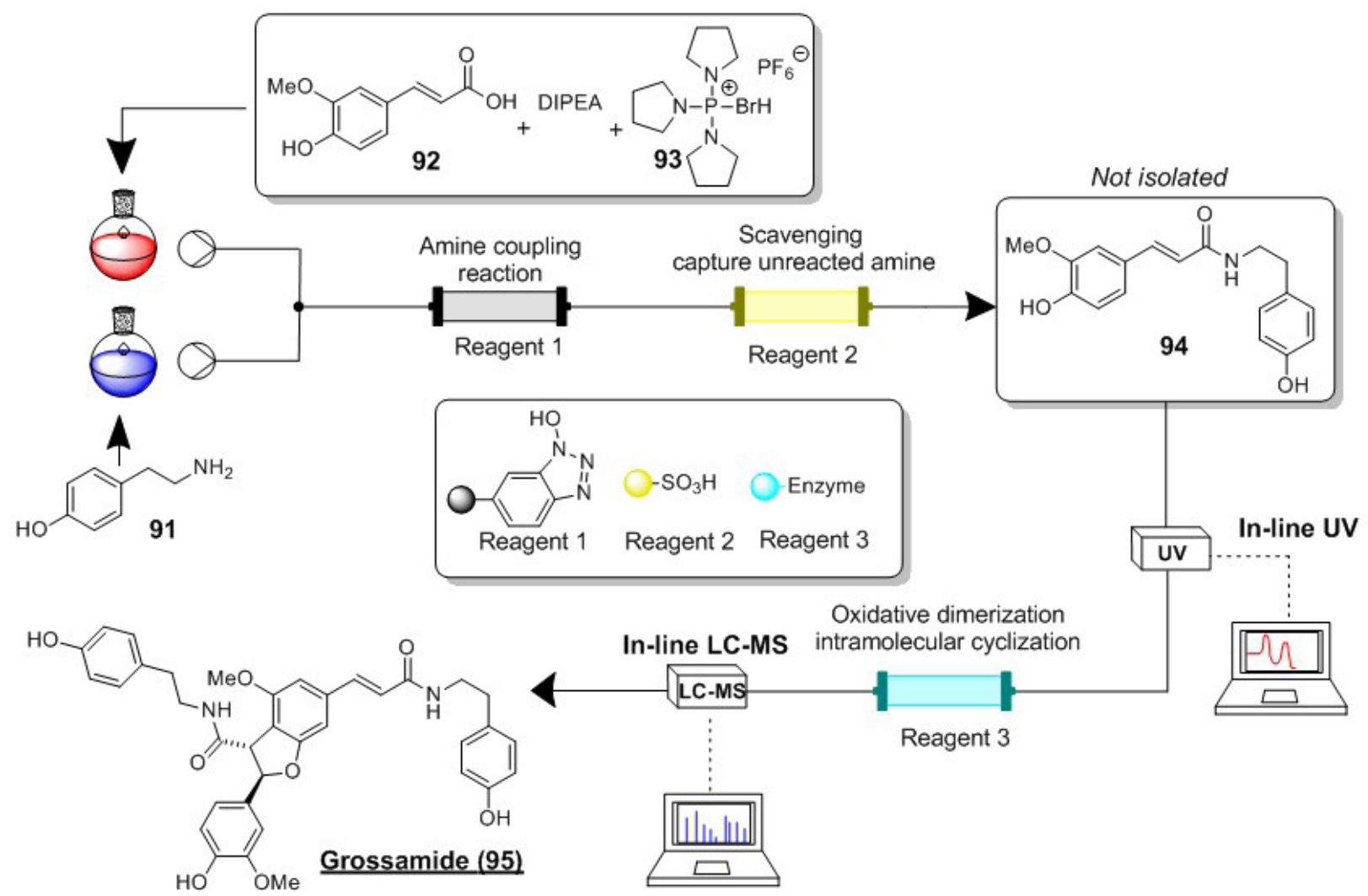

Scheme 28 - Simplified set-up for the synthesis of neolignan natural product grossamide (95) in flow.

in an elegant sequence in flow. For the sake of comparison, the synthesis in batch (Ley et al. 1999) using conventional RBFs requires at least four days of laboratory manipulation to prepare 104, while in a few hours the same seven steps were performed in flow. In this flow process, immobilized reagents, catalysts, scavengers or catch and release agents were efficiently used.

This seven-step sequence showcases the potential and what can be accomplished in flow for the synthesis of a complex target molecule. The sequence performed in flow reactors presents notable gains in terms of both the cost and efficiency of the process, since it reduces the use of extensive purification procedures. Moreover, the rapid optimization and precise control of reaction conditions allows a superior synthesis of oxomaritidine (104) with an impressive $40 \%$ overall yield.
In a review published in 2013, Ley and coworkers presented a wide variety of NPs already synthesized (Pastre et al. 2013a). Besides the syntheses of $( \pm$ )-oxomaritidine (104) and grossamide (95) described above, other syntheses include the saturated isoprenoid pristine (105), asparagine-linked oligosaccharides (106), (-)-perhydrohistrionicotoxin (107), vitamin $\mathrm{D}_{3}$ (74), aplysamine (108), pseudomonas quinolone signal (PQS) (109), (+)-dumetorine (110), $o$-methylsiphonazole (111), pauciflorol F (112), artemisinin (28), the ladder-shaped polyether yessotoxin (113), and (-)-hennoxazole A (114) (Figure 6). Most of these syntheses are integrated processes and combine batch and continuous flow processes, taking advantage of the benefits of each regime.

Since 2013 other important contributions in NP syntheses have been published, along with 

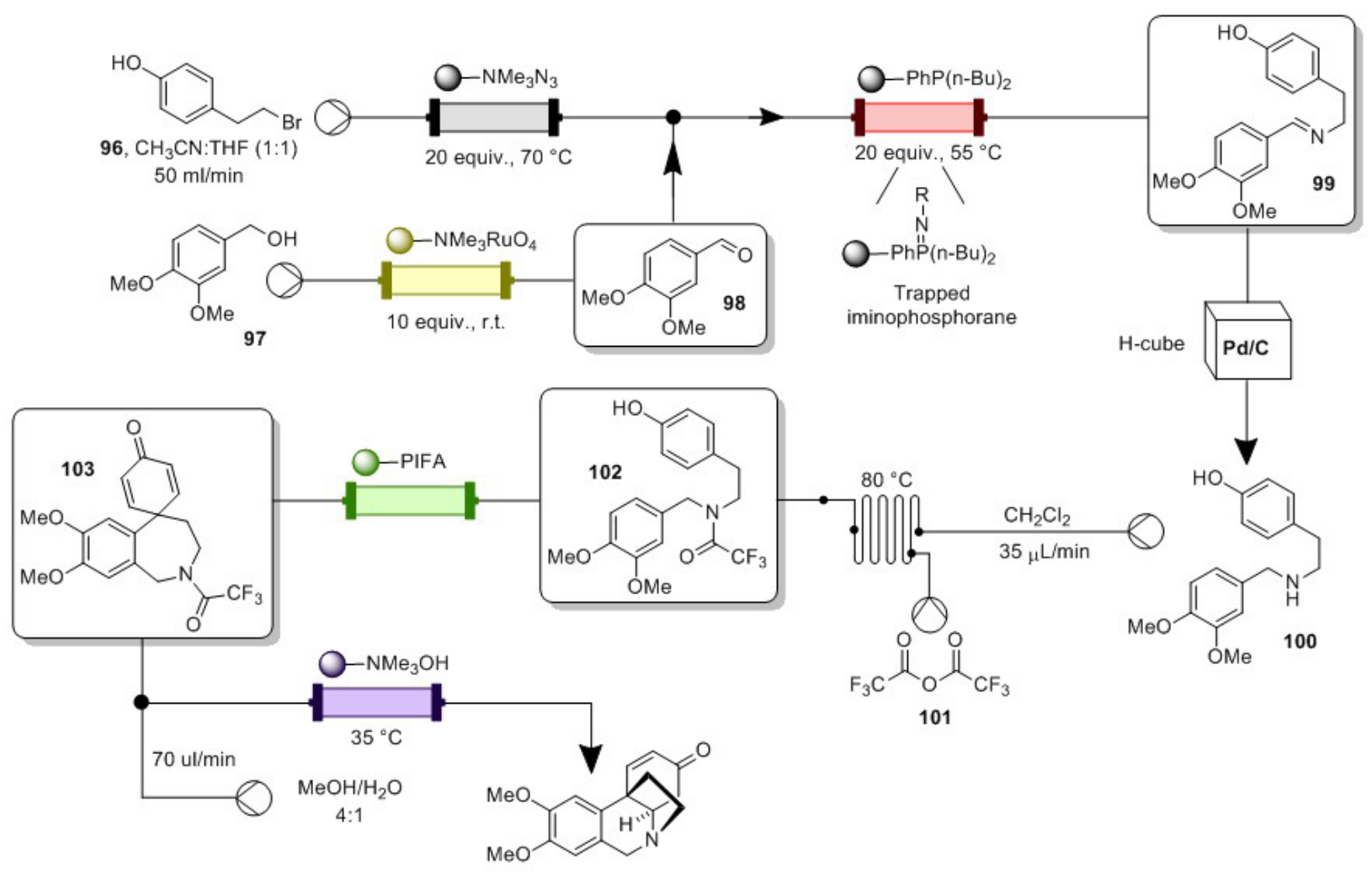

(士)-oxomaritidine (104)

Scheme 29 - Continuous flow synthesis of ( \pm )-oxomaritidine (104).

the development of novel technologies in flow chemistry (Elvira et al. 2013, Fanelli et al. 2017, Ley et al. 2015).

In 2014, Ley's group reported the most ambitious synthesis of a complex NP, the spirocyclic polyketide spirodienal A(147), using a combination of batch and flow processes (Schemes 30-33) (Newton et al. 2014). Additional and innovative tools were demonstrated and used to accomplish the planned synthesis. The strategy adopted was based on the coupling of two key fragments, an aldehyde 135 and a bis-alkyne 144 (Scheme 33), both containing the same three stereocenters in the 1,3-dioxane ring. In order to prepare the aldehyde 135, the homoallylic alcohol 122 was first synthesized in five steps under continuous flow conditions (Scheme 30), using the in-house tube-in-tube reactor (Matthew et al. 2010) for the catalytic hydrogenation reaction.
The aldehyde fragment $\mathbf{1 3 5}$ was synthesized in $11.6 \%$ overall yield for thirteen steps, nine of them performed in the flow regime (Scheme 31).

The synthesis of the bis-alkyne 144 (Scheme 32) required the use of several solid-supported reagents and different types of reactors such as coil, microchip and fixed-bed reactors. In addition, some reactions already used to prepare aldehyde 135 were again addressed here, demonstrating the versatility and reproducibility of flow reactions as reaction platforms.

Bis-alkyne 144 was prepared in 8 steps (7 in flow and 1 in batch) in $22 \%$ overall yield and, interestingly, a continuous flow liquid-liquid separator was employed to deliver this compound in high purity. Liquid-liquid separators based on membrane technologies are now commercially available and offer a viable alternative to polymersupported reagents for in-line work-up procedures. 

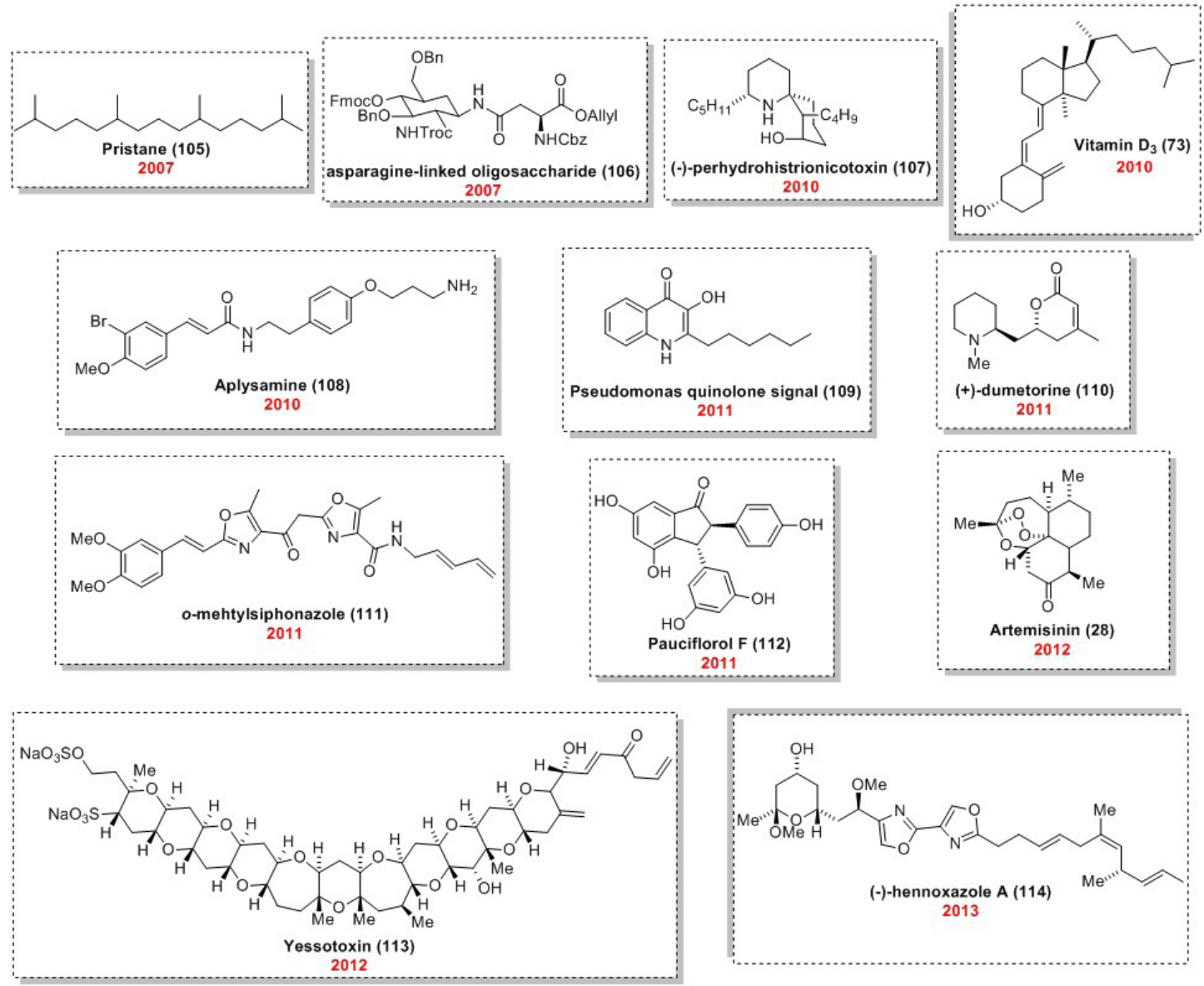

Figure 6 - NPs prepared using combined batch and continuous flow processes up to 2013.

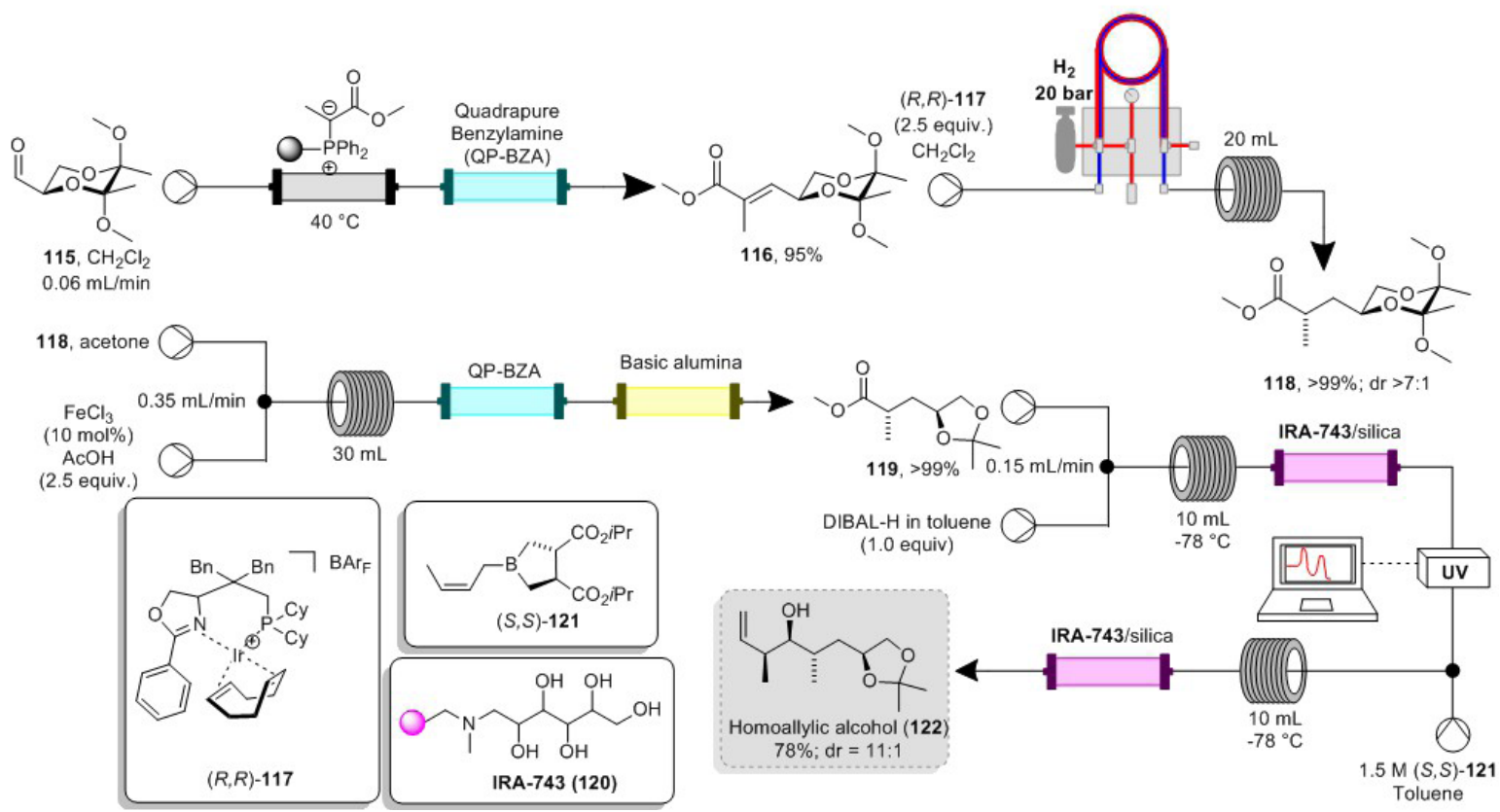

Scheme 30 - Continuous flow synthesis of the homoallylic alcohol 122. 


\section{Synthesis of Aldehyde 135 in flow}

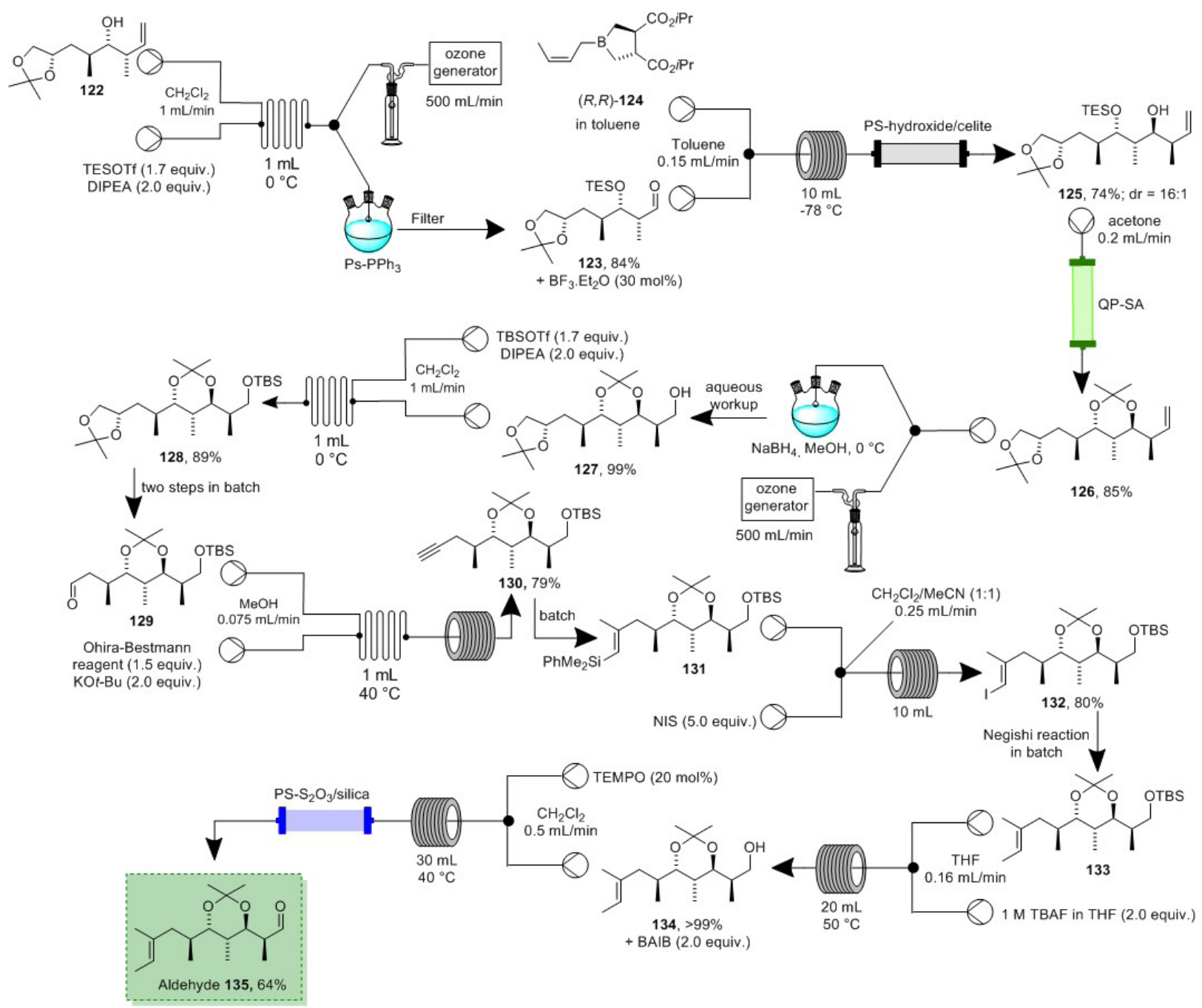

Scheme 31 - Integrated batch and flow synthesis of the key aldehyde 135.

With aldehyde 135 and the bis-alkyne 144 in hands, 10 more steps were carried out in batch to complete the total synthesis of the spirocyclic polyketide spirodienal A (147) (Scheme 33).

Valuable transformations such as automated reagent additions, ozonolysis, silylations/ desilylations, olefinations, crotylations, and oxidations were efficiently carried out in flow (Fitzpatrick et al. 2016, Ley et al. 2015, Elvira et al. 2013), showing the potential for either method development or total synthesis.
Moving to more recent studies performed in flow, Figure 7 exhibits the latest NPs prepared in either the end-to-end approach or using a combination of batch and flow regimes.

In 2013, Ley's group demonstrated an integrated batch and continuous flow process for the synthesis of goniothalamin (151) (Pastre et al. 2013b). The addition of a Grignard reagent was performed in flow, proving that the handling of such sensitive materials (Browne et al. 2013) can be easily performed in a safe manner. The 


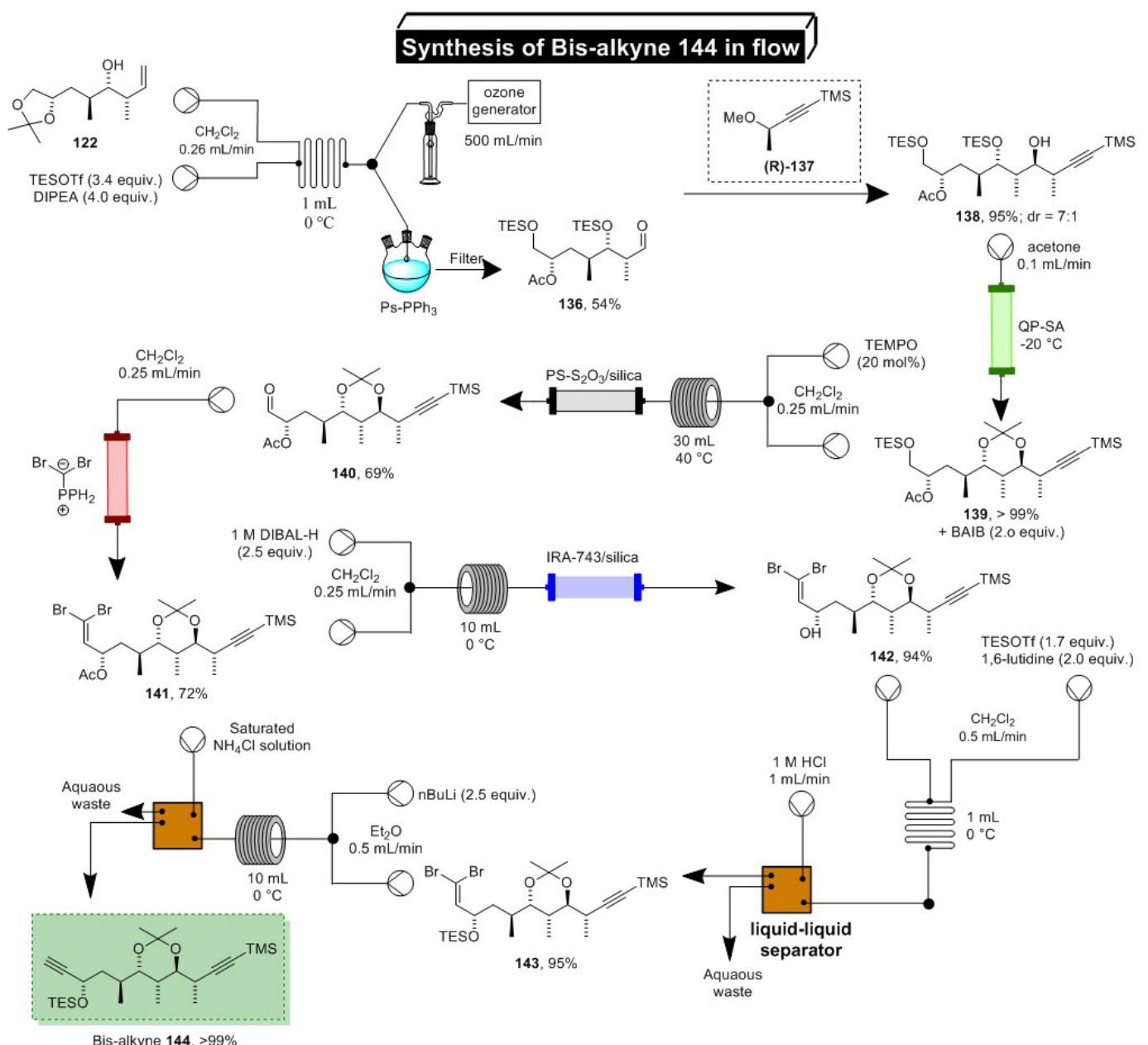

Scheme 32 - Continuous flow synthesis of the bis-alkyne 144.
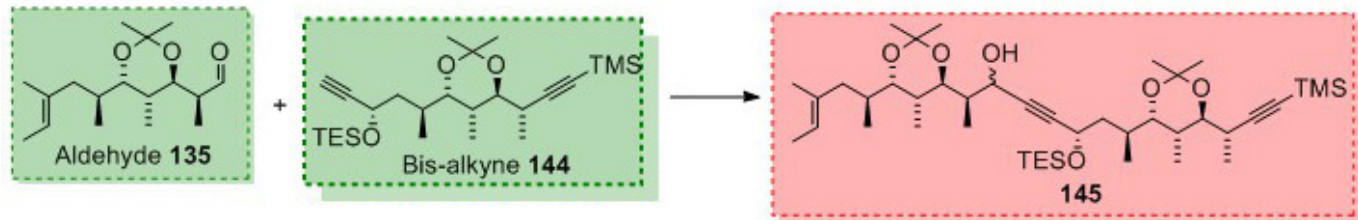

10 more steps in batch
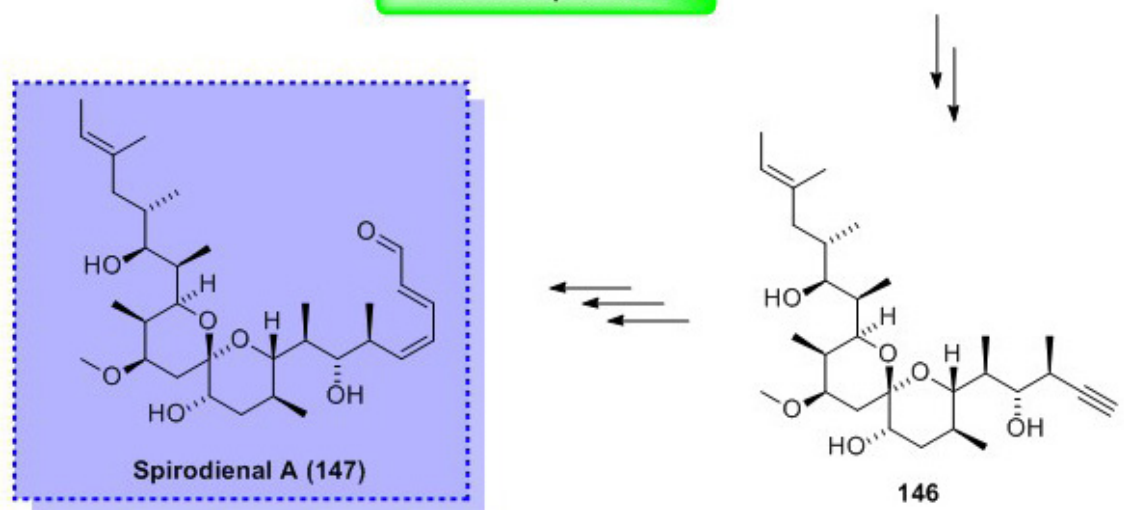

Scheme 33 - Final steps of the spirodienal A (147) synthesis. 

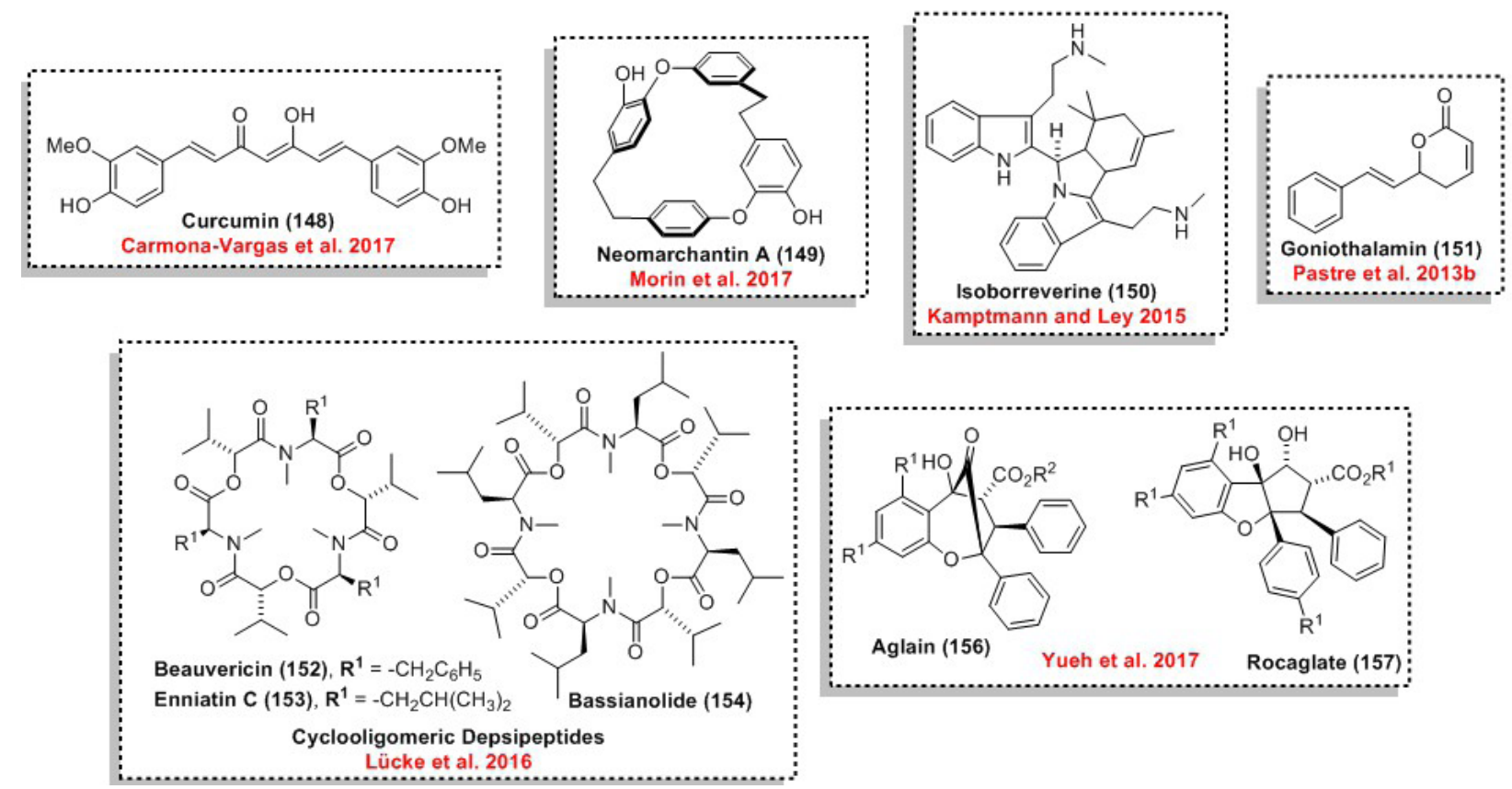

Figure 7 - NPs prepared using batch and flow integrated approaches, since 2014.

strategy used by the authors to introduce the a,b-unsaturated six-membered ring lactone was based on a metathesis reaction using the secondgeneration Grubbs catalyst (GII) in flow regime. In 2015, the same group reported the synthesis of isoborreverine (150) in flow regime (Kamptmann and Ley 2015). This NP was synthesized in a single step using a column packed with polymersupported boron trifluoride which catalyzes the ring opening reaction of borrerine. A diene intermediate is generated in this process and rapidly undergoes a Diels-Alder reaction to afford isoborreverine (150). In this study, the ability to rapidly change temperature and flow rates was essential for a fast optimization of reaction conditions for the desired biomimetic synthesis.

In 2016, Ley and coworkers presented the synthesis of cyclooligomeric depsipeptides, such as 152-154, using a macrocyclization reaction to form the challenging $N$-methylated amides (Lücke et al. 2016). Superior yields were obtained using a telescoped process in flow when compared to batch procedures: beauvericin (152), $26 \%$ yield in batch and 36\% yield in flow; enniatin C (153), 15\% yield in batch and $44 \%$ yield in flow; bassianolide (154), 24\% yield in batch and $43 \%$ yield in flow. Although the synthesis of oligopeptides can be performed using automated synthesizers, these results using microreactors bring opportunities for their synthesis, notably when scale-up is required.

Collins and coworkers performed the synthesis of neomarchantin A (149) using batch and flow combined procedures (Morin et al. 2017). Two key bond formations involving $\mathrm{C}-\mathrm{O}\left(\mathrm{S}_{\mathrm{N}} \mathrm{Ar}\right.$ reaction) and $\mathrm{C}-\mathrm{C}$ (olefin metathesis reaction) bonds were intensified using continuous flow techniques.

Beeler and coworkers exploited the benefits of flow chemistry for the synthesis of aglain (156) and rocaglate natural product analogues 157 (Yueh et al. 2017). In this case, an ESIPT-mediated $[3+2]$-photocycloaddition reaction was performed with good productivity $\left(1.0-1.9\right.$ g.h $\left.\mathrm{h}^{-1}\right)$ using a photochemical flow reactor.

Recently, the natural product curcurmin (148) and two other curcuminoids were prepared by de Oliveira and coworkers in an end-to-end strategy 
in flow regime (Carmona-Vargas et al. 2017). An interesting comparison between batch, flow and the combined strategies was demonstrated: curcumin (148) was obtained in 69\% yield in batch (STY $=12.0 \mathrm{~g}$ per day), whereas a clear advantage was reported in the flow regime ( $60 \%$ yield; STY $=24.1$ g per day).

Natural products and structures inspired by their molecular scaffolds have played a significant role in the drug discovery field, representing more than half of all small-molecule drugs approved between 1981 and 2014 (Appendino et al. 2014, Morrison and Hergenrother 2014). In view of their unique structural diversity, NPs are still considered privileged scaffolds for drug discovery. However, even considering all the advances experienced in the last decades such as new methodologies based on catalytic methods, protecting group-free syntheses, C-H activation approaches and late stage functionalization, there are many challenges to be addressed in order to achieve more efficient and concise syntheses.

Based on the NP syntheses presented herein, it is clear that enabling technologies, especially continuous flow chemistry, can play a major role in the synthesis of complex NPs, leading to a fundamental change in the way we perform total syntheses. Flow chemistry facilitates the scale-up of advanced intermediates, which is often limited in batch and by the use of in-line tools. The number of individual purifications can be dramatically reduced, allowing for the integration of several steps and decreasing the time spent to deliver a complex NP. It is time to make better use of our financial and human resources, and therefore the opportunities brought by machine-assisted NP synthesis should be emphasized.

\section{API SYNTHESIS \& CONTINUOUS MANUFACTURING}

Active pharmaceutical ingredients (APIs) are, in general, synthesized in batch manufacturing plants and then shipped to other sites to be converted into a form that can be given to patients, such as tablets, drug solutions, or suspensions (finished medicines). This system offers little flexibility to respond to surges in demand and is susceptible to severe disruption if one of the plants has to shut down. Worldwide, companies such as Novartis, Lilly, Lonza and others are investigating continuous manufacturing of new drug substances in order to reduce their manufacturing costs, and to provide a more robust way of producing the desired molecules. This demand has an incredible effect on the development of new technologies such as flow reactors, phase separators, pumps, among others. Some companies have established new businesses by designing their own reactor systems, like the Lonza FlowPlate ${ }^{\circledR}$ micro and milli-reactors (Vaccaro et al. 2014, Wiles and Watts 2014, Gutmann et al. 2015, Kobayashi 2016, Britton and Raston 2017, Fanelli et al. 2017, Plutschack et al. 2017).

In academia, an initiative directed by Gupton at Virginia Commonwealth University - USA, in collaboration with the Bill \& Melinda Gates Foundation, called Medicines for All, seeks cheaper and more efficient ways to manufacture drugs, particularly those needed to treat HIV and AIDS in developing countries. The main idea behind their strategy was to start with very simple commodity chemicals, in order to make it feasible for developing economies. So far these strategies are not completely applied in industry (Longstreet et al. 2013).

Another initiative funded by the Defense Advanced Research Projects Agency (DARPA) and MIT researchers came up with a small transportable device suitable for small-scale syntheses of drug molecules (Adamo et al. 2016). Their new system can produce 1,000 doses of four drugs formulated as solutions or suspensions in 24 hours; i.e benadryl, lidocaine, valium, and prozac. A refrigeratorsized continuous-flow apparatus [1.0 m (width) 
x $0.7 \mathrm{~m}$ (length) x $1.8 \mathrm{~m}$ (height), $\sim 100 \mathrm{~kg}$ ] is capable of complex multistep synthesis, multiple in-line purifications, post synthesis work-up and handling, semi-batch crystallization, real-time process monitoring, and ultimately formulation of high-purity drug products. The continuous flow strategy towards the synthesis of diphenyldramine hydrochloride is shown in Scheme 34.

Recently, Lilly (Cole et al. 2017) has enabled a kilogram synthesis of prexasertib monolactate monohydrate (166) under continuous flow conditions and GMP (good manufacturing practice) qualifications. This medicine has been assessed in phase 1 and 2 clinical trials in combination with cytotoxic chemotherapy, targeted agents, and as a monotherapy, and is the first CHK1 inhibitor to demonstrate objective clinical responses as a monotherapy. During discovery and initial clinical trials a nine-step route was used, but deemed unsuitable for long-term manufacturing due to several hazardous reagents and moderate yields. Lilly has now opened up a new route to prexasertib by exploring the continuous flow environment (Scheme 35).
The first step has serious restrictions when conducted under batch conditions due to the use of hydrazine in a large excess and the high temperatures needed for reaction completion. Using continuous flow technology and a plug-flow reactor, it was possible to reduce the amount of hydrazine and operate safely at $130^{\circ} \mathrm{C}$. It is important to note that only $0.49 \%$ of the overall production is inside the reactor at any time, reducing material at risk and increasing process safety. The first step was conducted with $89.6 \%$ yield at $3.08 \mathrm{~kg} /$ day, arriving at the final product with only $2 \mathrm{ppm}$ of hydrazine and less than $1 \%$ of impurities. The next step was accomplished with $88.7 \%$ yield on a 2.56 $\mathrm{kg}$ /day basis. Unlike the first step, this intermediate needed further purification, since it was necessary to remove residual starting material, regioisomers and other minor impurities. The desired product was obtained on a continuous deprotection and batch crystallization process, leading to a final yield of $85 \%$ and $1.99 \mathrm{~kg}$ /day for the final step.

Safety is a decisive matter for Boehringer Ingelheim Pharmaceuticals (Marsini et al. 2017) when deciding to implement a continuous flow process for the synthesis of a CCR1 antagonist

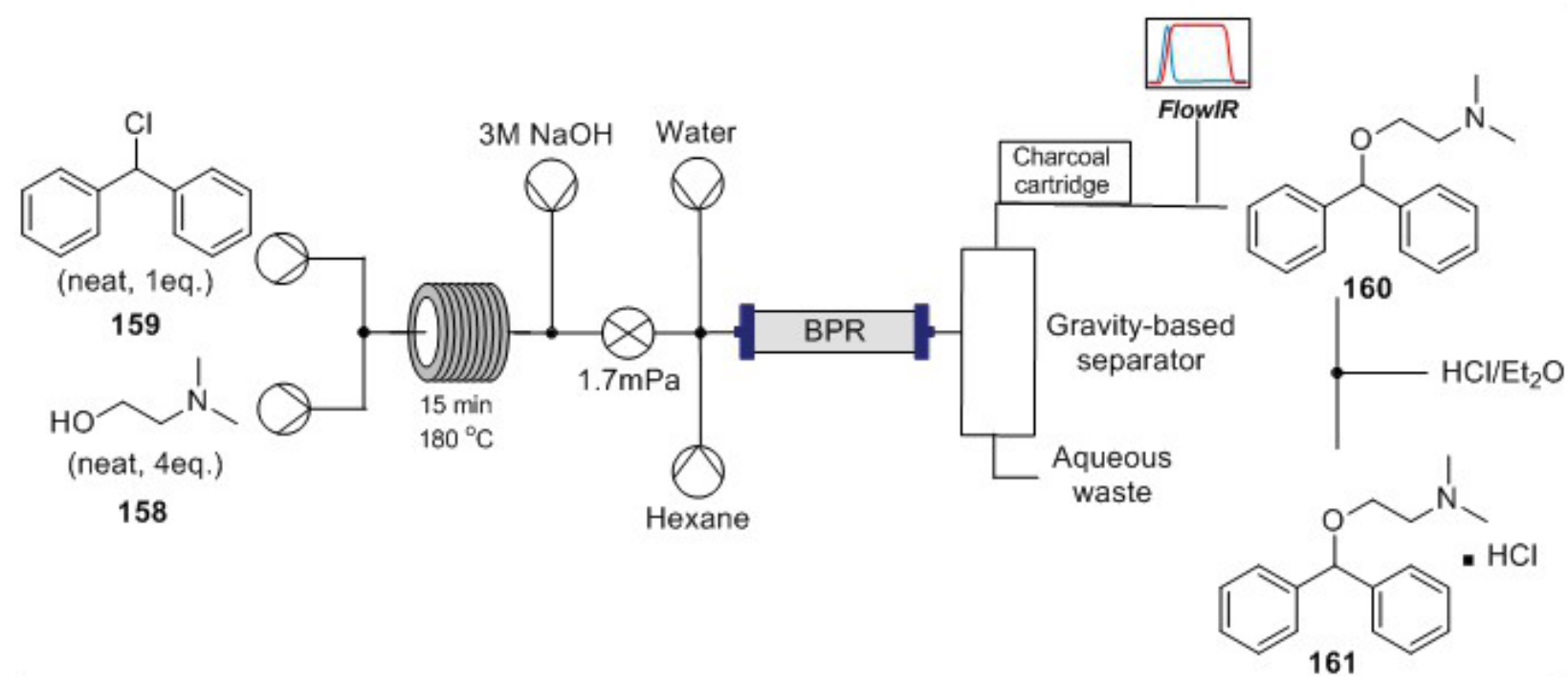

Scheme 34 - An example of end-to-end continuous flow synthesis with integrated analysis and separation for diphenyldramine hydrochloride (161). 


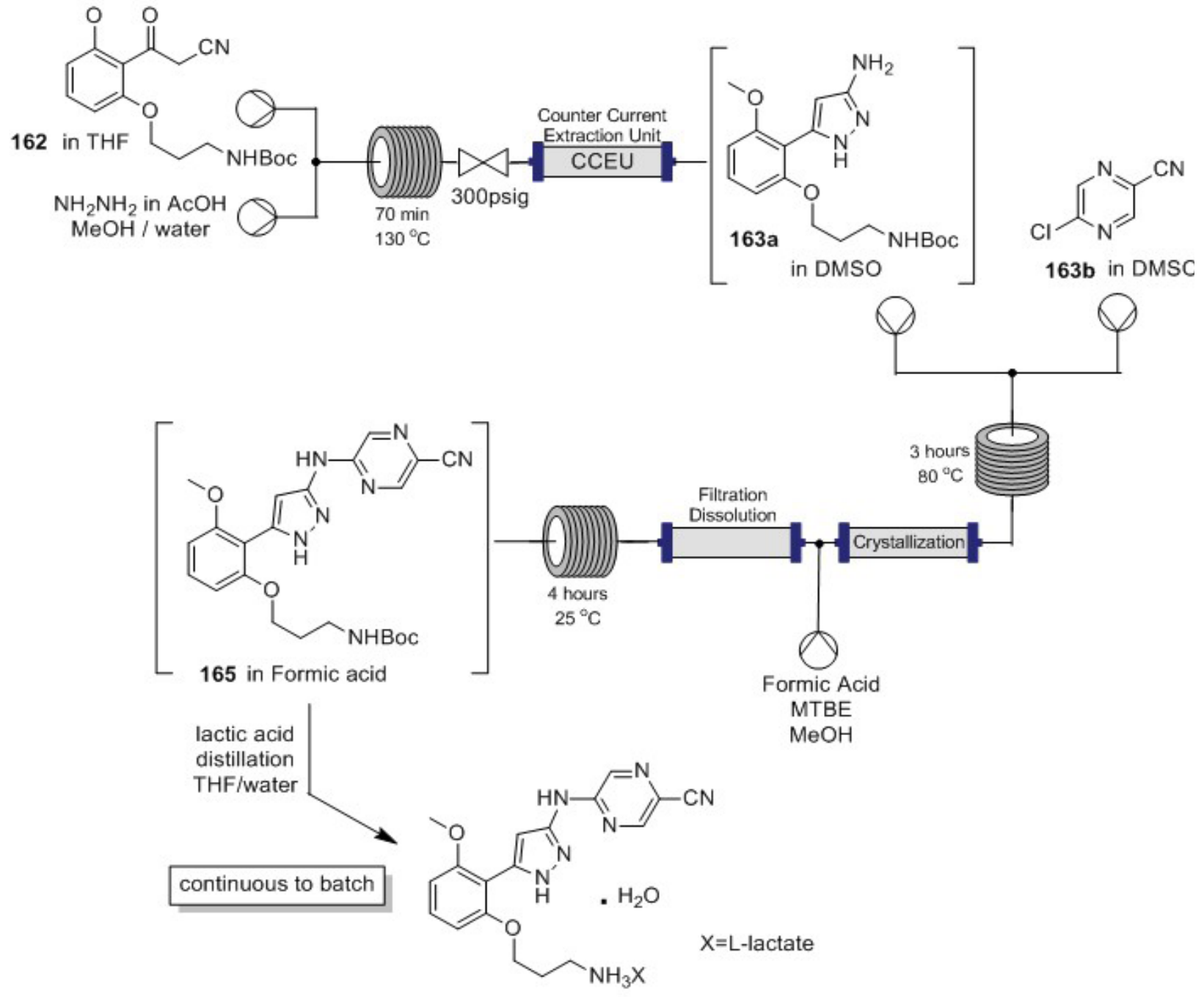

prexasertib monolactate monohydrate (166)

Scheme 35 - Continuous flow three-step synthesis of prexasertib monolactate monohydrate (166) under GMP conditions.<smiles>COSc1cc(C2(C(=O)O)CC2)ccn1</smiles>

Scheme 36 - Semi-continuous isocyanate formation followed by Curtis rearrangement. 
(169), which has an acyl azide and/or isocyanate as intermediates (Scheme 36).

The batch process started with the formation of an acyl azide, in order to lead to the carbamate product by Curtis rearrangement. Decoupling azide formation from isocyanate trapping was successful, due to the key potential drawback of undesired acyl azide accumulation in the CSTR (continuous stirred-tank reactor) upon further scale-up. When implementing the continuous flow protocol the isocyanate intermediate formation was optimized for a residence time of $3 \mathrm{~min}$ in $76 \%$ overall yield, and $56 \%$ more efficient than the original Curtis batch process, allowing a further scale-up to $40 \mathrm{~kg}$ of the final product.

D\&M Continuous Solutions, Eli Lilly and Lilly Research Laboratories (May et al. 2016) have developed an efficient continuous iridiumcatalyzed homogeneous high pressure reductive amination reaction to produce the penultimate intermediate (172) in evacetrapib synthesis. The continuous process operated under GMP conditions for 24 days and produced over $2 \times 10^{6}$ tons of $\mathbf{1 7 2}$ in $95 \%$ yield after batch workup, crystallization, and isolation (Scheme 37).

A final reaction condition was optimized where $\mathrm{H}_{2}$ pressure and substrate/catalyst ratio maximizes product formation leading to minor undesired impurities such as the cis regioisomer.
The presence of TBAI was crucial as it appears to hold the $\operatorname{Ir}(\mathrm{I})$ in a more stable anionic form which is less prone to degradation under the reaction conditions. For those who are afraid of working with hydrogenation reactions at large-scales, the authors say "the reactor operates at $>98 \%$ liquid filled with the hydrogen distributed throughout the 45 pipes and downflow tubes resulting in a steady venting of nitrogen-diluted hydrogen over time (20 $\mathrm{g} / \mathrm{h}$ at scale)... It is for these reasons that the continuous process is viewed as a low risk process in spite of its operation at high pressure". They could show the linear scale-up capability of the continuous flow process going from $48 \mathrm{~L}$ reactors up to $360 \mathrm{~L}$ reactors for production scale, giving the desired product in $95 \%$ isolated yield.

One of the first examples of a continuous flow process applied to APIs was presented by DSM (Braune et al. 2009) on the nitration reaction towards the production of naproxinod, an antiinflammatory drug (Scheme 38).

The task faced by DSM was to develop a safe and highly efficient nitration process, selectively nitrate only one hydroxyl group and handle the very hazardous nitrated product. After optimization found the exact nitric acid concentration needed $(65 \%)$, it could be taken for scale-up. The operation unit has a total volume around $150 \mathrm{~mL}$ and process capability of $13 \mathrm{~kg} / \mathrm{h}$ working at GMP conditions.

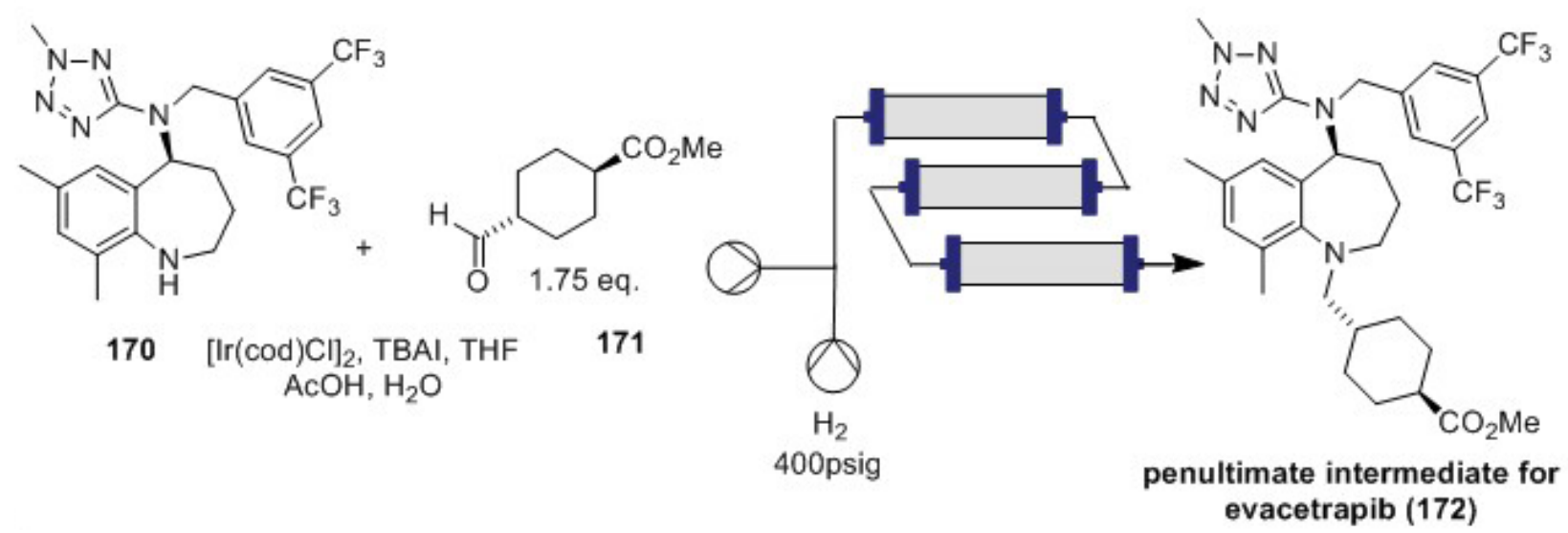

Scheme 37 - Homogeneous continuous flow reductive amination of an intermediate of evacetrapib synthesis. 


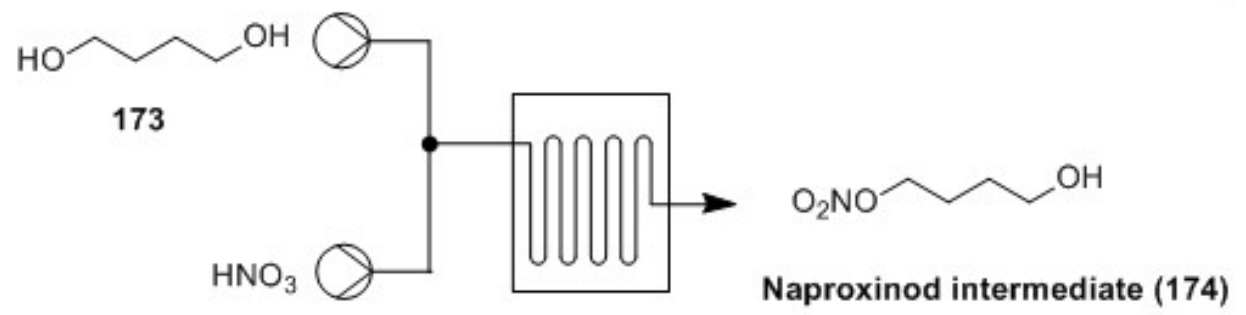

Scheme 38 - DSM continuous-flow nitration process.

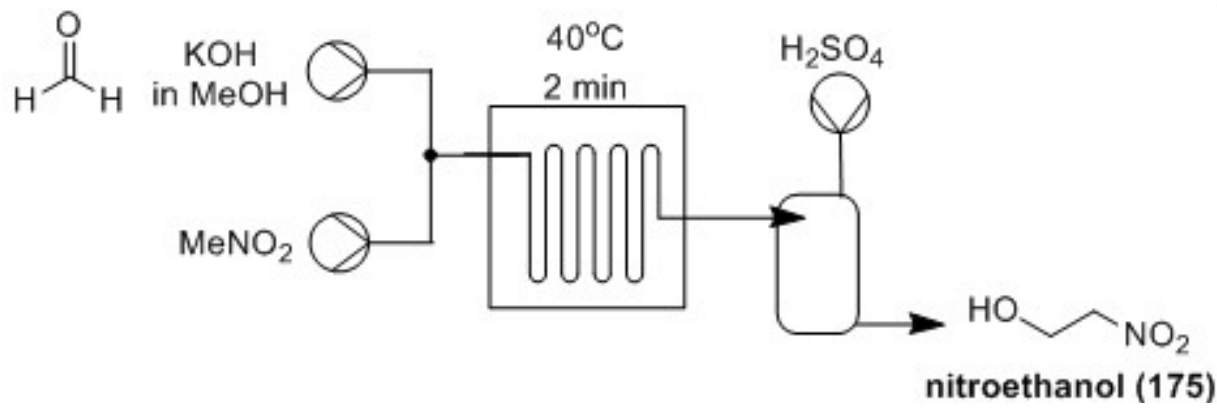

Scheme 39 - Nitroethanol continuous flow synthesis developed for aliskiren production.

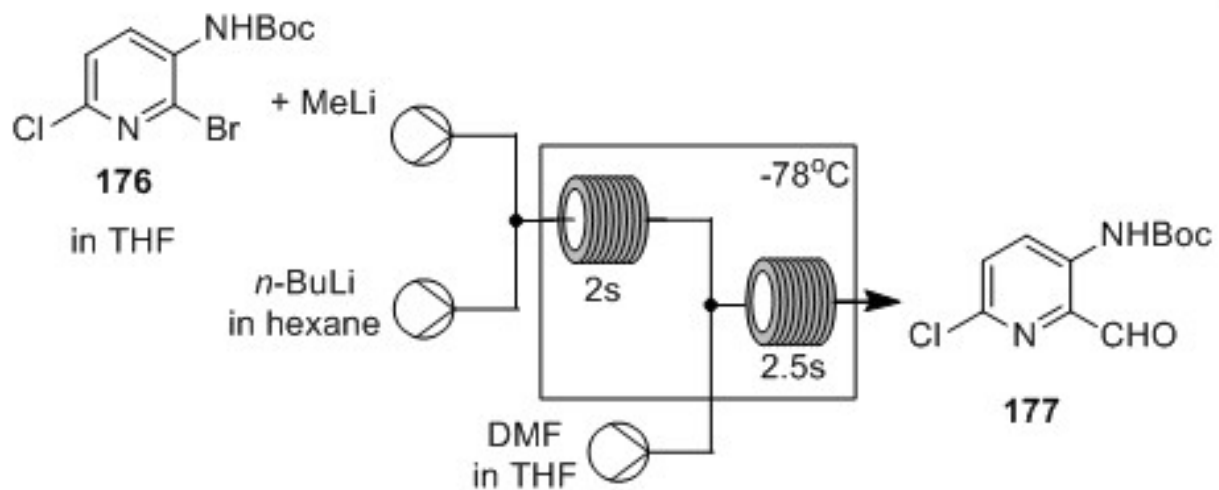

Scheme 40 - The formylation process developed by Merck, in order to avoid batch scale-up problems.

During the pilot plant campaign $500 \mathrm{~kg}$ of qualified product could be produced under the developed conditions.

Lonza and Novartis (Roberge et al. 2014) have worked together in order to overcome a problem related to starting material nitroethanol in the aliskiren API synthesis. This reagent is required in $\mathrm{kg}$ amounts, since it is used in an organo-catalytic reaction between nitroethene and isovaleric aldehyde to form 2(R)-isopropyl-4nitro-1-aldehyde, subsequently reduced by sodium borohydride to furnish the desired 2(R)-isopropyl- 4-nitro-propan-1-ol. Since lower nitroalkanes are potentially explosive, a continuous flow process was developed for the production of nitroethanol (175) in high yields (95\%) and very short residence times (Scheme 39).

An API developed by Merck (Grongsaard et al. 2012) as an allosteric Akt inhibitor used for cancer treatment, had one step optimized under continuous flow conditions in order to ensure the production of kilogram quantities for clinical trials. During reaction optimization under batch conditions and gram scale, the design process worked as expected, 
but under a larger scale the formylation reaction did not behave as expected. The reaction solution turned into a thick gel, a phenomenon that had not been observed in gram scale experiments. The batch temperature had to be raised to $-45^{\circ} \mathrm{C}$ and the agitator manually manipulated until the mixture was sufficiently mobile to allow stirring to continue automatically. The final yield was not affected but raised concerns about a possible scaleup. With these results in hands, the authors decided to develop a continuous flow protocol in order to overcome the reaction media instability observed under batch conditions (Scheme 40).

The continuous flow process was performed mixing the amine and MeLi. This solution was fed into a stainless-steel tube reactor with an internal diameter of $6.35 \mathrm{~mm}$, and kept at $-78^{\circ} \mathrm{C}$ using a dryice/ acetone bath. After the first deprotonation the amide stream was mixed with $n-\mathrm{BuLi}$, to form the dianion in the first residence tube, and the dianion was then combined with the DMF/THF feed solution in order to produce the desired formylated product $\mathbf{1 7 7}$ in $65 \%$ yield and purity equal to that obtained under batch conditions. The very short residence times operated in this process which uses flow rates up to $175 \mathrm{~mL} \mathrm{~min}^{-1}$, allow the production of $1 \mathrm{~kg}$ of the aldehyde after just 1 hour.

Continuous API production is a reality for big pharma, which certainly intends to migrate from batch to flow protocols in a few years. Many safety and low-cost production problems are addressed with this change, but most importantly the logistics will be significantly improved with much smaller GMP areas required for flow plants.

\section{APPLICATION OF CONTINUOUS FLOW CHEMISTRY TO MEDICINAL CHEMISTRY}

Lead compound identification and optimization, synthesis of chemical libraries, and supply of materials in sufficient quantity for clinical assays, are time-consuming and a laborious task for medicinal chemists. Therefore, further advances are needed to reduce the time taken to synthesize libraries of compounds, identify potential hits/leads, optimize synthetic routes to afford the final compounds, and put drug candidates into production.

Continuous flow chemistry is finding increasing use as an enabling technology in academic and industrial environments, providing a number of advantages over batch processes, and leading to a variety of interesting and exciting opportunities. As we have mentioned before, continuous flow processing enables simple scale-up of reactions, enhanced mixing, temperature and pressure control, decrease of waste generation and energy consumption, and integration of several reaction steps (telescoped synthesis). Furthermore, the volumes of reagents/solvents are reduced, which facilitates the screening of reaction conditions, and consequently, the rapid generation of focused compounds libraries (Malet-Sanz and Susanne 2012, Yavorskyy et al. 2012b, Baraldi and Hessel 2012). These advantages become more appealing if one considers that solvents account for $c a$. $80 \%$ of the waste generated in the production of APIs.

Although the pharmaceutical industry still relies on the use of multipurpose batch reactors in its production lines, it is clear that continuous flow chemistry is already making the manufacturing of APIs faster and simpler. It should also have a profound impact on the discovery of new drug candidates, synthesis of chemical libraries, and scale-up of reactions for clinical trials (Fitzpatrick et al. 2016, Baraldi and Hessel 2012, Malet-Sanz and Susanne 2012, Rankovic and Morphy 2010, Poh et al. 2016).

In this context, an increasing number of studies have been reported, and selected families of heterocycles with pharmacological importance prepared in flow are shown in Figure 8. These efforts highlight the application of continuous flow chemistry as a reliable enabling technology for the 
fast generation of compound libraries for biological screening in drug discovery programs.

For those interested in the molecules shown in Figure 8, the publication by Britton and Jamison for the synthesis of pyrazoles and pyrazolines is a good example of the use of flow chemistry in the synthesis of chemical libraries (Britton and Jamison 2017). A sequence of coil reactors was used to generate substituted diazoalkanes in situ which then undergo a [3+2] cycloaddition reaction with alkynes and alkenes to afford pyrazoles and pyrazolines, respectively. More than thirty compounds were prepared using the optimized conditions in a straightforward manner (Scheme 41) (He and Jamison 2014, Mykhailiuk 2015).

The ability to perform several steps in flow without the need for individual purifications was also explored (Britton and Jamison 2017). Three flow modules were added which allows further reactions with the recently formed azole core. Thus, C-N arylation/methylation, amidation and TMS removal reactions were sequentially performed and gave access to some therapeutics and a human lung cancer suppression candidate. For example, Scheme 42 shows an integrated sequence of five steps in a continuous flow regime to prepare the measles therapeutic AS-136A (183). Other highly substituted pyrazoles can be prepared using this unified continuous flow assembly for their evaluation in a MedChem program.

Another concept of flow chemistry that has stimulated research in the field of medicinal chemistry is the possibility to integrate steps that are typically performed alone: synthesis, purification, and evaluation of biological activities. (Guetzoyan et al. 2013, Baranczak et al. 2017). In this regard, many synthetic and biological laborious manual procedures can be avoided employing a machineassisted approach for complete evaluation of a target molecule (Ley et al. 2015).

In this context, Ley's group reported in 2013 the use of flow chemistry to perform the synthesis and biological evaluation in an integrated flow platform (Scheme 43) (Guetzoyan et al. 2013). The continuous flow synthesis of a series of imidazo[1,2- $a$ ]pyridines, including two anxiolytic drugs (zolpidem and alpidem), was evaluated and directly coupled to a frontal affinity chromatography (FAC) screening assay in order to investigate their interaction with the Human Serum Albumin (HSA) protein (Kragh-Hansen 1990).

Advantages of flow processes in this set-up are evident, since it allows different aminopyridines and unsaturated ketones to be dispensed into the reactors to achieve a collection of compounds in a computer- and machine-assisted manner. Moreover, this transformation typically takes 24 hours in batch procedures (Guetzoyan et al. 2013).

By the use of immobilized reagents, this strategy proves that both the desired set of reactions and the workup and purification procedures can be accessed in a single process avoiding exhaustive manual operations. The authors did not present a fully integrated platform for the synthesis of compound libraries and their biological evaluation, but the instrumental components and assembly demonstrated in this study form the basis for future developments towards this goal.

Summarizing, flow chemistry has brought a new dimension for traditional medicinal chemistry with a huge difference when compared to combinatorial chemistry. Continuous protocols are more focused and deliver fast solutions for extensive screenings. The incorporation of in-line biological assays will speed up the process of drug discovery, placing continuous flow chemistry at the frontier of modern medicinal chemistry.

\section{CONCLUSIONS}

Chemical syntheses assisted by enabling technologies have been widely used in the last six decades by the petrochemical and chemical industries, and it is well accepted that continuous flow chemistry has been the key technology in 
<smiles>[R]C(=O)C1CN(S([R])(=O)=O)CC1([R])[X]</smiles>

Pyrrolidines 30 examples Baumann et al. 2011a<smiles>[R]C(=O)c1c(-c2ccc([R])cc2)nc2c([R])cc([R])cn12</smiles>

$\mathrm{GABA}_{\mathrm{A}}$ agonists

22 examples Guetzoyan et al. 2013<smiles></smiles>

Pyrrole-3-carboxylic acids 17 examples Herath and Cosford 2010<smiles>NCCCC1NCCc2c1[nH]c1cc[R]cc21</smiles>

Nazlinine analogues 6 examples<smiles>[R20]c1c(C([R])[R])c2cccn2c2c[R1]ccc12</smiles>

Pyrrolo[1,2-a]-quinolines 3 examples<smiles>[R]c1[nH]nc(C([R])(F)F)c1[R]</smiles><smiles>[R]C1=NNC(C([R])(F)F)C1[R]</smiles>

Pyrazoles and Pyrazolines 30 examples<smiles>[R]N1CCN(C(=O)c2ccc3ccc(N([R])[R1])n3c2)CC1</smiles>

3-Aminoindolizines 100 examples<smiles>[R]c1noc([R])n1</smiles>

1,2,4-oxadiazoles and triazoles 1,4-benzodiazepin-5-ones 50 examples Bogdan and Wang 2015<smiles>[R16]C1=Nc2cc(OC)c(OC)cc2C(=O)NC1</smiles>

Lange and James 2012<smiles>[R]c1ncc([Al])[nH]1</smiles>

1H,4-Imidazoles 13 examples Carneiro et al. 2015<smiles>[R]Sc1nnc([R])n1[R2]</smiles>

3-thio-1,2,4-triazoles

18 examples Damiăo et al. 2017

\section{Reagents}

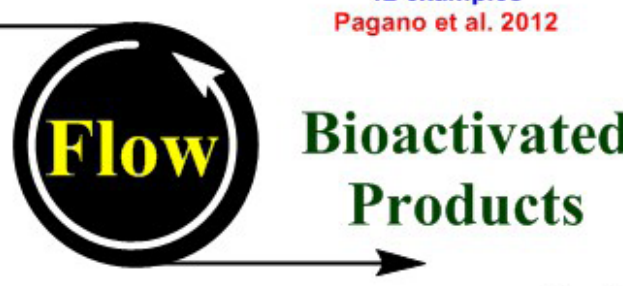<smiles>[R1]c1ccc2[nH]cc([R])c(=O)c2c1</smiles>

Pyrimidinones and Quinolones 17 examples Tsoung et al. 2017<smiles>[R]c1ccc2c(c1)C1(Nc3ccccc3C(=O)N1[R])C(=O)N2[R]</smiles>

Spiro-oxindole Dihydroquinazolinones 9 examples

Engen et al. 2017<smiles>[R]C1([R])NC(=O)NC1=O</smiles>

Hydantoins 10 examples Vukelic et al. 2017<smiles>[R]N([R])c1nn([R2])nc1C#N</smiles>

1,2,3-triazole-4-carbonitriles 9 examples Jacq and Pasau 2014<smiles>[R]C1NC1([R1])[R]</smiles>

Aziridines

9 examples Baumann and Baxendale 2016b<smiles>[R]c1ccc2c(c1)c(-c1nc([R])cs1)c(C)n2[R]</smiles><smiles>[R]c1nsc([R])n1</smiles>

1,2,4-thiadiazoles 9 examples Baumann and Baxendale 2017 Indolylthiazoles 12 examples Pagano et al. 2012
Bioactivated Products

Figure 8 - Selected examples of bioactive heterocyclic molecules prepared in continuous flow regime. 


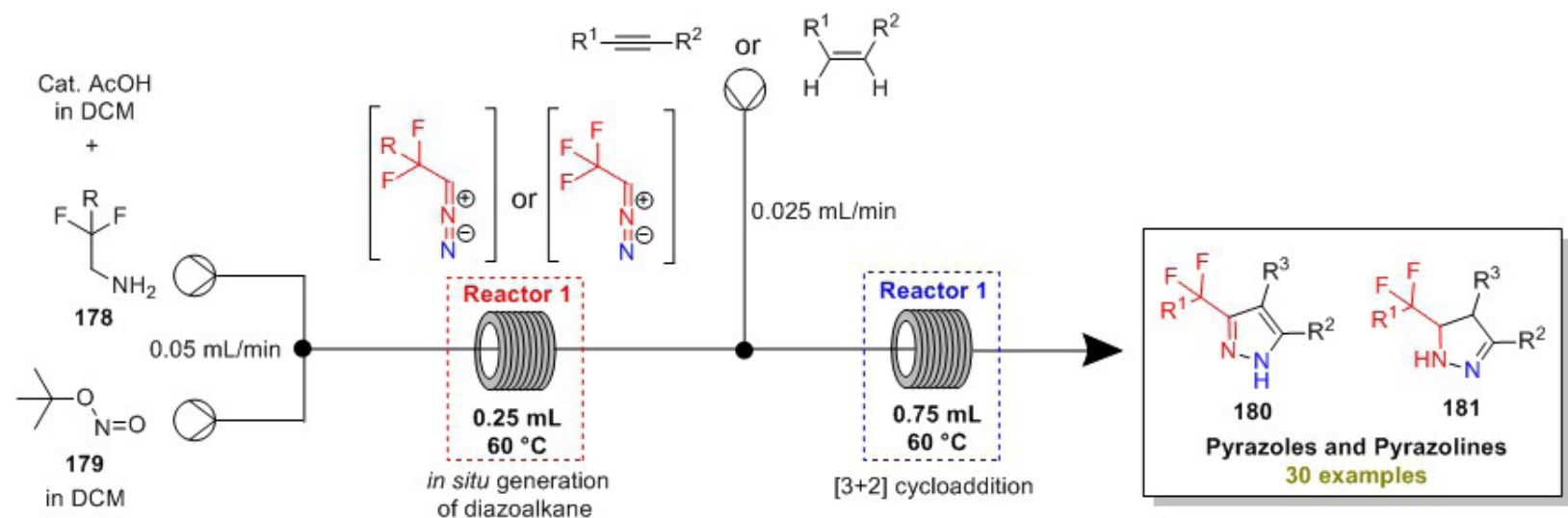

Scheme 41 - Continuous flow synthesis of highly substituted pyrazoles and pyrazolines.

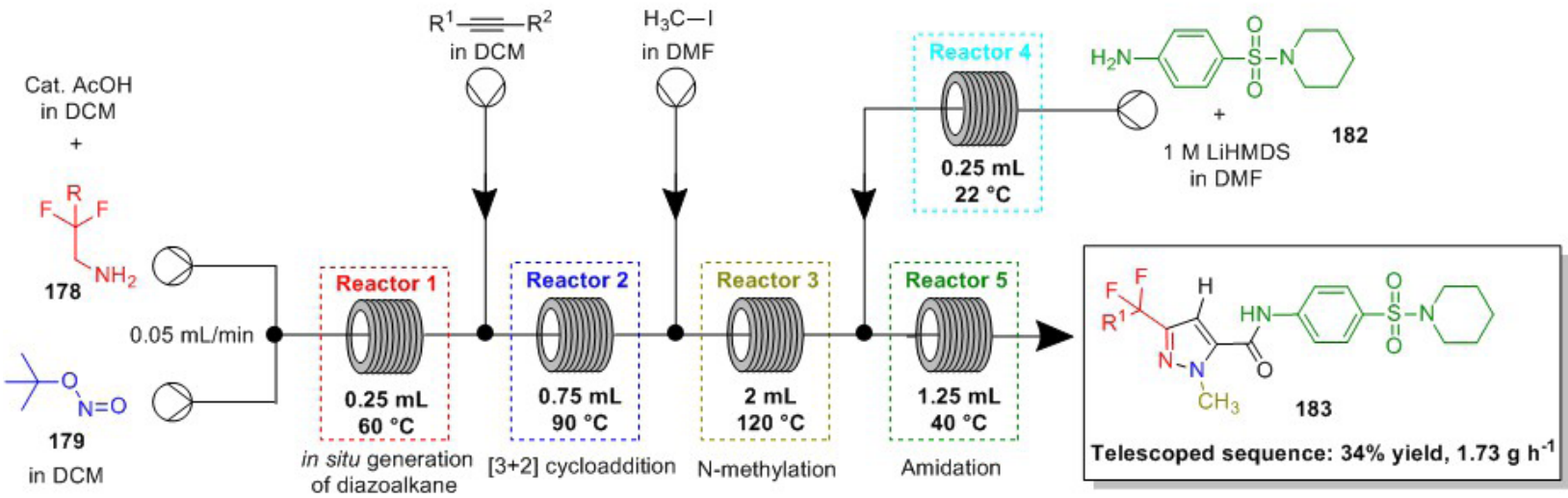

Scheme 42 - Synthesis of AS-136A using a unified continuous flow platform.

this scenario. However, only in the last 20 years has this technology attracted the attention of big pharma and academia as a real and useful tool to expand accessible chemical space and support scale-up, safety, profitability and sustainability of chemical and API synthesis. In this review we have shown the many facets and possibilities of enabling technologies in chemical synthesis, highlighting essential examples using flow chemistry but, most importantly, trying to show the broad scenario in which chemists and chemical engineers are inserted. To finish, we should always remember that Nature knows best; biosynthesis is much more a continuous flow process than batch.

Our principal perspective is that enabling technologies such as continuous flow chemistry are not a promise, but are very important tools already present, and certainly are the future of developments in chemical synthesis.

\section{ACKNOWLEDGMENTS}

The authors gratefully acknowledge financial support from the Fundação de Amparo à Pesquisa do Estado de São Paulo (FAPESP, awards 2011/13993-2, 2013/07276-1, 2014/26378-2, 2014/25770-6, and 2015/2110-4). Thanks are also due to Conselho Nacional de Desenvolvimento Científico e Tecnológico (CNPq, JMS fellowship, awards 453862/2014-2, 444435-2014-0 and 302458/2016-6) and CAPES (R.G. fellowship).

\section{REFERENCES}

ADAMO A ET AL. 2016. On-demand continuous-flow production of pharmaceuticals in a compact, reconfigurable system. Science 352: 61-67. 


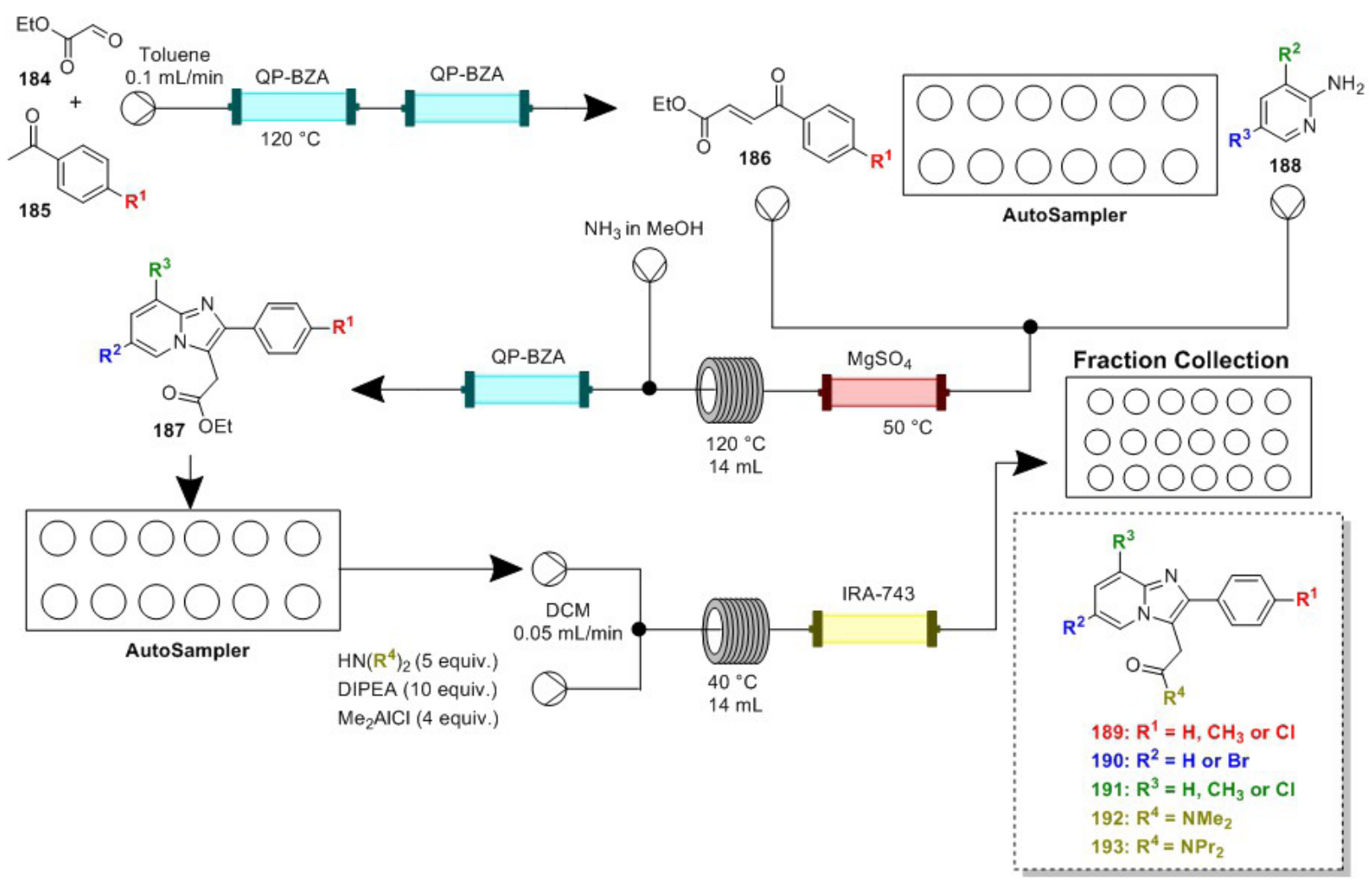

Scheme 43 - Sequence in flow to prepare imidazo[1,2- $a$ ]pyridine scaffolds.

Imidazo[1,2-a]pyridines

AKHLAGHINIA B, EBRAHIMAMBADI H, GOHARSHADI EK, SAMIEE S AND REZAZADEH S. 2012. Ceria nanoparticles as an efficient catalyst for oxidation of benzylic C H bonds. J Mol Catal A Chem 357: 67-72.

ALVES LC, DESIDERÁ AL, DE OLIVEIRA KT, NEWTON S, LEY SV AND BROCKSOM TJ. 2015. A Practical Deca-gram Scale Ring Expansion of (R)-(-)-Carvone to (R)-(+)-3-methyl-6-isopropenyl-cyclohept-3-enone-1. Org Biomol Chem 13: 7633-7642.

APPENDINO G, MINASSIA A AND TAGLIALATELASCAFATI O. 2014. Recreational drug discovery: natural products as lead structures for the synthesis of smart drugs. Nat Prod Rep 31: 880-904.

BARALDI PT AND HESSEL V. 2012. Micro reactor and flow chemistry for industrial applications in drug discovery and development. Green Process Synth 2: 149-167.

BARANCZAK A, TU NP, MARIANOVIC J, SEARLE PA, VASUDEVAN A AND DJURIC SW. 2017. Integrated Platform for Expedited Synthesis-Purification-Testing of Small Molecule Libraries. ACS Med Chem Lett 8: 461465.

BARONA-CASTAÑO JC, CARMONA-VARGAS, CC, BROCKSOM TJ, DE OLIVEIRA KT, 2016. Porphyrins as Catalysts in Scalable Organic Reactions. Molecules 21: 310-337.

BAUMANN M AND BAXENDALE IR. 2015. Batch and Flow Synthesis of Pyrrolo[1,2-a]-quinolines via an AlleneBased Reaction Cascade. J Org Chem 80: 10806-10816.

BAUMANN M AND BAXENDALE IR. 2016a. Continuous photochemistry: the flow synthesis of ibuprofen via a photo-Favorskii rearrangement. React Chem Eng 1: 147150.

BAUMANN M AND BAXENDALE IR. 2016b. ContinuousFlow Synthesis of 2H-Azirines and Their Diastereoselective Transformation to Aziridines. Synlett 27: 159-163.

BAUMANN M, BAXENDALE IR, KURATLI C, LEY ST, MARTIN RE AND SCHNEIDER J. 2011a. Synthesis of a Drug-Like Focused Library of Trisubstituted Pyrrolidines Using Integrated Flow Chemistry and Batch Methods. ACS Comb Sci 13: 405-413.

BAUMANN M, BAXENDALE IR, LEY SV AND NIKBIN N. 2011b. An overview of the key routes to the best-selling 5-membered ring heterocyclic pharmaceuticals. Beilstein J Org Chem 7: 442-495.

BAUMANN M AND BAXENDALE IR. 2017. A continuous flow synthesis and derivatization of 1,2,4-thiadiazoles. Bioorganic Med Chem 1;25(23): 6218-6223 
BAUMANN M, GARCIA AMR AND BAXENDALE IR. 2015. Flow synthesis of ethyl isocyanoacetate enabling the telescoped synthesis of 1,2,4-triazoles and pyrrolo-[1,2-c] pyrimidines. Org Biomol Chem 13: 4231-4239.

BAXENDALE IR, DEELEY J, GRIFFITHS-JONES CM, LEY SV, SAABY S AND TRANMER GK. 2006b. A flow process for the multi-step synthesis of the alkaloid natural product oxomaritidine: a new paradigm for molecular assembly. Chem Commun 24: 2566-2568.

BAXENDALE IR, GRIFFITHS-JONES CM, LEY SV AND GEOFFREY K. 2006a. Preparation of the Neolignan Natural Product Grossamide by a Continuous-Flow Process. SYNLETT 3: 0427-0430.

BEDORE MW, ZABORENKO N, JENSEN KF AND JAMISON TF. 2010. Aminolysis of Epoxides in a Microreactor System: A Continuous Flow Approach to $\beta$-Amino Alcohols. Org Process Res Dev 14: 432-440.

BERGMEIER SC. 2000. The synthesis of vicinal amino alcohols. Tetrahedron 56: 2561-2576.

BOGDAN AR AND WANG Y. 2015. A high-throughput synthesis of 1,2,4-oxadiazole and 1,2,4-triazole libraries in a continuous flow reactor. RSC Adv 5: 79264-79269.

BOGDAN AR, POE SL, KUBIS DC, BROADWATER SJ AND MCQUADE DT. 2009. The continuous-flow synthesis of Ibuprofen. Angew Chem Int Ed 48: 85478550.

BOTTECCHIA C, ERDMANN N, TIJSSEN PMA, MILROY L-G, BRUNSVELD L, HESSEL V AND NÖEL T. 2016. Batch and Flow Synthesis of Disulfides by Visible-LightInduced $\mathrm{TiO}_{2}$ Photocatalysis. ChemSusChem 9: 17811785.

BOTTECCHIA C, RUBENS M, GUNNOO SB, HESSEL V, MADDER A AND NÖEL T. 2017. Visible-Light-Mediated Selective Arylation of Cysteine in Batch and Flow. Angew Chem Int Ed 56: 12702-12707.

BORUKHOVA S, NÖEL T, METTEN B, DE VOS E AND HESSEL V. 2013. Solvent- and Catalyst-Free Huisgen Cycloaddition to Rufinamide in Flow with a Greener, Less Expensive Dipolarophile. ChemSusChem 6: 2220-2225.

BRAUNE S, PCCHLAUER P, REINTIENS R, STEINHOFER S, WINTER M, LOBET O, GUIDAT R, WOEHL P AND GUERMEUR C. 2009. Selective nitration in a microreactor for pharmaceutical production under cGMP conditions. Chim Oggi-Chem Today 27: 26-29.

BRITTON J AND JAMISON TF. 2017. A Unified Continuous Flow Assembly-Line Synthesis of Highly Substituted Pyrazoles and Pyrazolines. Angew Chem Int Ed 56: 88238827.

BRITTON J AND RASTON CL. 2017. Multi-step continuousflow synthesis. Chem Soc Rev 46: 1250-1271.

BROCKSOM TJ, DESIDERÁ AL, ALVES LC AND DE OLIVEIRA KT. 2015. The new directions of organic synthesis. Curr Org Synth 12: 496-522.
BROWNE DL, PASTRE JC, BUTTERS C, GUTHRIE D AND LEY SV. 2013. Continuous flow-processing of organometallic reagents using an advanced peristaltic pumping system and the telescoped flow synthesis of (E/Z)-tamoxifen Murray. Org Proc Res Dev 17: 11921208.

CAMBIÉ D, BOTTECCHIA C, STRAATHOF NJW, HESSEL V AND NOËL T. 2016. Applications of Continuous-Flow Photochemistry in Organic Synthesis, Material Science, and Water Treatment. Chem Rev 116: 10276-10341.

CARMONA-VARGAS CC, ALVES LC, BROCKSOM TJ AND OLIVEIRA KT. 2017. Combining batch and continuous flow setups in the end-to-end synthesis of naturally occurring curcuminoids. React Chem Eng 2: 366-364.

CARNEIRO PF, GUTMANN B, DE SOUZA ROMA AND KAPPE CO. 2015. Process Intensified Flow Synthesis of 1H-4-Substituted Imidazoles: Toward the Continuous Production of Daclatasvir. ACS Sustainable Chem Eng 3: 3445-3453.

CASTELLAN A, BART JCJ AND CAVALLARO S. 1991. Industrial production and use of adipic acid. Catal Today 3: 237-254.

COLE KP ET AL. 2017. Kilogram-scale prexasertib monolactate monohydrate synthesis under continuousflow CGMP conditions. Science 356: 1144-1150.

COREY EJ AND LI JJ. 2013. Total Synthesis of Natural Products - At the Frontiers of Organic. Springer-Verlag Berlin Heidelberg, 270 p.

COREY EJ, CZAKÓ B AND KURTI L. 2007. "Molecules and Medicine". J Wiley and Sons, Hoboken, NJ, USA. See especially the chapters on Aspirin, Amoxicillin and Oral Contraceptives.

CROOK KE AND MCELVAIN SM. 1930. Piperidine derivatives X. The phenylpiperylcarbinols. J Am Chem Soc 52: 4006-4011.

DALE DJ, DUNN PJ, GOLIGHTLY C, HUGHES ML, LEVETT PC, PEARCE AK, SEARLE PM, WARD G AND WOOD AS. 2000. The chemical development of the commercial route to sildenafil: acase history, Org Proc Res Dev 4: 17-22.

DAMIAO MCFCB, GALAVERNA R, KOZIKOWSKI A, EUBANKSC J AND PASTRE J. 2017. Telescoped continuous flow generation of a library of highly substituted 3-thio-1,2,4-triazoles. React Chem Eng 2017(2): 896-907.

DAVIS DD. 1985. Ullman's Encyclopedia of Industrial Chemistry. $5^{\text {th }}$ ed., J Wiley and Sons, New York Vol, A1.

DE OLIVEIRA KT, MILLER LZ AND MCQUADE DT. 2016. Exploiting photooxygenations mediated by porphyrinoid photocatalysts under continuous flow conditions. RSC Adv 6: 12717-12725.

DE OLIVEIRA KT, DE SOUZA JM, GOBO NRS, DE ASSIS FF AND BROCKSOM TJ. 2015. Basic Concepts and 
Applications of Porphyrins, Chlorins and Phthalocyanines as Photosensitizers in Photonic Therapies. Rev Virtual Quím 7: 310-335.

DECORTE BL. 2016. Underexplored opportunities for natural products in drug discovery. J Med Chem 59: 9295-9304.

DESAI H, D'SOUZA BR, FOETHER D, JOHNSON BF AND LINDSAY HA. 2007. Regioselectivity in a highly efficient, microwave-assisted epoxide aminolysis. Synthesis 6: 902910.

EASTGATE MD, SCHMIDT MA AND FANDRICK KR. 2017. On the design of complex drug candidate syntheses in the pharmaceutical industry. Nat Rev Chem 1: 0016.

ELLIOTT LD, BERRY M, HARJI B, KLAUBER D, LEONARD J AND BOOKER-MILBURN KI. 2016. A Small-Footprint, High-Capacity Flow Reactor for UV Photochemical Synthesis on the Kilogram Scale. Org Process Res Dev 20: 1806-1811.

ELVIRA KS, SOLVAS XC, WOOTTON RCR AND DEMELLO AJ. 2013. The past, present and potential for microfluidic reactor technology in chemical synthesis. Nat Chem 5: 905-915.

ENGEN K, SÄVMARKER J, ROSENSTRÖM U, WANNBERG J, LUNDBÄCK T, JENMALM-JENSEN A AND LARHED M. 2014. Microwave Heated Flow Synthesis of Spiro-oxindole Dihydroquinazolinone Based IRAP Inhibitors. Org Process Res Dev 18: 1582-1588.

FANELLI F, PARISI G, DEGENNARO L AND LUIS R. 2017. Contribution of microreactor technology and flow chemistry to the development of green and sustainable synthesis. Beilstein J Org Chem 13: 520-542.

FEDERSEL HJ. 2009. Chemical process research and development in the 21 st century: challenges, strategies, and solutions from a pharmaceutical industry perspective. Acc Chem Res 42: 671-680.

FEDERSEL HJ. 2013. En route to full implementation: driving the green chemistry agenda in the pharmaceutical industry. Green Chem 15: 3105-3115.

FILIPPONI P AND BAXENDALE IR. 2016. The Generation of a Library of Bromodomain-Containing Protein Modulators Expedited by Continuous Flow Synthesis. Eur J Org Chem 2000-2012.

FITZPATRICK DE, BATTILOCCHIO C AND LEY SV. 2016. Enabling Technologies for the Future of Chemical Synthesis. ACS Cent Sci 2: 131-138.

FLICK AC, DING HX, LEVERETT CA, KYNE JRRE, LIU KK-C, FINK SJ AND O'DONNELL CJ. 2017. Synthetic approaches to the new drugs approved during 2015. J Med Chem 60: 6480-6515.

FUSE S, TANABE N, YOSHIDA M, YOSHIDA H, DOIB T AND TAKAHASHI T. 2010. Continuous-flow synthesis of vitamin D3. Chem Commun 46: 8722-8724

GEORGIÁDES A, ÖTVÖS SB AND FÜLÖPA F. 2015. Exploring Novel Parameter Spaces for the Oxidative
Homocoupling of Aniline Derivatives: Sustainable Synthesis of Azobenzenes in a Flow System. ACS Sustainable Chem Eng 3: 3388-3397.

GLÖCKNER S, TRAN DN, INGHAM RJ, FENNER S, WILSON ZE, BATTILOCCHIO C AND LEY CS. 2015. The rapid synthesis of oxazolines and their heterogeneous oxidation to oxazoles under flow conditions. Org Biomol Chem 13: 207-214.

GRONGSAARD P ET AL. 2012. Convergent, Kilogram Scale Synthesis of an Akt Kinase Inhibitor. Org Process Res Dev 16: 1069-1081.

GUETZOYAN L, NIKBIN N, BAXENDALE IR AND LEY SV. 2013. Flow chemistry synthesis of zolpidem, alpidem and other GABAA agonists and their biological evaluation through the use of in-line frontal affinity chromatography. Chem Sci 4: 764-769.

GUTMANN B, CANTILLO D AND KAPPE CO. 2015. Continuous-Flow Technology: A Tool for the Safe Manufacturing of Active Pharmaceutical Ingredients. Angew Chem Int Ed 54: 6688-6728.

HAFNER A, MEISENBACH M AND SEDELMEIER J. 2016. Flow Chemistry on Multigram Scale; Continuous Synthesis of Boronic Acids within 1 s. Org Lett 18: 36303633.

HALPERIN SD, KWON D, HOLMES M, REGALADO EL, CAMPEAU LC, DIROCCO DAAND BRITTON R. 2015. Development of a Direct Photocatalytic C-H Fluorination for the Preparative Synthesis of Odanacatib. Org Lett 17: 5200-5203.

HARTMAN RL, MCMULLEN JP AND JENSEN KF. 2011. Deciding Whether to go with the Flow: Evaluating the Merits of Flow Reactors for Synthesis. Angew Chem Int Ed 50: 7502-7519.

HAWKINS JM. 2015. Streamlining drug synthesis. Nature 520: 302-303.

HE Z AND JAMISON TF. 2014. Continuous Flow Aerobic Alcohol Oxidation Reactions Using a Heterogeneous $\mathrm{Ru}(\mathrm{OH}) \mathrm{x} / \mathrm{A} 12 \mathrm{O} 3$ Catalyst. Angew Chem Int Ed 53: 3353 3357.

HERATH A AND COSFORD NDP. 2010. One-Step Continuous Flow Synthesis of Highly Substituted Pyrrole3-carboxylic Acid Derivatives via in Situ Hydrolysis of tert-Butyl Esters. Org Lett 12: 5182-5185.

HESSEL V, CORTESE B AND DE CROON MHJM. 2011. Novel process windows - Concept, proposition and evaluation methodology, and intensified superheated processing. Chem Eng Sci 66: 1426-1448.

HESSEL V, KRALISCH D AND KRTSCHIL U. 2008. Sustainability through green processing - novel process windows intensify micro and milli process technologies. Energy Environ Sci 1: 467-478.

HESSEL V, KRALISCH D, KOCKMANN N, NÖEL T AND WANG Q. 2013. Novel Process Windows for 
Enabling, Accelerating, and Uplifting Flow Chemistry. ChemSusChem 6: 746-789.

HESSEL V, KRALISCHN D and KOCKMANN N. 2015. Novel Process Windows: Innovative Gates to Intensified and Sustainable Chemical Processes Weinheim: WileyVCH Verlag GmbH \& Co., 344 p.

HESSEL V, LÖL P AND LÖWE H. 2005a. Development of reactors to enable chemistry rather than subduing chemistry around the reactor-potentials of micro- structured reactors for organic synthesis. Curr Org Chem 9: 765-787.

HESSEL V. 2009. Novel Process Windows - Gate to Maximizing Process Intensification via Flow Chemistry. Chem Eng Technol 32: 1655-1681.

HIRSCHMANN R. 1991.Medicinal chemistry in the golden age of biology: lessons from steroid and peptide research. Angew Chem Int Ed Engl 30: 1278-1301.

HOLBROOK SYL AND GARNEAU-TSODIKOVA S. 2017. What is medicinal chemistry? - demystifying a rapidly evolving discipline! Med Chem Commun 2017(8): 17391741

HOUWER J, TEHRANI KA AND MAES BUW. 2012. Synthesis of Aryl(di)azinyl Ketones through Copperand Iron-catalyzed Oxidation of the Methylene Group of Aryl(di)azinylmethanes. Angew Chem Int Ed 51: 27452748.

ILLG T, LÖB P AND HESSEL V. 2010. Flow chemistry using milli- and microstructured reactors - From conventional to novel process windows. Bioorg Med Chem 18: $3707-$ 3719 .

JACQ J AND PASAU P. 2014. Multistep Flow Synthesis of 5-Amino-2-aryl-2H-[1,2,3]-triazole-4-carbonitriles. Chem Eur J 20: 12223-12233.

KABESHOV MA, MUSIO B, MURRAY PRD, BROWNE DL AND LEY ST. 2014. Expedient Preparation of Nazlinine and a Small Library of Indole Alkaloids Using Flow Electrochemistry as an Enabling Technology. Org Lett 16: 4618-4621.

KAMPTMANN SB AND LEY SV 2015. Facilitating biomimetic syntheses of borrerine derived alkaloids by means of flow-chemical methods. Aust J Chem 68: 693696.

KOBAYASHI S. 2016. Flow "Fine" Synthesis: High Yielding and Selective Organic Synthesis by Flow Methods. Chem Asian J 11: 425-436.

KRAGH-HANSEN U. 1990. Structure and ligand binding properties of human serum albumin. Dan Med Bull 37: 57-84.

KUIJPERS KPL, VAN DIJK MAH, RUMEUR Q G, HESSEL V, SU Y AND NÖEL T. 2017. A sensitivity analysis of a numbered-up photomicroreactor system. React Chem Eng 2:109-115.

LANGE PPAND JAMES K. 2012. Rapid Access to Compound Libraries through Flow Technology: Fully Automated
Synthesis of a 3-Aminoindolizine Library via Orthogonal Diversification. ACS Comb Sci 14: 570-578.

LEE SL, O'CONNOR TF, YANG X, CRUZ CN, CHATTERJEE S, MADURAWE RD, MOORE CMV, YU LX AND WOODCOCK J. 2015. Modernizing Pharmaceutical Manufacturing: from Batch to Continuous Production. J Pharm Innov 10: 191-199.

LÉVESQUE F AND SEEBERGER PH. 2012. ContinuousFlow Synthesis of the Anti-Malaria Drug Artemisinin. Angew Chem Int Ed 51: 1706-1709.

LEY SV, FITZPATRICK DE, MYERS RM, BATTILOCCHIO C AND INGHAM RJ. 2015. Machine-Assisted Organic Synthesis. Angew Chem Int Ed 54: 10122-10136.

LEY SV, SCHUCHT O, THOMAS AW AND MURRAY PJ. 1999. Synthesis of the alkaloids $( \pm)$-oxomaritidine and $( \pm)$-epimaritidine using an orchestrated multi-step sequence of polymer supported reagents. J Chem Soc Perkin Trans 10: 1251-1252.

LI F, NIE J, SUN L, ZHENG Y AND MA J-A. 2013. SilverMediated Cycloaddition ofAlkynes with CF3CHN2: Highly Regioselective Synthesis of 3-Trifluoromethylpyrazoles. Angew Chem Int Ed 52: 6255-6258.

LÜCKE D, DALTON T, LEY SV AND WILSON ZE. 2016. Synthesis of Natural and Unnatural Cyclooligomeric Depsipeptides Enabled by Flow Chemistry. Chem Eur J 22: 4206-4217.

LONGSTREET AR, OPALKA SM, CAMPBELL BS, GUPTON BF AND MCQUADE DT. 2013. Investigating the continuous synthesis of a nicotinonitrile precursor to nevirapine. Beilstein J Org Chem 9: 2570-2578.

MALET-SANZ L AND SUSANNE F. 2012. Continuous Flow Synthesis. A Pharma Perspective. J Med Chem 55: 40624098.

MARKER RE, WAGNER RB, ULSHAFER PR, WITTBECKER EL, GOLDSMITH DPJ AND RUOF CH. 1947.Steroidal sapogenins. J Am Chem Soc 69: $2167-$ 2230.

MARSINI MA ET AL. 2017. Development of a concise, scalable synthesis of a CCR1 antagonist utilizing a continuous flow Curtius rearrangement. Green Chem 19: 1454-1461.

MATTHEW O'B, BAXENDALE IR AND LEY SV. 2010. Flow Ozonolysis Using a Semipermeable Teflon AF-2400 Membrane To Effect Gas-Liquid Contact. Org Lett 12: 1596-1598

MAY SA ET AL. 2012. Rapid Development and Scale-Up of a 1H-4-Substituted Imidazole Intermediate Enabled by Chemistry in Continuous Plug Flow Reactors. Org Process Res Dev 16: 982-1002.

MAY SA ET AL. 2016. Development and Manufacturing GMP Scale-Up of a Continuous Ir-Catalyzed Homogeneous Reductive Amination Reaction. Org Process Res Dev 20: 1870-1898. 
MOMO PB, BELLETE BS, BROCKSOM TJ, DE SOUZA ROMA AND DE OLIVEIRA KT. 2015. Exploiting Novel Process Windows for the Synthesis of meso-Substituted Porphyrins under Continuous Flow Conditions. RSC Adv 5: 84350-84355.

MORIN E, RAYMOND M, DUBART A AND COLLINS SK. 2017. Total Synthesis of Neomarchantin A: Key Bond Constructions Performed Using Continuous Flow Methods. Org Lett 19: 2889-2892.

MORRISON FM AND HERGENROTHER PJ. 2014. Natural products as starting points for the synthesis of complex and diverse compounds. Nat Prod Rep 31: 6-14.

MOVSISYAN M, DELBEKE EIP, BERTON J, BATTILOCCHIO C, LEY SV AND STEVENS CV. 2016. Taming harzardous chemistry by continuous flow technology. Chem Soc Rev 45: 4892-4928.

MUDD WH AND STEVENS EP. 2010. An efficient synthesis of rufinamide, an antiepileptic drug. Tetrahedron Lett 51: 3229-3231.

MUSSER MT. 2005. Adipic Acid - Ullmann's Encyclopedia of Industrial Chemistry. Weinheim: Wiley-VCH, p. 1-11.

MYKHAILIUK PK. 2015. A Novel One-Pot Method for the Preparation of Pyrazoles by 1,3-Dipolar Cycloadditions of Diazo Compounds Generated in Situ. Angew Chem Int Ed 54: 6558-6560.

NADIN A, HATTOTUWAGAMA C AND CHURCHER I. 2012. Lead-oriented synthesis: A new opportunity for synthetic chemistry. Angew Chem Int Ed 51: 1114-1122.

NAKANISHI M AND BOLM C. 2007. Iron-Catalyzed Benzylic Oxidation with Aqueous tert-Butyl Hydroperoxide. Adv Synth Catal 349: 861-864.

NEWMAN DJ AND CRAGG GM. 2016.Natural products as sources of new drugs from 1981 to 2014. J Nat Prod 79: 629-661.

NEWTON S, CARTER CF, PEARSON CM, ALVES LC, LANGE H, THANSANDOTE P AND LEY SV. 2014. Accelerating Spirocyclic Polyketide Synthesis using Flow Chemistry. Angew Chem Int Ed 53: 4915-4920.

NICOLAOU FC AND RIGOL S. 2017. The Evolution and Impact of Total Synthesis on Chemistry, Biology and Medicine. Isr J Chem 57: 179-191.

NICOLAOU KC AND MONTAGNON T. 2008. Molecules That Changed the World. Wiley-VCH, Weinheim, Germany.

NOËL T, GELONCH M AND HUVAERE K. 2017. Photochemical Processes in Continuous Flow Reactors From Engineering Principles to Chemical Applications, Singapore: World Scientific Publishing Company, Amsterdam, p. 260-261.

NOËL T, SUY AND HESSEL V. 2015. Beyond Organometallic Flow Chemistry: The Principles Behind the Use of Continuous-Flow Reactors for Synthesis. Top Organomet Chem 57: 1-41.
OELGEMÖLLER M AND SHVYDKIV O. 2011. Recent Advances in Microflow Photochemistry. Molecules 16: $7522-7550$.

PAGANO N, HEIL ML AND COSFORDA NDP. 2012. Automated Multistep Continuous Flow Synthesis of 2-(1HIndol-3-yl)thiazole Derivatives. Synthesis 16: 2537 2546.

PASTRE JC, BROWNE DL AND LEY SV. 2013a. Flow chemistry syntheses of natural products. Chem Soc Rev 42: 8849-8869.

PASTRE JC, MURRAY PRD, BROWNE DL, PILLI RAAND LEY SV. 2013b. Integrated Batch and Continuous Flow Process for the Synthesis of Goniothalamin. Brazilian Meeting on Organic Synthesis. DOI: 10.5151/chempro15bmos-BMOS2013_2013914162426].

PASTRE JC, BROWNE DL, O'BRIEN M AND LEY SV. 2013c. Scaling-up of Continuous Flow Processes with Gases Using a Tube-in-Tube Reactor: In-Line Titrations and Fanetizole Synthesis with Ammonia. Org Process Res Dev 17: 1183-1191.

PIEBER B AND KAPPE CO. 2013. Direct aerobic oxidation of 2-benzylpyridines in a gas-liquid continuous-flow regime using propylene carbonate as a solvent. Green Chem 15: 320-324.

PLUTSCHACK MB, PIEBER B, GILMORE K AND SEEBERGER PH. 2017. The Hitchhiker's Guide to Flow Chemistry. Chem Rev 117: 11796-11893.

POH J-S, BROWNE DL AND LEY SV. 2016. A multistep continuous flow synthesis machine for the preparation of pyrazoles via a metal-free amine-redox process. React Chem Eng 1: 101-105.

PORTA R, BENAGLIA M AND PUGLISI A. 2016. Flow chemistry: recent developments in the synthesis of pharmaceutical products. Org Proc Res Dev 20: 2-25.

RAMSHAW C. 1999. Process intensification and green chemistry. Green Chem 1: G1517.

RANKOVIC Z AND MORPHY R. 2010. Lead Generation Approaches in Drug Discovery, J Wiley \& Sons, 295 p.

RAZZAQ T AND KAPPE CO. 2010. Continuous Flow Organic Synthesis under High Temperature/Pressure Conditions. Chem Asian J 5: 1274-1289.

REIZMAN BJ AND JENSEN KF. 2016. Feedback in flow for accelerated reaction development. Acc Chem Res 49: 1786-1796.

ROBERGE DM, NOTI C, IRLE E, EYHOLZER M, RITTINER B, PENN G, SEDELMEIER G AND SCHENKEL B. 2014. Control of Hazardous Processes in Flow: Synthesis of 2-Nitroethanol. J Flow Chem 4: 26-34.

SATO K, AOKI M AND NOYORI R. 1998. A “Green” route to adipic acid: direct oxidation of cyclohexenes with 30 percent hydrogen peroxide. Science 281: 1646-1647.

SHANG M, NÖEL T, WANG Q AND HESSEL V. 2013. Packed-Bed Microreactor for Continuous-Flow Adipic 
Acid Synthesis from Cyclohexene and Hydrogen Peroxide. Chem Eng Technol 6: 1001-1009.

SNEAD DR AND JAMISON F. 2015. A Three-Minute Synthesis and Purification of Ibuprofen: Pushing the Limits of Continuous-Flow Processing. Angew Chem 54: 983-987.

STANKIEWICZ AJ AND MOULJIN JA. 2000. Process intensification: Transforming chemical engineering. Chem Eng Prog 96: 2234.

ŠTERK D, JUKIČ M AND ČASAR Z. 2013. Application of Flow Photochemical Bromination in the Synthesis of a 5-Bromomethylpyrimidine Precursor of Rosuvastatin: Improvement of Productivity and Product Purity. Org Process Res Dev 17: 145-151.

STOUTEN SC, NÖEL T, WANG Q AND HESSEL V. 2013. A View Through Novel Process Windows. Aust J Chem 66: 121-130.

SU Y, STRAATHOF NJW, HESSEL V AND NOËL T. 2014. Photochemical Transformations Accelerated in Continuous-Flow Reactors: Basic Concepts and Applications. Chem Eur J 20: 10562-10589.

SU Y, KUIJPERS K, HESSEL V AND NOËL T. 2016. A convenient numbering-up strategy for the scale-up of gasliquid photoredox catalysis in flow. React Chem Eng 1: 73-81.

TALLA A, DRIESSEN B, STRAATHOF N, MILROY LG, BRUNKSVELD L, HESSEL V AND NÖEL T. 2015. Metal-Free Photocatalytic Aerobic Oxidation of Thiols to Disulfides in Batch and Continuous-Flow. Adv Synth Catal 357: 2180-2186.

TSOUNG J, BOGDAN AR, KANTOR S, WANG Y, CHARASCHANYAMAND DJURIC SW. 2017. Synthesis of Fused Pyrimidinone and Quinolone Derivatives in an Automated High-Temperature and High-Pressure Flow Reactor. J Org Chem 82: 1073-1084.

VACCARO L, LANARI D, MARROCCHI A AND STRAPPAVECCIA G. 2014. Flow approaches towards sustainability. Green Chem 16: 3680-3704.

VERLEE A, HEUGEBAERT T, MEER T, KERCHEV PI, BREUSEGEM FV AND STEVENS CV. 2017.
A chemoselective and continuous synthesis of m-sulfamoylbenzamide analogues. Beilstein J Org Chem 13: 303-312.

VIVIANO M, GLASNOV TN, REICHART B, TEKAUTZ G AND KAPPE CO. 2011. A Scalable Two-Step Continuous Flow Synthesis of Nabumetone and Related 4-Aryl-2butanones. Org Process Res Dev 15: 858-870.

VIVIANO M, MILITE C, RESCIGNO D, CASTELLNO S AND SBARDELLA G. 2015. A continuous-flow synthesis of 1,4-benzodiazepin-5-ones, privileged scaffolds for drug discovery. RSC Adv 5: 1268-1273.

VUKELIC S, KOKSCH B, SEEBERGER PHAND GILMORE K. 2016. A Sustainable, Semi-Continuous Flow Synthesis of Hydantoins. Chem Eur J 22: 13451-13454.

WILES C AND WATTS P. 2014. Continuous process technology: a tool for sustainable production. Green Chem 16: 55-62.

YAVORSKYY A, SHVYDKIV O, HOFFMANN N, NOLAN K AND OELGEMÖLLER M. 2012a. Parallel Microflow Photochemistry: Process Optimization, Scale-up, and Library Synthesis. Org Lett 14: 4342-4345.

YAVORSKYY A, SHVYDKIV O, LIMBURG C, NOLAN K, DELAURÉ YMC AND OEGELMÖLLER M. 2012b. Photooxygenations in a bubble column reactor. Green Chem 14: 888-892.

YAYLA HG, PENG F, MANGION IK, MCLAUGHLIN M, CAMPEAU LC, DAVIES IW, DIROCCO DA AND KNOWLES RR. 2016. Discovery and mechanistic study of a photocatalytic indoline dehydrogenation for the synthesis of elbasvir. Chem Sci 7: 2066-2073.

YUEH H, GAO Q, PORCO JA AND BEELER AB. 2017. A photochemical flow reactor for large scale syntheses of aglain and rocaglate natural product analogues. Bioorg Med Chem 25(23): 6192-6202.

ZHANG J, WHANG Z, WANG Y, WAN C, ZHENG X AND WANG Z. 2009. A metal-free catalytic system for the oxidation of benzylic methylenes and primary amines under solvent-free conditions. Green Chem 11: 1973-1978. 